\title{
A molecular epidemiological study on colorectal cancer: meat, fat, smoking and genetic alterations
}

Citation for published version (APA):

Luchtenborg, M. (2005). A molecular epidemiological study on colorectal cancer: meat, fat, smoking and genetic alterations. [Doctoral Thesis, Maastricht University]. Maastricht University. https://doi.org/10.26481/dis.20050701ml

Document status and date:

Published: 01/01/2005

DOI:

10.26481/dis.20050701ml

Document Version:

Publisher's PDF, also known as Version of record

\section{Please check the document version of this publication:}

- A submitted manuscript is the version of the article upon submission and before peer-review. There can be important differences between the submitted version and the official published version of record.

People interested in the research are advised to contact the author for the final version of the publication, or visit the DOI to the publisher's website.

- The final author version and the galley proof are versions of the publication after peer review.

- The final published version features the final layout of the paper including the volume, issue and page numbers.

Link to publication

\footnotetext{
General rights rights.

- You may freely distribute the URL identifying the publication in the public portal. please follow below link for the End User Agreement:

www.umlib.nl/taverne-license

Take down policy

If you believe that this document breaches copyright please contact us at:

repository@maastrichtuniversity.nl

providing details and we will investigate your claim.
}

Copyright and moral rights for the publications made accessible in the public portal are retained by the authors and/or other copyright owners and it is a condition of accessing publications that users recognise and abide by the legal requirements associated with these

- Users may download and print one copy of any publication from the public portal for the purpose of private study or research.

- You may not further distribute the material or use it for any profit-making activity or commercial gain

If the publication is distributed under the terms of Article $25 \mathrm{fa}$ of the Dutch Copyright Act, indicated by the "Taverne" license above, 
A MOLECULAR EPIDEMIOLOGICAL STUDY ON COLORECTAL CANCER:

MEAT, FAT, SMOKING AND GENETIC ALTERATIONS 


\section{A MOLECULAR EPIDEMIOLOGICAL STUDY ON COLORECTAL CANCER:}

MEAT, FAT, SMOKING AND GENETIC ALTERATIONS

\section{Margreet Lüchtenborg}

ISBN: 90-6464-966-9

\section{COVER Mee Beran \\ LAY-OUT Margreet Lüchtenborg \\ PRINTED BY Grafisch bedrijf Ponsen en Looijen BV. Wageningen}

@ 2005, Margreet Lüchtenborg

All rights reserved. No part of this thesis may be reproduced or transmitted in any form or by any means, electronic or mechanical. including photocopying, recording or any information storage or retrieval system without permission in writing from the cuthor, or, when appropriote. from the publisher of the publications. 


\section{A MOLECULAR EPIDEMIOLOGICAL STUDY ON COLORECTAL CANCER: \\ MEAT, FAT, SMOKING AND GENETIC ALTERATIONS}

ter verkrijging van de graad van doctor aan de Universiteit Maastricht, op gezag van de Rector Magnificus, Prof. mr. G.P.M.F. Mols, volgens het besluit van het College van Decanen.

in hel openbaar te verdedigen

op vrijdag 1 juli 2005 om 12:00 uur

door

Margreet Lüchtenborg 


\section{PROMOTORES}

Prof. dr. ir. P.A. wan den Brandt

Prof. dr. ir. P. van 't Veer (Wageningen Universiteit)

\section{CO-PROMOTORES}

Dr. ir. M.P. Weijenberg

Dr. A.F.P.M. de Goeil

\section{BEOORDELINGSCOMMISSIE}

Prof. dr. A. Bast (voorzitter)

Prof. dir. M.J.A.P. Daemen

Dr. H.J. van Kranen (Rijksinstituut voor Volksgezondheid en Milieu, Bilthoven)

Prof. dr. ir. F. E. van Leeuwen (Nederlands Kanker Instituut, Amsterdam)

Prof. dr. F.C.S. Ramaekers

This project was funded by grants from the Netherlands Organization for Scientific Research (NWO grant no. 980-10-026] and the Dutch Cancer Society [KWF grant no. UM-99-1980].

The studies presented in this thesis were conducled at Maastricht University, at the Department of Epidemiology, Nutrition and Toxicology Research Institute Maastricht (NUTRIMI. which participates in the Graduate School VLAG-2 [Food Technology. Agrabiotechnology. Nultrition and Health Sciences] accredited by the Royal Netherlands Academy of Arts and Sciences (KNAW). and the Department of Pathology, Research Institute Growth and Development [GROW], in cooperation with the Division of Human Nutrition of the Wageningen University, Wageningen, and the Department of Pathology of the Universily Medical Centre St. Radboud. Nijmegen. 


\section{$\begin{array}{llllllll}C & O & N & T & E & N & T & S\end{array}$}

CHAPTER 1

Introduction

CHAPTER 2

APC mutations in sporadic colorectal carcinomas from the Netherlands Cohort Study

\section{CHAPTER 3}

Mutations in APC, CTNNBI and K-ras genes and expression of hMLHI in sporadic colorectal cancer

\section{CHAPTER 4}

Meat and fish consumption, APC gene mutations and hMLHI expression in colon and rectal cancer: a prospective cohort study

\section{CHAPTER 5}

Dietary fat and risk of colorectal cancer with aberrant hMLH1 expression. APC or K-ras genes

\section{CHAPTER 6}

Cigarette smoking and colorectal cancer: APC mutations, hMLHI expression and GSTMI and GSTT! polymorphisms

\section{CHAPTER 7}

General discussion

Summary 


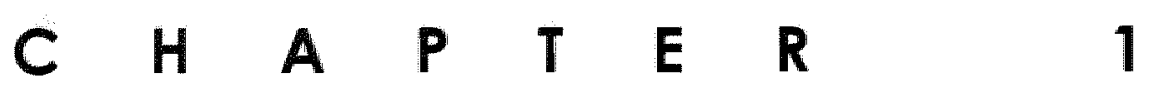


IN T 
10 


\section{B A C K G ROUND}

The burden of colorectal cancer is high, with approximately one million new cases worldwide each year.' Colorectal cancer is one of the most common causes of morbidity and mortality among European and North American populations. Approximately one half of these populations will develop a colorectal adenoma by the age of 70 . A fraction of these adenomas will progress to cancer, equivalent to a lifetime cancer risk in the general population of about $5 \%$. In the Netherlands, where the studies described in this thesis were carried out, approximately 8,500 new colorectal cancer cases are diagnosed each year and around $40 \%$ of these cases eventually result in death. ${ }^{2}$ Colorectall cancer is the third most common cancer fafter lung and prostate cancer) in men and the second most common cancer (after breast cancer) in women in the Netherlands. ${ }^{2}$

Colorectal cancer is a multi-factorial disease. As with other types of cancer, the risk of colorectal cancer increases with advancing age. A positive family history of colorectal cancer gives rise to a two-fold increase in the risk of developing colorectal cancer. ${ }^{3 .}{ }^{4}$ suggesting a hereditary component. However, less than $10 \%$ of colorectal cancers are attributable to familial cancer syndromes, the two most well known being hereditary non-polyposis colorectal cancer (HNPCC), and familial adenomatous polyposis (FAP). The overall majority of colorectal cancers seem to arise in a non-hereditary, sporadic fashion.

World-wide, the age-standardised incidence of colon cancer varies 20 -fold with the highest rates observed in more developed countries' ' which indicates that ethnic background or lifestyle factors may play a role in the detiology of colorectal cancer. Migrant studies have shown that incidence rates in groups moving from a low-risk to a high-risk area adapt to the incidence rate of the high-risk area within one or two generations, ${ }^{5}$ suggesting that the development of a colorectal tumour can, for a large part, be ascribed to environmental factors, of which dief is a likely candidate.

The epithelium of the colon and rectum is continuously exposed to dietary and other environmental factors that may bear carcinogenic potential and exposure to these factors may eventually result in the formation of a tumour. In addition, systemic exposure to these potential carcinogens may affect the colon and rectum. Factors that possibly increase the risk of colorectal tumour development include a high intake of fat, meat, alcohol, and cigarette smoking, whereas vegetables, fibre and possibly fruit may decrease the risk of colorectal cancer. ${ }^{6}$ However, evidence is weak and sometimes inconsistent. In part, this may be due to the fact that the various molecular alterations underlying the carcinogenic process have not been taken into account in most studies to date.

In the following paragraphs, the molecular alterations contributing to colorectal cancer and the risk factors thought to play a role in the aetiology of colorectal cancer are described, which will lead to the rationale and the aims of the studies described in this thesis. 


\section{MOLECULAR ALTERATIONS CONTRIBUTING TO COLORECTAL CANCER}

The normal adult colon cantains approximately $10^{7}$ crypts. Four to six stem cells at the bottom of each crypt replenish the whole crypt. The progeny of stem cells migrates up the crypt and continues to divide until it reaches its midportion. Subsequently, the migrating epithelial cells stop dividing and instead differentiate into mature cells. When the differentiated cells reach the top of the crypt. they undergo apoptosis and are engulfed by stromal cells or are shed directly into the lumen. This journey from the base of the crypt to its apex takes around three to six days. Normally, the birth rate of the colonic epithelial cell precisely equals the rate of cellular loss from the crypt apex. If the birth/loss ratio increases, this results in hyperproliferation, which may eventually progress to a neoplasm.

It is widely believed that most adenomas develop from normal stem cells at the bases of the colorectal crypts that acquire a mutation. ${ }^{8}$ Although aberrant crypt foci have been recognised as putative pre-neoplastic lesions that may not develop through the adenoma stage." the large majority of colorectal tumours progresses through a series of histopathological stages ranging from dysplastic crypts through small benign adenomas and ultimately resulting in malignant tumours with metastatic properties. This chain of events takes five to 40 years.

Underlying this process are genetic alterations. A first somatic mutation is thought to cause a clonal expansion that initiates the neoplastic process. ${ }^{10}$ Successive somatic mutations result in additional rounds of clonal expansion. The progression of a dysplastic crypt into a malignant tumour is generally believed to be the result of a series of genetic changes that involves activation of oncogenes and inactivation of tumour suppressor genes that control cell growth, differentiation and apoptosis. 10

An elegant model describing colorectal tumourigenesis as proceeding through a series of genetic alterations in key genes, such as adenomatous polyposis coli (APC). Kirsten-ras (K-ras). deleted in colorectal cancer (DCC). and tumour protein 53 (TP53) was proposed by Fearon and Vogelstein in 1990." Although it is generally acknowledged that mutations in APC, K-ras and TP53 are the cornerstones of the pathway leading to colorectal cancer, a recent report has shown that colorectal cancer is much more heterogeneous and that most fumours do not show simultaneous occurrence of mutations in all of those three genes and that colorectal cancer is probably a multi-pathway disease. ${ }^{12}$ in addition, epi-genetic silencing through methylation of tumour suppressor and DNA repair genes are thought to contribute to the development of a carcinoma. The accumulation of lepi-jgenetic alterations is probably more important than the sequential order of events. ${ }^{3}$

Genetic instability is seen in most types of cancer. ${ }^{14}$ It is as yet under debate whether genetic instability preceeds the carcinagenic process and leads to aberrations in genes that subsequently result in tumour progression or whether mutations in certain genes may cause genetic instability. ${ }^{15}$ Two distinct types of 
genetic instability are found in colorectal cancer: chromosomal and microsatellite instability. ${ }^{16}$ Chromosomal instability results in gains of losses of entire chromosomes or parts of them and gives rise to aneuploid tumours and occurs in the majority of cancers. Approximately 10 to $15 \%$ of colorectal cancers displays microsatellite instability, represented by diploid cells acquiring thigh mutation rates, and was found to be associated with defective mismatch repair. ${ }^{17}$ These tumours are less likely to harbour mutations in genes associated with chromosomally instable and generally aneuploid tumours, such as APC, $K$ ras and TP53.18-26

Although numerous molecular alterations have been identified in colorectal carcinogenesis, within the framework of this molecular epidemiological study on environmental factors and colorectal cancer, we have studied mutations in the genes that are thought to be important in the early stages of carcinogenesis (APC. CTNNBI, K-ras) and human MUt-L homologue I (hMLHI) deficiency that probably represents a separate pathway. Additionally, we have considered genes (GSTMI and GSTII) that are involved in carcinogen metabolism and detoxification and may determine individuall susceptibility to the exposure to potential carcinogens. These genetic aspects will be briefly described in the following paragraphs.

\section{APC}

The familial adenomatous polyposis coli syndrome is marked by a germline mutation in the APC gene that predisposes individuals to developing large numbers of (benign) adenomas that eventually may develop into (malignant) carcinomas. ${ }^{27}$ Inactivating mutations in the APC gene can result in adenoma formation. ${ }^{28}$ Mutations in the gate-keeping APC gene are considered an early event in colorectal carcinogenesis and it is estimated that up to $80 \%$ of sporadic colorectal tumours have somatic mutations in the APC gene. ${ }^{29}$ Whereas germline mutations in FAP are confined to the 5 ' half of the APC gene. somatic mutations are clustered in the central region of the open reading frame, spanning codons 1,286 to 1,513 of exon $15,30,31$ Although this mutation eluster region represents only $8 \%$ of the 8,535 bp APC gene, 68 to $77 \%$ of somatic mutations in APC are found in this region. 32.33

The tumour suppressing APC gene is located on chromosome $5 q_{2127}$ and encodes a large protein $(312 \mathrm{kDa})$ that is involved in many cellular processes. ${ }^{3 \mathrm{~A}}$ Central to APC's tumour suppressive function is its down-regulatory capacity of $\beta$-catenin, a key component of the Wnt signalling transduction pathway. This pathway pllays an important role in both embryonic development and tumourigenesis. In the central region of $A P C$, seven motifs of 20 amino acids were identified, which not only bind $\beta$-catenin but also facilitate downregulation of $\beta$-catenin through interactions with Axin and GSK3 $3.35,36$ Through inactivating mutations in the central and $\mathrm{N}$-terminal part of the APC gene. which often lead to complete or partial loss of function of this region. $\beta$ catenin can accumulate in the cell and translocate to the cell nucleus where it serves as a co-activator of Tcf/Lef proteins that activate transcription of Wnt target genes, which a.o. leads to enhanced proliferation.,37-39 


\section{CTNNBI}

Nuclear $\beta$-catenin levels can also be upregulated directly through mutations in the CTNNBI gene encoding $\beta$-catenin. Indeed, in a small proportion of tumours that lack inactivating mutations in the APC gene, mutations in exon 3 of the CTNNBI gene encoding $\beta$-catenin. were observed.40 These mutations are generally found at any of four phosphorylation sites (codons 33, 37, 41 and 45, located in exon 3) that play a crucial role in the down-regulation of $\beta$-catenin.41

\section{K-RAS}

A second step occurring early in colorectal cancer progression is the mutational activation of the K-ras ancogene, which is assaciated with the transitory state of an early adenoma into an intermediate adenoma. Ten to $15 \%$ of adenomas smaller than $1 \mathrm{~cm}$ and 30 to $60 \%$ of larger adenomas and colorectal carcinomas harbour such a mutation. ${ }^{11}$. 42 The $K$-ras gene is located on chromosome $12 \mathrm{p}$ and encodes a $21 \mathrm{kDa}$ protein that transduces extracellular signals via multiple downstream effectors to the nucleus. The hallmark of Ras activation is a transactivation switch between the inactive state, in which it is bound to GDP and the active state, in which conversion to GIP occurs. In the activated state, Ras can transduce mitogenic signals. Mutations in codons 12 and 13 of exon 1 and codon 61 of exon 2 of the $K$-ras gene result in prolonged activation of the Ras protein that stimulates proliferation of the cell. Mutations in codons 12 and 13 are more frequently observed (90 to $95 \%$ ) than mutations in codon 61 (approximately $5 \%$ ). ${ }^{42}$

\section{HMLH 1}

The majority of colorectal tumours are marked by chromosomal instability and this is associated with mutations in a number of proto-oncogenes and tumour suppressor genes, whereas approximately 10 to $15 \%$ of sporadic colorectal tumours display microsatellite instability. ${ }^{43}, 44$ Microsatellite instability is the result of defective mismatch repair. Hereditary non-polyposis colorectal cancer or Lynch syndrome is a relatively common cancer syndrome that is marked by a genetic defect in the mismatch repair mechanism, predisposes patients to developing colorectall cancer, but also endometrial, ovarian, and gastric cancer. ${ }^{45}$, 46. The majority of germline mutations occur in the RMLHI and human Mut-S homologue 2 (hMSH2) mismatch repair genes. ${ }^{47}$ In sporadic colorectal cancer, the hMLHI and hMSH2 genes are usually silenced due to hypermethylation of the promotor regions of these genes resulting in suppressed expression of the protein. $48-50$ Approximately $90 \%$ of microsatellite instable tumours show absence of hMLHI expression..51

\section{GENETIC SUSCEPTIBILITY}

Most carcinogens require metabolic activation before being able to cause DNA damage. Genetic polymorphisms in genes involved in the metabolism of dietary factors and other environmental exposures, leading to increased or decreased activity of the encoded enzymes, may render individuals more or less susceptible to developing colorectal cancer. In humans, in the metabolism of certain carcinogens, two modification steps are required "the first of which is the activation by the phase I enzymes. Some of the intermediate metabalites formed by this process can give rise to adduct formation with proteins and DNA, thus causing damage to cells. After the phase I reactions, conjugating reactions 
by phase II enzymes render these metabolites water soluble, thus facilitating their excretion and this process may inactivate or further activate the metabolites. Variation in enzyme activity with regard to the detoxification or activation of carcinogens may lead to variation in susceptibility to cancer by environmental exposure.

\title{
GSTM1 AND GSTT 1
}

Glutathione S-transferases (GSTS) are phase II enzymes that may directly inactivate heterocyclic amines and mainly PAH metabolites, but may also play an indirect role through induction of CYP1A2. Polymorphisms in the GSTMI and GSTI genes consist of presence or absence of the alleles, thus giving rise to present or absent GST activity. Since GSTs are primarily involved in the metabolism of polycyclic aromatic hydrocarbons (PAH), differential susceptibility to cigarette smoke may be ascribed to polymorphism in the GST genes. Previous reports on the interaction between tobacco smoking and GSTMI and/or GSTI, however, have not shown a clear relationship between smoking and genotype. ${ }^{52-56}$

\section{ENVIRONMENTAL RISK FACTORS FOR COLORECTAL CANCER}

Factors that possibly increase the risk of colorectal tumour development include a high intake of fat, meat, alcohol, and cigarette smoking, whereas vegetables and fibre may decrease risk of colorectal cancer. ${ }^{6}$ In the studies described in the present thesis, we have focussed on three risk factors that previously have been associated with specific genetic aberrations, i.e. meat and fat consumption, and cigarette smoking.

\begin{abstract}
MEAT
With regard to meat consumption as a risk factor for colorectal cancer, the preparation of as well as the animal fat and haem iron content of meat have all been proposed as possible explanations. Nineteen heterocyclic aromatic amines have been isolated from cooked meat. ${ }^{57}$ These compounds are formed via condensation of creatine with the amino acid pool when meat is cooked at temperatures ranging from $150^{\circ} \mathrm{C}$ to $250^{\circ} \mathrm{C}$ e.g., by frying, broiling or barbecuing. ${ }^{58}$ The most abundant heterocyclic amine, 2-amino-1-methyl-6phenylimidazo[4,5-b]pyridine (PhIP) has been shown to produce colon tumours in male $\mathrm{F} 344$ rats and mammary tumours in female F344 rats.59 Barbecuing meat can result in the formation of PAH. PAH have been shown to specifically induce $\mathrm{G} \rightarrow \mathrm{T}$ transversions. 60,61
\end{abstract}

N-Nitrosamines and their precursors are compounds that can be formed endogenously, ${ }^{62}$ but have also been dletected in foods with added nitrates and nitrites, such as salt-preserved fish and meat, and in foods processed by smoking or direct-fire drying. ${ }^{63}$ Through their alkylating action, they can be carcinagenic. N-nitroso compounds can induce $G \rightarrow A$ transitions that have been observed in codons 12 and 13 of the $K$-ras gene in human colonic tissue. ${ }^{62}$ 
Population based case-cantrol studies have shown that red meat was associated with an increased risk of JP53 mutated cancers. ${ }^{64}$ an increased risk of colorectal adenomas without a truncating APC mutation, 65 but colon carcinomas with a truncating mutation in the APC gene. ${ }^{66}$ Finally, a high intake of red meat was inversely associated with microsatellite instable tumours. ${ }^{67}$

\section{DIETARY FAT}

Dietary fats may exert direct effects on colorectal tumourigenesis by augmenting bile acid production and subsequently increased colonic cell proliferation and ultimately increased risk of endogenous mutations. ${ }^{68}$ Systemic effects include the effect of specific types of fat an membrane characteristics of cells, thereby influencing risk of insulin resistance and survival of tumour cells, the protective effect of $n-3$ fatty acids by decreasing prostaglandin E2 production, and the effect of essential polyunsaturated fatty acids on inflammatory responses. ${ }^{68}$ Previously, there has been emphasis on the effect of the quantity of fotal fat in the diet, however, it seems that fat quality in combination with quantity is more important in predisposing to colorectal cancer. For example, n-3 polyunsaturated fatty acids seem to have protective properties at different stages of colorectal carcinogenesis. ${ }^{69}$ whereas n-6 PUFA may increase risk of colorectal cancer. A plausible explanation for the potentially carcinogenic properties of the $n-6$ polyunsaturated fatty acids lies in the peroxidation products of malondialdehyde and 4-hydroxynonenal that can form adducts with DNA and induce $G \rightarrow T$ and $G \rightarrow A$ transitions. ${ }^{70-74}$

Whereas Bautista et $a^{75}$ observed a decreased risk of tumours with wild type $K$ ras with high intake of total fat and monounsaturated fatty acids, Slattery et al76 found associations between dietary fat, saturated fat and monounsaturated fatty acids and tumours harbouring specific $G \rightarrow T$ mutations in the K-ras gene only. Brink et al ${ }^{77}$ observed an increased risk of polyunsaturated fatty acids and linoleic acid and colon tumours harbouring a K-ras mutation, whereas total fat and monounsaturated fatty acids seemed to decrease risk of tumours with specific $G \rightarrow C$ and $G \rightarrow T$ mutations in the $K$-ras gene in colon tumours. With regard to mutations in the APC gene, in a recent case-control study, high intake of fat seemed to increase the risk of adenomas without a truncating APC mutation. ${ }^{65}$ However, in colon carcinomas, positive associations were observed for fat with tumours that harboured a truncating APC mutation. ${ }^{66}$

\section{CIGARETIE SMOKING}

Carcinogenic compounds present in tobacco smoke may cause irreversible damage to the colorectal mucosal ${ }^{78}$ The burning of tobacco produces numerous genotoxic compounds, including $\mathrm{PAH}$, heterocyclic aromatic amines (HCA) and $\mathrm{N}$-nitrosamines.78 The colon and rectum may become exposed to these carcinogens directly, by ingestion of tobacco smoke or indirectly, through contact with blood or bile that may contain potential carcinogens. ${ }^{78}$ In rodent studies benzo(a)pyrene was found to induce $G \rightarrow T$ transversions and $N$ nitrosamines to induce $G: C \rightarrow A: T$ transitions in ras oncogenes, ${ }^{20}$ both of which are important constituents of cigarette smoke.

Cigarette smoking was found to be associated with microsatellite instable colorectal tumors in three case-control studies, 26, 81, 82 whereas another casecontrol study could not confirm this. ${ }^{83}$ 


\section{RATIONALE AND AIMS OF THIS THESIS}

Environmental factors may have a direct effect on carcinogenesis through induction of DNA damage, resulting in mutations that potentially affect the function of encoded proteins or may drive the selection of tumours harbouring specific mutations. A few molecular epidemiological studies have included the mutation status of the tumour (K-ras oncogene. APC and TP53 tumour suppressor genes, and microsatellite instabilityl and have observed differences in associations between certain exposures and colon and rectal tumours with and without such aberrations. However, apart from one cross-sectional and one small case-control study, these studies were performed within the framework of one large case-contral study in the United States, and a case-control study in the Netherlands. The only studies in a cohort study setting were on the associations between dietary factors and K-ras mutations in colorectal cancer and these have previously been carried out within the cohort study that was also the setting of the studies described in this thesis. ${ }^{77.84 .85}$

The aim of the studies described in this thesis was two-fold. Firstly, we sought to describe the genetic alterations present in incident colorectal tumours from our cohort study and secondly, we assessed associations between proposed risk factors and colorectal tumours, according to genetic alterations present.

All studies were performed in the population-based, prospective Netherlands Cohort Study on diet and cancer that was initiated in September 1986.86 At baseline, 58.279 men and 62.573 women aged between 55 and 69 years, who originated from a random sample from 204 municipal population registries throughout the Netherlands, completed a self-administered food frequency and lifestyle questionnaire. After baseline exposure assessment, a subcohort of 1,688 male and 1,812 female subjects was randomly drawn from the cohort and the vital status of these subjects was followed-up biennially to determine accumulated person years in the subcohort. Tumour material was obtained from the majority of the 929 colorectal cancer patients that were identified within the cohort after 7.3 years of follow-up [and excluding the first 2.3 years]. which enabled us to study several molecular alterations that are thought to be important to colorectal cancer development in a large group of patients.

In the first study, we have investigated the occurrence of mutations in the APC gene of colorectal tumours from patients identified within the cohort and investigated whether certain mutations were related to patient or tumour chararacteristics (chapter 2). The mutation status of the APC tumour suppressor, and CTNNBI and $K$-ras oncogenes as well as the hMLHI expression status of the tumour were included in a second study, in which potential differences between different groups of tumours according to their mutation status were investigated (chapter 3). Chapters 4 through 6 describe the studies on the associations between possible risk factors, consumption of meat and fish (chapter 4), dietary fat (chapter 5) and of cigarette smaking (chapter 6) and colon and rectal cancer with and without specific molecular alterations. The last study also took into account the genetic susceptibility as determined by polymorphisms in the GSTMI and GSTII genes, to investigate whether imputed 
differences in GST activity may alter the risk of cigarette smoking on colorectal cancer. Finally, the results and their implications are discussed in chapter 7 . 


\section{REFERENCES}

1. Fenlay J. Bray F. Pisani P. GLOBOCAN 2000: cancer incidence, mortality and prevalence worldwide, verson 1.0. Cancer base No.5. Lyon: IARC. 2001.

2. Visser 0 , Coebergh JWW. Van Dijck JAAM. Siesling $S$. Incidence of cancer in the Netherlands 1998. Utrecht (The Netherlands): Vereniging van Integrale Kankercentra, 2002.

3. Fuchs CS. Giovannucel EL, Colditz GA. Hunter DJ. Speizer FE, Willett WC. A prospective study of family history and the risk of colorectal cancer. N Engl J Med 1994:331 (25):1669-74.

4. Johns LE, Houlston RS. A systematic review and meta-analysis of familial colorectal cancer risk. Am J Gastroenterol 2001;96:110):29:92-3003.

5. Potter JD. Slattery ML, Bostick RM, Gapstur SM. Colon cancer: a review of the epidemiology. Epidemial Rev 1993:15(2):499-545.

6. Warld Cancer Research Fund. American Institute for Cancer Research. Food, nutrition and the prevention of cancer: A global perspective, ed. 1st. Washington, DC: WCRF/AIRC, 1997.

7. Yatabe Y. Tavare S. Shibata D. Investigating stem cells in human colon by using methylation patterris. Proc Natl Acad SCi U S A 2001:98(19):10839-44.

8. Bach SP. Renehan AG. Potten CS. Stem cells: the intestinal stiem cell as a paradigm. Carcinogenesis 2000;21(3):469-76.

9. Bird RP. Role of aberrant crypt foci in understanding the pathogenesis of colon cancer. Cancer Leth 1995:93/1):55-71.

10. Nowell PC. Tumor progression: a brief historical perspective Semin Cancer Biol 2002;12(4);261-6.

11. Fearon ER, Vogelstein B. A genetic model for colorectal tumorigenesis. Cell 1990;61 (5):759-67.

12. Smith G. Carey FA, Beattie J, Wikie MJ, Lightfoot TJ, Coxhead J, Ganner RC. steele R., Walf CR. Mutations in APC. Kirsten-ras, and p53 -alternative genetic pathways to calorectal cancer. Proc Notl Acad Sci U S A 2002:99: 14):9:433-8.

13. Hanahan D. Weinberg RA. The hallmarks of cancer. Cell 2000;100(1):57-70.

14. Lengaver $C$. Kinzler $\mathrm{KW}$, Vogelstein B. Genetic instabilities in human cancers. Nature $1998 ; 396[6712]: 643-9$.

15. Nowak MA, Komarova NL, Sengupta $A$, Jallepalli PV, Shih le $M_{*}$ Vogellstein $B$, Lengaver $C$. The role of chromosomal instability in fumor initiation. Proc Natl Acad Sci U S A 2002;99/25]:16226-31.

16. Lengaver $C$. Kinzler $K W$. Vogelstein B. DNA methylation and genefic instability in colorectal cancer cells. Proc Natl Acad Sci U S A 1997;94(6):2545-50.

17. Kolodner RD. Marsischky GT. Eukaryotic DNA mismatch repair. Curr Opin Genet Dev 1999:9(1):89 96.

18. Aaltonen LA, Peltomaki P, Leach FS, Sistonen P. Pylkkanen L, Mecklin JP, Jarvinen H, Powell SM, Jen 1 . Hamilton $S R$, ef al. Clues to the pathogenesis of familial colorectal cancer. Science 1993:2601:51091:812-6.

19. Heinen $C D$. Richardson $D$. White $R$, Groden J. Microsatellite instabilify in colorectal adenocarcinoma cell lines that hove full-length adenomatous polyposis coli protein. Camcer Res $1995: 55: 211: 4797-9$.

20. Konishi M, Kikuchi-Yanoshita R, Tanaka K, Muraoka M, Onda A, Okumura Y, Kishi N, Iwamal T, Mon T. Koike M. Ushio K. Chiba M. Nomizu S. Konishi F. Utsunomiya J, Miyaki M. Molecular nafure of colon tumors in hereditary nonpolypasis colon cancer, familial polyposis, and sporadic colon cancer. Gastroenterology 1996:11 11:2]:307-17.

21. Huang J, Papadopoulos N, MCKinley AJ, Farrington SM. Curtis LJ, Wyllie AH, Zheng S, Witson Jik, Markowitz SD, Marin P, Kinzler KW, Vogelstein B, Dunlop MG. APC mutalians in coloreclal tumors with mismatch repair deficiency. Proc Natl Acad SciU S A 1996:93[17]:9049-54.

22. Olschwang $S$, Hamelin R, Laurent-Puig P. Thuille B, De Rycke Y, Li $Y J$. Muzedu F, Grodet J, Salmon R.J. Thomas $G$. Alternative genetic pathways in colorectal carcinogenesis. Prac Natl Acad Sci U S A $11997: 94: 22): 12122-7$.

23. Salahshor S. Kressner U, Pahlman L. Glimelius B, Lindmark G. Lindblom A. Colorectal cancer with and without microsatellite instability involves different genes. Genes Chromosomes Cancer $1999: 26(3): 247-52$.

24. Shitoh K, Konishi F, Mivaki M, lijma T, Furukawa T, Tsukamato T, Nagai $H$. Pathogenesis af nonfamilial colorectal carcinomas with high microsatellite instability. J Clin Pathol 2000;53/111:841-5.

25. Fujiwara T, Stoker JM. Watanabe T, Rashid A, Longo P, Eshleman JR, Booker S. Lynch HT, Jass JR, Green JS, Kim H, Jen J, Vogelstein B, Hamilton SR. Accumulated clonal genetic alterations in familial and sporadic colorectal carcinomas with widespread instability in microsiatellite sequences. Am J Pathol 1998:153[4]":1063-78. 
26. Silattery ML, Curtin K. Anderwon K. Ma KN, Ballard L. Edwards S. Schaffer D. Potter J. Leppert M, Samowitz WS. Associotions between cigarette smoking, lifestyle factors, and microsatellite instiability in collon tumors. 1 Natt Cancer linst 2000:92/22):1831-6.

27. Bodmer WF. Boiley CJ, Bodmer J, Bussey HJ, Ellis A, Gorman P, Lucibello FC. Murday VA, Rjder SH, Scambler $P$, ef all. Localization of the gene for fomilial adenomatous polyposis on chromosome 5 . Nature 1987:328161311:614-6.

28. Lamlum H, Papadopoulou A, llyas M, Rowan A, Gillet C, Honby A, Talbot I, Bodmer W, Tamlinson I. APC mulations are sufficient for the growth of early colorectal adenomas. Proc Natl Acad Sci U S A. 2000:97 $[5]: 2225-8$.

29. Powell SM, ZikZ N Beczer-Barclay Y. Bryan TM, Hamilton SR, Thibodeau SN, Vogelstein B, Kinzler KW. APC mutations occur early during colorectal iumorigenes is. Nature 1992;359(6392):235-7.

30. Polakis P. The adenomatous polyposis coli (APC) fumor suppressor. Biochim Biophys Actio $1997: 1332(3): F 127-47$

31. Nagase H. Nakamura Y. Mutations of the APC (adenomatous polyposis coli) gene. Hum Mutat $1993: 2(6): 425-344$

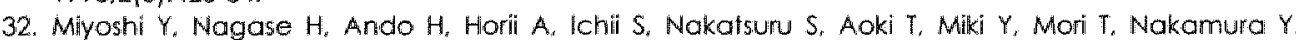
Somatic mutations of the A.PC gene in colorectal tumors: mutation cluster region in the APC gene. Hum Moll Genet 1992:1 (4):22:-33

33. Miyaki M, Konishi M, Kikuchi-Yanioshita R. Emomoto M, Igari $T$, Tanaka K. Muraoka M, Takahashi $H$ Amada $Y$. Fukayama $M$, et al. Characteristics of somatic mutation of the adenomatous polyposis coll gene in colorectal tumars. Cancer Res 1994:54(11):3011-20.

34. Foddle R. The multiple functions of tumour suppressors: if's all in APC. Nat Cell Biol 2003;5:31:190-2.

35. Yost C. Torres M, Miller JR, Huang E, Kimelman D, Moon RT. The axis-inducing activity, stability, and subcellular distribution of beta-catenin is regulated in Xenopus embryos by glycogen synthase kinase 3. Genes Dev 1996:10112):1443-54

36. Rubinfeld B, Albert I, Porfiri E, Fiol C. Munemitsu S. Polakis. P. Binding of GSK3beta to the APC-betacatenin complex and regulation of complex assembly. Science 1996;272(5264):1023-6.

37. Akilyama T. Whit/betamCatenin signaling. Cytokine Growth Factor Rev 2000;1/(4):273-82.

38. Bienz $M$, Clevers Hi, Linking colorectal cancer to Wint signaling. Cell 2000;103(2):311-20.

39. Polakis P. Wht signaling and cancer. Genes Dev 2000:14(15):1837-51.

40. Sparks AB. Marin PJ, Vogelstein B. Kinzler KW. Mutational analysis of the APC/beta-catenin/Tcf pathway in colorectal cancer. Cancer Res 1998:58(6):1 130 4.

41. Morin PJ. Sparks AB, Korinek W. Barker N. Clevers H. Vagelstein B, Kinzler KW. Activation of betacaltenin-Tcl signaling in colon cancer by mutations in beta-catenin or APC [see comments] Science 1997:27515307):1787-90.

42. Vagelstein $B$, Fearon ER. Hamilton SR, Kern SE, Preisinger AC, Leppert M. Nakamura Y, White R, Smits AM. Bos JL. Genetic alterations during colorectaltumor development. N Engl J Med 1988:319191:525:32.

43. Thibodeau SIN. Bren G. Schald D. Microsatelite instability in cancer of the proximal colon. Science $1993 ; 28015109 ;: 81699$

44. Peltomaki $P$, Aaltonen LA, Sistonen P. Pylkkanen L, Mecklin JP, Jarvinen $H$, Green JS, Jass JR, Weber JL, Leach FS, et al. Genetic mapping of a locus predisposing to human colorectal cancer Science 1993:260151091:810-2.

45. Lynch HT, Smyrk TC. Watson P. Lanspa SJ, Lynch JF, Lynch PM, Cavalieri RJ, Boland CR. Genetics, natural history, tumor spectrum, and pathology of hereditary nonpolyposis colorectal cancer: an updated review. Gastroenterology 1993:104 [5]:1535-49.

46. Watson P. Lyinch HT. Extracolonic cancer in hereditary nompolyposis colorectal cancer. Cancer 1993:71(3):677-85.

47. Milchell RJ. Farrington SM, Dunlop MG. Campbell H. Mismatch repair genes hMLHIl and hMSH2 and colorectal cancer: a HuGE review. Am J Epidemiol 2002:156(10):885-902.

48. Herman JG. Umar $A$, Polyak $K$, Graff JR, Ahuja N, Issa JP. Markowitz S, Willson JK, Hamilton SR, Kinzler KW. Kane MF, Kolodner RD, Vogelstein B, Kunkel TA, Baylin SB. Incidence and functiona consequences of hMLHI promoter hypermethylation in calorectal carcinoma. Proc Natl Acadl Sci US A 1998:95(12):6870-5.

49. Kane MF, Loda M. Gaida GM. Lipman 1. Mishra $R$, Galdiman $H$, Jessup JM, Kolodner $R$. Wethylation of the hMLHI promoter correlates with lack of expression of hMLHII in sporadic colon tumors and mismatch repair-defective human fumor cell lines. Cancer Res 1997:57151:808-11. 
50. Myakura $Y$, Sugano K, Konishi F, Ichikawa A, Maekawa M, Shitoh K, lgarashi S, Kotake K, Koyama $\checkmark$. Nagai $H$. Extensive methylation of hMLHI promater region predominates in proximal colon cancer with microsatellite instability. Gastroenterolagy 2001:121/61:1300-9.

51. Thibodeau SN, French AJ. Cunningham JM, Tester D. Burgarl U., Roche PC. MCDonnell SK, Schaid DJ, Vockley CW. Michels WV. Farr GH.Jr. O'Connell MJ. Microsatellite instability in colorectal cancer: different mutatior phenotypes and the principal involvement of hMLH1. Cancer Res $1998: 58(8): 1713-8$.

52. Lin HJ. Probst-Hensch NM, Ingles SA, Han CY, Lin BK, Lee DB. FrankI HD, Lee ER, Longnecker MP, Haile RW". Glutathione transferase (GSTMI] null genotype, smoking, and prevallence of colorectal adenomas. Cancer Res 1995:55(6):1224-6.

53. Gertig DM. Stampfer M, Haiman C. Hennekens CH. Kelsey K. Hunter DJ. Glultathione S-transferase GSTMI and GSTI polymorphisms and colorectal cancer risk: a prospective study. Cancer Epidemiol Biomarkers Prev 1998:7111):1001-5.

54. Slattery ML. Potter JD, Samowitz W, Bigler J, Caan B. Leppert M. NAT2, GSTMk 1, cligarette smoking. and risk of colon cancer. Cancer Epidemiol Biomarkers Prev 1998:7112]:1079-84.

55. van der Hell OL, Bueno de Mesquita HB, Roest M. Slothouber $B$, van Gls $C$, wan Maord PA, Grobbee DE, Peeters PH. No modifying effect of NAII. GSIMI, and GSTII on the relation between smoking and colorectal cancer risk. Cancer Epidemiol Biomarkers Prev 2003;12:77]:681-2.

56. Slattery ML. Edwards $S$, Cuitin $K$, Schaffer D. Neuhausen S. Associations belween smoking. passive smoking, GSTM-1. NAT2, and rectal cancer. Cancer Epidemiol Biomarkers Prev 2003; 12[9]:882-9.

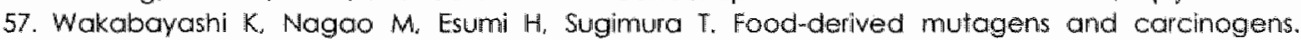
Cancer Res 1992,52(7 Suppl):20925-98s.

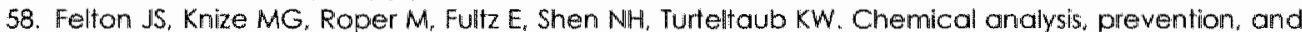
low-level dosimetry of heterocyclic amines from cooked foad. Cancer Res 1992:5217 Suppil:21035$07 \mathrm{~s}$.

59. Ito $N$, Hasegawa R. Sano M. Tamano S. Esumi H. Takayama S, Sugimura T. A new collon and mammary carcinogen in cooked foad, 2-amino-1-methyl-6-phenylimidazo[4,5-b]pyridine (PhIP]. Carcinogenesis 1991;12(8):1503-6.

60. Eisenstadt $E$. Warren AJ, Porter $J$, Atkins D. Miller JH. Carcinogenic epoxides of benzo[a]pyrene and cyclopenta[cd]pyrene induce base substitutions via specific transversions. Froc Natl Acad Sci U S A 1982:79(6):1945-9.

61. Stevens $C W$. Manoharan TH. Fahl WE. Characterization of mutagen-activated cellular oncagenes that confer anchorage independence to human fibroblasts and fumorigenicity to NIH $3 \mathrm{~T}_{3}$ cells: sequence analysis of an enzymatically amplified mutant HRAS allele. Proc Nall Acad Sci U S A 19:88:85:(1 1):3875-9.

62. Bingham SA, Hughes R. Cross AJ. Effect of white versus red meat on endogenous $N$-nitrosation in the human colon and further evidence of a dose response. I Nutr 2002:132(11 Suppl):3522S-255.

63. Mirvish SS. Haorah J. Zhou L. Clapper ML, Harrisan KL. Povey AC. Total $\mathrm{N}$-nitroso compounds and their precursors in hot dogs and in the gastiointestinal tract and feces of rats and mice: possitble etiologic agents for colon cancer. I Nuir 2002:132(1) Suppl):35265-295.

64. Slatteny ML, Curtin K. Ma K, Edwards S, Schaffer D. Anderson K, Samowilz W. Diet activity, and lifestyle assaciations with p53 mutations in coton tumors. Cancer Epidemiol Biomarkers Prev $2002: 11161: 541-8$.

65. Diergaarde B, Temersma E. Braam H, van Muljen G. Nagiengast F, Kok F. Kampman E. Dielary factors and truncating APC mutations in sporadic colorectal adenomas. Int $\mathrm{I}$ Cancer 2005:113:126-32.

66. Diergaarde B. van Geloof WL, van Mujien GN, Kok FJ Kampman E. Dietary factors and the occurrence of truncating APC mutations in sporadic colon carcinomas: a Dutch population. based study. Carcinagenesis 2003:24(2):283-90.

67. Diergaarde B, Braam H, van Muijen GN. Ligtenberg MJ, Kak FJ, Kampman E. Dietary lactors and microsatellite instability in sporadic colon carcinomas. Cancer Epidemiol Biomankers Prev 2003:120111 P\$ 11:1130-6.

68. Giowannucci $\mathrm{E}$, Goldin B. The role of lat, fatty acids, and tolal energy intake in the ellology of human colori cancer. Am J Clin Nutr 1997:6, (6 Suppl):1564\$-71\$.

69. Roynette CE. Calder PC. Dupertuis YM, Pichard C. $\mathrm{n}-3$ polvunsaturated fatty acids and colon cancer prevention. Clin Nutr 2004:23(2):139-51.

70. Leuratti C. Watson MA, Deag EJ. Welch A, Singh R, Gottschalg E, Marnett LJ, Atkin W, Day NE Shuker DE, Bingham SA. Detection of malondialdehyde DNA adducts in human colorectal 
muecsa: relationship with diet and the presence of adenomas. Cancer Epidemiol Biomarkers Prev 2002:1113::267-73

71. Mamell L. Oxyradicals and DNA damage. Carcincgenesis 2000:21/3):361-70.

72. Sharna RA, Iresan CR, Verschoyle RD. Hill KA, Williams ML. Leuratti C. Manson MM, Marnett LJ. steward WP. Gescher $A$. Effects of dietary curcumin on glutathione S-ftransferase and malondicidehyde-DNA adducts in rat liver and colon mucosa: relationship with drug levels. Clin Cancer Res 2001:715:14:52-8.

73: Burcham PC. Intemal hazards: baseline DNA damage by endogenous products of normal metabolism, Mutat Res 1999,443,1-21:11-36

74. Fink SP. Reddy GR. Mamett L. Mutagenicity in Escherichia coli of the major DNA adduct derived from the endogenous mulagen malondialdehyde. Proc Natl Acad Sci U SA 1997:94(1.61:8652-7.

75. Boutista D, Obrador A, Moreno V. Cabeza E, Canet R. Benito E. Bosch X. Costa J. Kïras mutation modifies the profective effect of dietary monounsaturaled fat and calcium on sporadic colorectal cancer Cancer Epidemiol Biomarkers Prev 1997:611):57-61.

76. Slattery ML. Curtin K. Anderson K, Ma KN, Edwards S, Leppert M, Potter J, Schaffer D, Samowitz WS. Associations between dietary intake and Kiras mutations in colon fumors: a population-based study. Cancer Res 2000;60(24):6935-41.

77. Brink M, Weijenberg MP; De Goeij AF, Schouten LJ, Koedijk FD, Roemen GM, Lentjes MH, De Bruine AP, Goldbohm RA, Van Den Brandt PA. Fat and $K$-ras mutations in sporadic colorectal cancer in The Netherlands Cohort Study. Carcinogenesis 2004:25191:1619-28.

78. Glovannuci E, Rimm EB. Stampfer MJ, Colditz GA. Ascherio A, Kearney J. Willelt WC. A prospective sfudy of cigarette smoking and risk of colorectal adenomal and colorectal cancer in U.S. men. INati Cancer Inst 1994:86 (3):183-91.

79. Hoffmann D. Hotfmann I. The changing cigarette, 1950-1995. J Toxicol Environ Health 1997:50(4):307-64.

80. Harris CC. Chemical and physical carcinogenesis: advances and perspectives for the 1990 s. Cancer Res 1991:511 (18 Suppl):5023s-44:s.

81. Yang P. Cunningham JM. Halling KC. Lesnick TG, Burgart LJ, Wiegert EM, Christensen ER, Lindor NM, Katzmann JA, Thibadeau SN. Higher risk of mismatch repair-deficient colorectal cancer in alpha(1)-antitrypsin deficiency carriers and cigarette smakers. Mol Genet Metab 2000;71 (4):63945.

82. Wu AH, Shibata D, YU MC. Lai MY. Ross RK. Dietary heterocyclic amines and microsatellite instability in colon adenocarcinomas. Carcinogenesis 2001;22(10):1681-4.

83. Diergaarde $B$, Virieling $A$, van Kraats A. van Muijen GN, Kok F and genetic alterations in sporadic colon carcinomas. Carcinogenesis $2003 ; 24(3): 565-71$.

84. Brink $M$, Weijenberg MP, de Goeil AF, Roemen GM, Lentjes MH, de Bruine AP, van Engeland $M_{\text {. }}$ Goldbohm RA, van den Brandt PA. Dietary folate intake and k-ras mutations in sporadic colon and rectal cancer in the Netherlands Cohort Study. Int I Cancer 2004.

85. Brink M, Weljenberg MP, de Goeij AF, Roemen GM, Lentjes MH, de Bruine AP, Goldbohm RA. Brandt.P.A. vd. Meat consumplion and Kras mutations in sporadic colorectal cancer in The Netherlands Cohort Study, Br J Cancer 2005;92:4):1310-20.

86. van den Brandt PA, Goldbohm RA, van 't Veer P. Volovics A, Hermus R.J, Sturmarns F. A large-scale prospective cohort study on diet and Cancer in The Netherlands. J Clin Epidemiol 1990:43/3!:285. 95 


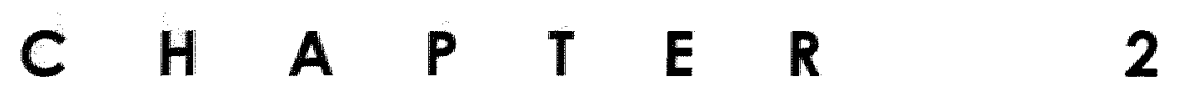




\section{APC MUTATIONS IN SPORADIC COLORECTAL CARCINOMAS FROM THE NETHERLANDS COHORT STUDY}

\footnotetext{
MARGREET LUCHTENBORG

MATTY P WEIJENBERG

GUIDO MJM ROEMEN ADRIAANN P DE BRUIINE

PIET A VAN DEN BRANDT MARJOLEIN HFM LENTJES MIRIAM BRINK MANON VAN ENGELAAND

R ALEXANDRA GOLDBOHM ANTON FPM DE GOEIJ
} 


\section{ABSTRACT}

The adenomatous palyposis coli (APC) gene is considered to be a gatekeeper in colorectal fumourigenesis. Inactivating mutations in APC have been reported in 34 to $70 \%$ of sporadic colorectal cancer patients, the majority of which occur in the mutation cluster region.

In this study, fumour tissue from 665 incident colorectal cancer patients, who originate from 120,852 men and women (55-69 years of age at baseline) participating in the Netherlands Cohart Study, was evaluated for the occurrence and type of APC mutations with regard to age at diagnosis, sex, family history of colorectal cancer, Dukes' stage, tumour differentiation and sub-locallisation. Mutation analysis of the mutation cluster region, which spans codons $1,286-1,513$, was performed on archival adenocarcinoma samples using macrodissection, nested PCR and direct sequencing of purified PCR fragments.

A large number of genetic aberrations $(n=978)$, including point mutations $(n=833)$, deletions $(n=126)$ and insertions $(n=19)$ was detected in APC's mutation cluster region, in $72 \%$ of patients (479/665). In particular, we observed a large number of missense mutations, more than previously reported. This may indicate involvement in colorectal carcinogenesis, although their significance for APC functions is unclear. Truncating mutations were found in $37 \%$ of patients (248/665). Patients with rectosigmoid and rectum fumours relatively more frequently harboured $C \rightarrow T$ nonsense mutations and truncating frameshiff mutations as compared to patients with proximal and distal colon tumours $(p=0.009$ and $p=0.045$, respectively).

Differences in occurrence of truncating mutations with regard to tumour sublocalisation suggest a different aetiology of turnourigenesis in colon and rectum. 


\section{INTRODUCTION}

It is well established that sporadic colorectal cancer arises through a gradual series of histological changes, which are accompanied by specific genetic alterations involving tumour suppressor genes (e.g., APC, DCC, SMAD4, TP53) and oncogenes (e.g., K-ras)..1. 2 Adenomatous polyposis coli (APC) gene mutation is considered to be an early event in colorectal carcinogenesis.

Linkage analysis of families with the autosomal dominant inherited disease familial adenomatous polyposis coli (FAP) has led to mapping of the APC gene to $5 q 21 .{ }^{3}$ This large gene with 21 exons, was subsequently cloned, identified and characterised. ${ }^{4}$ Mutations in both APC alleles were also found in most sporadic colorectal tumours. ${ }^{5}$ Whereas germline mutations in FAP are confined to the $5^{\prime}$ half of the APC gene, somatic mutations are clustered in the central region of the open reading frame, spanning codons 1,286 to $1,5.13$ of exon 15.5 .6 Although this mutation cluster region represents only $8 \%$ of the 8.535 bp APC gene, 68 to $77 \%$ of somatic multations in APC occur in this region.7.8

The APC protein consists of 2,843 amino acids, and comprises a number of functional domains, motifs and other signatures, as reviewed by Polakis. ${ }^{6} \mathrm{APC}$ is capable of binding $\beta$-catenin through its 15 amino acids repeats, situated between amino acids 1,020 and 1.169 .9 More importantly, in the central region of APC, seven motifs of 20 amino acids were identified, which not only bind $\beta$ catenin but also facilitate downregulation of $\beta$-catenin through interactions with Axin and GSK3 $\beta .{ }^{10 .}$ " Through inactivating mutations in the central part of the APC gene, which often lead to complete or partial loss of function of this region, $\beta$-catenin levels are upregulated and the Wnt signalling pathway is activated, which in turn may lead to enhanced proliferation. ${ }^{12}$ In addition to its role in the Wnt pathway. APC has other functions. Through its binding of $\beta$ catenin APC is also linked to E-cadherin and $\alpha$-catenin, which in turn bind actin and actin-associated proteins, thus taking part in intercellular adhesion. ${ }^{13}$ Additionally, APC associates with the microtubule cytoskeleton directly through its carboxyl terminus. There is also evidence that APC may play a rolle in the regulation of apoptosis. ${ }^{14}$

Frequencies and specific types of somatic mutations in the APC gene have been investigated in a number of studies. Somatic mutations in APC have been found in 34 to $70 \%$ of sporadic tumours in colorectal cancer patients. $7,8,15-21$ Higher prevalences of 75 to $95 \%$ have been found in studies on the occurrence of somatic APC mutations in colorectall cancer cell lines. ${ }^{22-24}$ The large majority of mutations observed in different studies would lead to a truncated and therefore inactivated APC protein, either by nonsense point mutations $(30 \%)$ or by frameshift mutations (68\%), as reviewed by Béroud. ${ }^{25}$ Most reports, however. were based on limited numbers of (Usually selected) patients. Studies on somatic APC mutations are often based on FAP patients and it has been shown that the occurrence of a second mutation in the APC gene is somehow dependent on the position of the germline mutation, thereby introducing a bias. ${ }^{26}$ Examination of APC mutations in colorectal cell lines has indicated that there may also be an interdependence of the two hits in APC in sporadic colorectal cancer. ${ }^{23}$ Furthermore, results from different reports are difficult to 
compare as different methods of detecting mutations in APC have been used and different regions of the APC gene have been studied.

In the current report, the frequency and type of APC gene mutations are assessed in a large series of unselected, incident colorectal cancer patients from The Netherlands identified in a prospective cohort study. The occurrence and type of A.PC gene mutations in the mutation cluster region are reporfed with regard to age at diagnosis, sex, family history of colorectal cancer, Dukes stage, tumour differentiation and sub-localisation.

\section{MATERIALS AND METHODS}

\section{STUDY POPULATION}

A prospective cohorf study on diet and cancer was initiated in the Netherlands in September 1986. The study design has been described in detail elsewhere. ${ }^{27}$ Briefly, at baseline a total of 58,279 men and 62,573 women, between the ages of 55 and 69 years, completed a self-administered food frequency and lifestyle questionnaire. The study population originated from 204 municipal population registries throughout the country. Incident cancer cases are ideritified by monitoring of the entire cohort for cancer occurrence through annual record linkage to the Netherlands Cancer Registry (NCR), nine regional cancer registries throughout The Netherlands, and to the Pathologisch Anatomisch Landelijk Geautomatiseerd Archief (PALGA), a nationwide database of pathology reports. ${ }^{28}$ The PALGA database was used to identify and locate tumour tissue in Dutch Pathology laboratories. The first 2.3 years of follow up were excluded due to incomplete nationwide coverage of PALGA. From 1989 until 1994, 819 incident cases with histologically confirmed colorectal cancer were identified. Colorectal cancer was classified according to site as follows, proximal colon: cecum through transverse colon (ICD-O codes 153.0, 153.), 153.4. 153.5. 153.6); distal colon: splenic flexure through sigmoid colon (ICD-O codes 153.2, 153.3, 153.7); rectosigmoid (ICD-O code 154.0) and rectum (ICD-O code 154.1). Information about age at diagnosis, sex and family history of colorectal cancer (at baseline) was retrieved from the Netherlands Cohort Study on diet and cancer (NLCS) database. Information about tumour sublocalisation. Dukes" stage and differentiation was retrieved from the NCR database.

\section{TISSUE SAMPLES}

Tumour material of colorectal cancer patients was collected after approval by the Ethical Review Board of Maastricht University, PALGA and the NCR. Tissue samples from 819 colorectal cancer patients were retrieved from 54 pathology laboratories throughout the Netherlands. Tumour tissue specimen collection started in August 1999 and was completed in December of 2001 . Forty-four tumour tissue samples $(5 \%)$ could not be traced. Of 775 eligible tissue samples 737 (90\%) contained sufficient tumour material as confirmed by a pathologist (A.d.B.) for molecular analyses. 


\section{DNA ISOLATION}

DNA isolation was described in detail elsewhere. ${ }^{29}$ Briefly, one $5 \mu \mathrm{m}$ section were taken from each paraffin-embedded tumour tissue block and stained with haematoxylin and eosin (HE) for histopathological examination. Five $20 \mu \mathrm{m}$ sections of tumour tissue were taken from each sample for DNA isolation. After deparaffination of the sections, fumour tissue was separated from the normal colonic epithelium using the HE section as a reference. Genomic DNA was. extracted from macrodissected tumour tissue using proteinase K (Qiagen. 5t. Louis, MO, USA) and the Puregene DNA isolation kit (Gentra Systems. Minneapolis, MN, USA). DNA concentration and purity was measured in a spectrophotometer at 260 and $280 \mathrm{~nm}$. DNA from the fresh. unfixed colorectal cancer cell lines and the 10 fresh-frozen tissue samples was extracted as described for paraffin-embedded sections.

\section{APC MUTATION ANALYSIS}

Since the majority of somatic mutations in APC occur within the mutation cluster region, we amplified the mutation cluster region as four overlapping fragments (codons $1,286-1,520$ ) in a nested PCR strategy. Flank PCR was performed to generate two fragments $A$ and $B$. Genomic DNA (250 ng) was added to $50 \mathrm{mM}$ $\mathrm{KCl}, 10 \mathrm{mM}$ Tris- $\mathrm{HCl}(\mathrm{pH} 8.3), 2.0 \mathrm{mM} \mathrm{MgCl} 2,250 \mu \mathrm{M}$ dNTP (Pharmacia, Uppsala, Sweden), $200 \mathrm{nM}$ of each primer (table 1), and IU Platinum Taq (Invitrogen. Breda, the Netherlands) in a final volume of $50 \mu \mathrm{l}$. Fragment A was used as starting material for the amplification of nested fragments S1 and S2, and fragment B was used for nested fragments $\$ 3$ and $\$ 4$. An alternative seminested PCR strategy was chosen when nested PCR amplification failed for one or more fragments originating from flank $A$ or $B$. Alternative flank fragments $F 1$ to F4 were then generated for each of the four nested fragments S1 to S4, respectively. The (semi-) nested PCR was performed in a final volume of $50 \mu$, containing $5 \mu \mathrm{l}$ of a $1: 100$ dilution of the flank product, $50 \mathrm{mM} \mathrm{KCl}, 10 \mathrm{mM} \mathrm{Tris-HCl}$ (pH 8.3), 1.5-2.5 mM MgCl2, $250 \mu M$ dNTP, $200 \mathrm{nM}$ of each primer (table 1], and I I Platinum Taq. The four (semi-) nested fragments were labelled with biotin at one of the two primers for subsequent direct sequencing as indicated in table 1. The cycles for both flank, nested and semi-nested PCR consisted of 3 min predenaturation at $94^{\circ} \mathrm{C}, 40$ s at $94^{\circ} \mathrm{C}$ for denaturation, 11 min at $52^{\circ} \mathrm{C}$ to $57^{\circ} \mathrm{C}$ for annealing, 1 min at $72^{\circ} \mathrm{C}$ for elongation, and 10 min at $72^{\circ} \mathrm{C}$ for post-elongation. in each PCR one round of 35 cycles was performed using a Peltier Thermal Cycler-200 (MJ Research. Biozym, Landgraaf, The Netherlands) or a I-cycler (BioRad, Veenendaal, the Netherlands). In each PCR series positive (DNA from colorectal cancer cell lines) and negative controls (no DNA) were included. The length and concentration of the PCR products were checked by electrophoresis on $2 \%$ agarose gels and visualised with ethidium bromide.

Mutation analysis was performed by direct sequencing using the Autoload SPS Sequencing Kit according to the manufacturers instructions (Amersham Biosciences, Roosendad, the Netherlands). In brief, the biotinylated PCR product was captured on a sequencing comb coated with streptavidin. Alter removal of the non-biotinylated strands by alkaline denaturation, the remaining immobilised strand was used as a template for dideoxy sequencing reactions with extended Cy5 labelled primers (table 1) and T7 DNA polymerase. The sequence profile was analysed on ALFexpress DNA Analysis System using ALFwin 
Table 1. Fragment characteristics for the amplification and sequencing of the mutation chuster region of the APC gene

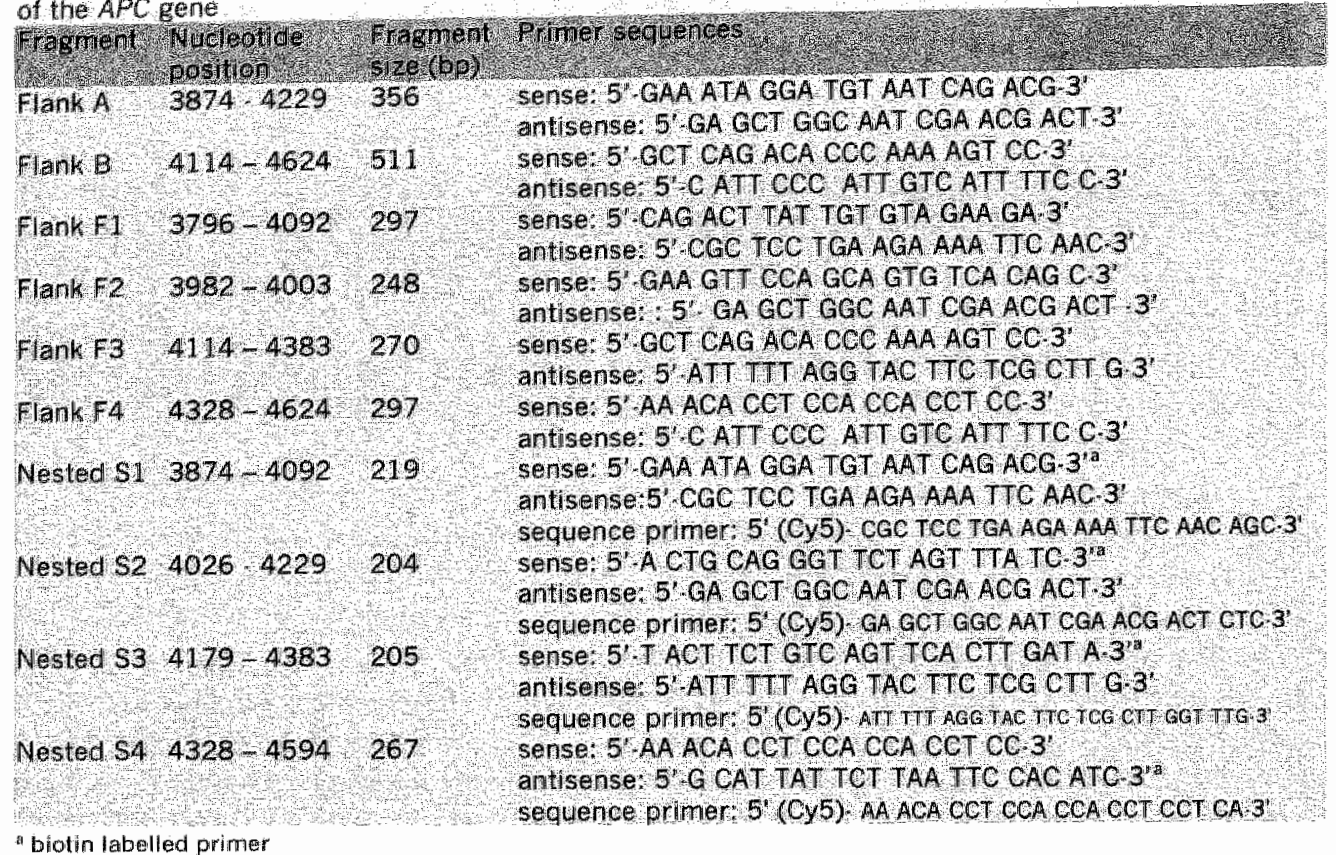

software (Amersham Biosciences, Roosendaal, the Netherlands). Evaluation of the sequence patterns was performed by two independent observers, based on the criteria that an increase of at least $5 \%$ is observed for the mutant peak, as well as a decrease of at least $5 \%$ of the wild type peak, relative to the wild type pattern in the same sequence run. The reference sequence for human APC was derived from Genbank Accession Number M74088.1. Data entry was performed blindly, by two independent observers.

From 72 patients of the 737 patients whose fumour samples contained sufficient DNA, one or more fragments of the mutation cluster region could not be amplified and these patients were not included in this study. The 665 patients, from whom mutation cluster region mutation analysis was complete, were comparable with the 819 colorectal cancer patients initially recognised within the cohort with respect to mean age at diagnosis, sex, family history of colorectal cancer, Dukes" stage, tumour differentiation and sub-localisation.

\section{VALIDITY AND REPRODUCIBILITY OF APC MUTATION ANALYSIS}

In order to validate mutation analysis on paraffin-embedded tissue, 10 freshly obtained calorectal cancer specimens were each divided in two adjacent tissue blocks, one of which was firesh-frozen, and the other routinely fixed and embedded in paraffin. Two samples contained wild type APC, three samples harboured a mutation and five samples had a polymorphism. These control specimens were obtained from patients who did not participate in the NLCS. Six colorectal cancer cell lines, i.e. HT29, Colo205, CaCo2, SW480, HCT116 and LOVO lobtained from the American Type Culture Collection, Rockville, MD, USA) were used to check the specificity of mutation detection in the mutation 
cluster region of APC. The detection limit of mutation analysis was determined by mixing homozygously mutated DNA isolated from $\mathrm{CaCo} 2$ cells $\mid \mathrm{C} \rightarrow T$ substitution at codon 1,367 ) with increasing concentrations of the corresponding wild type DNA sequence prepared from $\$ W 480$ cells. Reproducibility of mutation analysis was established by subjecting 72 fragments, derived from 54 NLCS adenocarcinoma specimens twice to the complete mutation analysis procedure, from flank PCR of genomic DNA to sequencing of the fragments S1-S4.

\section{STATISTICAL ANALYSIS}

The overall frequency of APC mutations as well as the type of mutation was computed for all 665 cases with respect to age at diagnosis, sex and family history of colorectal cancer. Since tumour subulocalisation was unknown for 11 patients, 654 patients could be analysed for different mutation types with regard to tumour sub-localisation. Differences in mean age at diagnosis were evaluated pairwise between patients with wild type APC and patients with APC mutations using the Mann-Whitney $U$ test. The mean age at diagnosis of patients with an APC mutation, i.e. silent, milssense or nonsense/frameshift mutations was compared to that of patients with wild type APC. Differences in the categorical variables sex and family history of colorectal cancer. Dukes'stage, tumour differentiation and sub-localisation between patients without and with APC mutations and type of mutation were evaluated using the $\chi^{2}$ test. A $p$-value of 0.05 or less was considered to be statistically significant. All statistical procedures were performed with SPSS software (SPSS version 10.0, SPSS Chicago, IL, USA).

\section{RES ULTS}

In the colorectal cancer cell lines HCT116, Colo205 and HT29, wild type sequences were confirmed for the mutation cluster region of APC. Direct sequencing of the mutation cluster region of $A P C$ revealed a homozygous $C \rightarrow T$ substitution at codon 1,367 in CaCo2 cells, a heterozygous $C \rightarrow T$ substitution at codon 1,338 in SW480 cells and a deletion of C at codon 1,430 in LOVO cells, as previously described.23 The effect of tissue processing as assessed in 10 specimens, showed that the mutation status of the mutation ciuster region of APC for the paraffin-embedded block was identical to fresh unfixed tissue. The lowest level of detection was 5\% mutant DNA in a background of wild type DNA as found in three independent experiments. In $85 \%(61 / 72)$ of the fragments anallysed for reproducibility assessment, the same APC mutation status was observed in duplicate experiments.

In $72 \%$ of tumours from colorectal cancer patients (479/665) a total of 978 mutations were observed in the mutation cluster region of the APC gene. The number of observed mutations per fumour ranged from one to eight mutations. In 215 tumours (45\%) one mutation was found, in 137 tumours (29\%) two mutations and in 127 tumours $(27 \%)$ more than two mutations were observed. Of all mutations observed, $85 \%$ (833/978) were point mutations and $15 \%$ (145/978) were insertions and deletions [table 2). Point mutations were 
Talble 2. Number and lype of mutations in the mutation chustar region of APC. All 978 mutations detected in tumours from 665 sporadic colorectal cancer patients are represented.

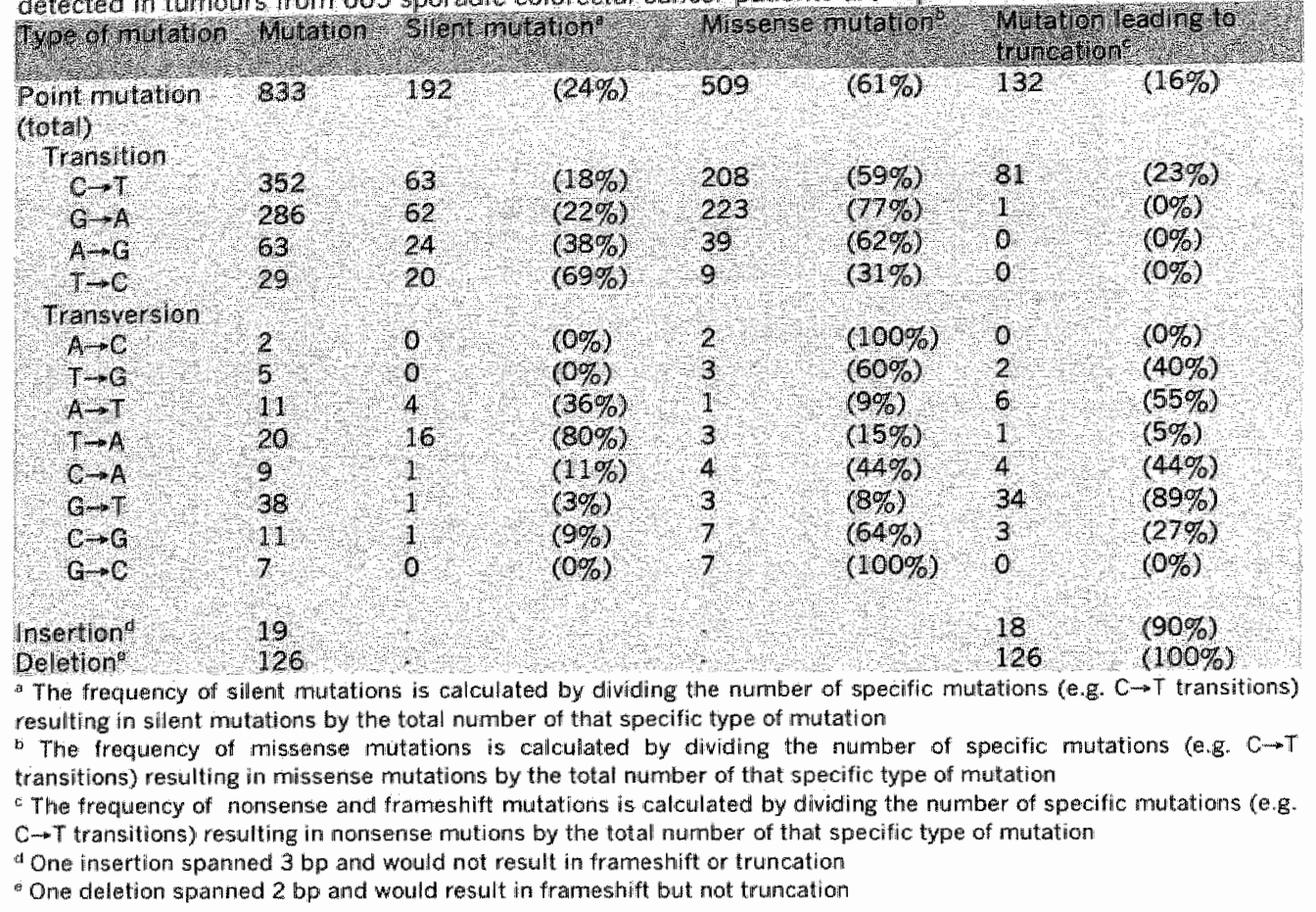

predominanfly missense mutations (61\%) and less frequently consisted of nonsense mutations (16\%) or silent mutations (23\%). Transitions were the most common type of point mutations $(730 / 833)$, in large majority represented by $C \rightarrow T$ and $G \rightarrow A$ transitions $(n=352$ and $n=286$, respectively). Of $C \rightarrow T$ and $G \rightarrow A$ transitions $23 \%$ occurred at CpG dinucleotides. A polymorphism (G4497A), which does not result in an altered amino acid. was observed in $74 \%(493 / 665)$ of patients.

Eighty-seven percent of frameshift mutations (126/145) were deletions (table 2). The length of the frameshift ranged from 1 to $5 \mathrm{bp}$ for insertions and 1 to $49 \mathrm{bp}$ for deletions. Generally, frameshift mutations would lead to serious alterations in the amino acid sequence downstream of the mutation and also result in the introduction of a stop codon. However, one insertion spanned 3 bp and would nat result in frameshift or truncation.

In the distribution of the truncating mutations several hot spots could be observed (figure 1, top panell. The frameshift mutations seem to cluster in the regions at codons $1,350-1,356,1,411-1,419,1,465,1,485-1,495$, and at codon 1,309 . where an AAAAG deletion was defected in 26 tumours. A high frequency of nonsense point mutations was detected at codons 1.294, 1,306, 1,328, 1,367, $1,378,1,406,1,429$ and 1,450 . The large number of missense mutations was distributed rather evenly throughout the mutation cluster region of APC and did not show distinct hat spots (figure 1, bottom panel). 

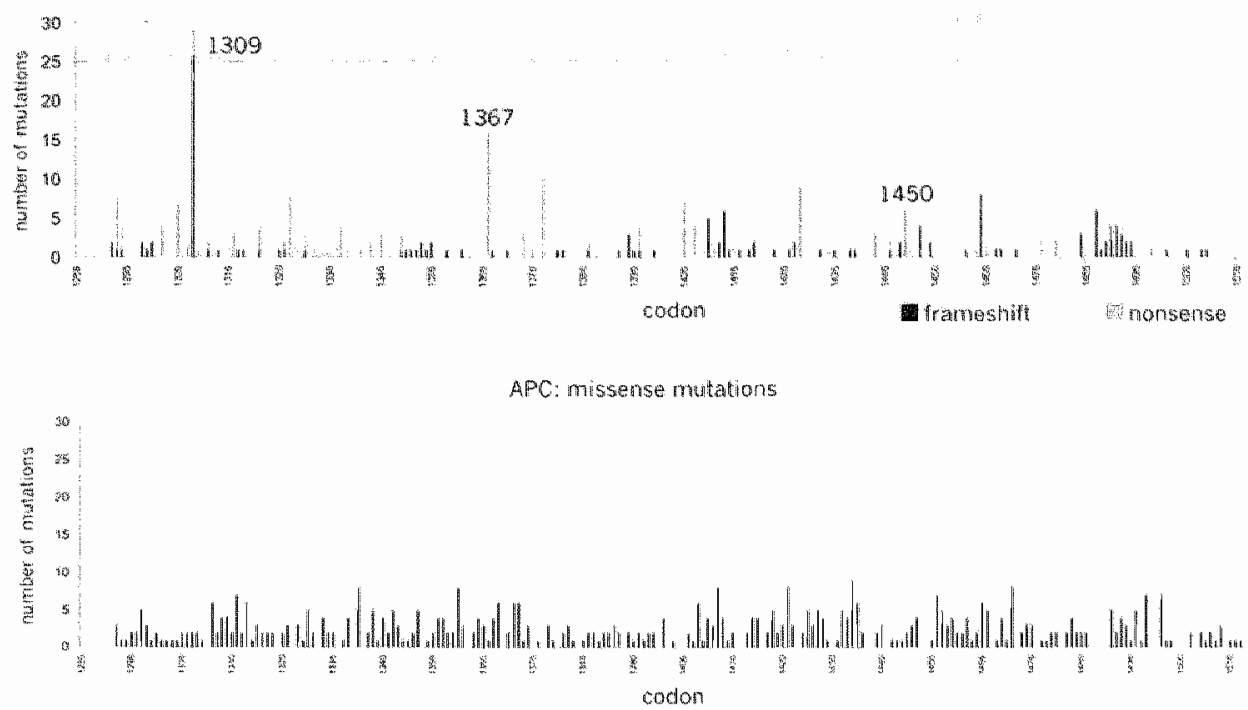

Figure 1. Distribution and frequency of 143 frameshift mutations and 132 nonsense mutations 1 thop panel) and 509 missense mutations (bottom panel) observed in fumour material from 665 sporadic colorectal cancer patients. The $x$-axis schematically represents the codons of the APC mutation cluster region.

The 479 patients that harboured mutations were divided into different groups on basis of having a tumour with either a wild type or a mutant APC with various types of gene mutations (table 3 ). In total, $52 \%$ (248/479) of the patients with a mutation in the mulation cluster region of APC, which corresponds to $37 \%$ of all patients $248 / 665$ ) harboured at least one nonsense or frameshift mutation that would result in a truncated APC protein. Of patients with a truncating mulation $59 \%$ (145/247) had more than one mutation leading to a change in the APC protein, i.e. another nonsense and frameshift mutation $(n=27)$ or missense mutation $(n=118)$. Forty per cent of the patients (191/479) with a mutation in the mutation cluster region, corresponding to $29 \%$ of all patients (191/665), harboured at least one missense mutation and no nonsense or frameshift mutations. Eighteen per cent of patients (84/479) had two or more missense mutations. Of all patients, 6\% (40/665) had one or more silent mutations and no other type of mutation, and six of these patients had two silent mutations (table 3).

The mean age at diagnosis was lower for patients with mutation(s) in APC as compared to patients with wild type APC $167.66 \pm 4.21$ versus $68.75 \pm 4.32$. respectively, $p=0.002$ ) (table 3). Detailed analysis of subgroups of mutations revealed that patients with silent mutations $(p=0.008)$, missense mutations $(p=0.065)$ and nonsense or frameshift mutations $(p=0.002)$ were relatively younger when diagnosed with a colorectal tumour as compared to patients with wild type APC (table 3). No differences were observed in the occurrence of APC mutations with respect to sex and family history of colorectal cancer $(p=$ 0.630 and $p=0.364$, respectively) (table 3 ). No statistically significant differences 
in the occurrence and type of APC mutations with respect to Dukes' stage and tumour differentiation were observed (data not shown).

No statisfically significant overall difference belween patients without and with any APC mutation was observed with respect to tumour sub-localisation. However, when considering specific types of mutations, patients with rectosigmoid and rectal tumours had a relatively higher frequency of truncating APC mutations as compared to patients with a proximal or distal colon tumour (53\% and $45 \%$ versus $31 \%$ and $32 \%$, respectively, $p=0.029$ ) (table 3 ).

Table 3. Characteristics of 665 colorectal cancer cases without an APC mutation or with at least one silent, missense or nonsense mutation

\begin{tabular}{|c|c|c|c|c|c|c|}
\hline 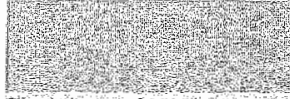 & (n) & 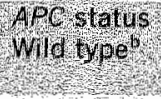 & 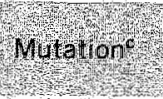 & 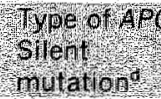 & 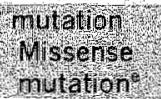 & Mulaturo \\
\hline Number of patients & 665 & 186 & 479. & 40 & $191 \mathrm{l}$ & 248 \\
\hline $\begin{array}{l}\text { Age at diagnosls } \\
\text { mean SD }\end{array}$ & $67,96,4,26$ & $68,75,4,32$ & $67,66,4,21$ & $66,85,4.21$ & $6797,4,31$ & $6755,4,12$ \\
\hline ptalues: & & & 0,002 & 0,01 & 0,07 & 0,002 \\
\hline $\mathrm{Sex}(\mathrm{g} / \mathrm{male})$ & 371 & $101(54)$ & $270(56)$ & $16(39)$ & $112(59)$ & $142(57)$ \\
\hline pValue & & & 0,63 & 0.10 & 0.40 & 0.54 \\
\hline $\begin{array}{l}\text { Fanulastory of } \\
\text { coloretalcancer }\end{array}$ & 64 & $21(1)$ & $43(9)$ & $4(10)$ & $16(8)$ & $23(9)$ \\
\hline $\begin{array}{l}(9 \text { yes }) \\
p . \text { Valuen }\end{array}$ & & & & 88 & $=$ & \\
\hline Sulb $10 \mathrm{cal} / \mathrm{sat} \mathrm{m}^{2}$ & 654 & 183 & 472 & 39 & 190 & 242 \\
\hline Proximal colon (o) & 223 & $71(32)$ & $152(68)$ & $5(7)$ & $68(31)$ & $69(3)$ \\
\hline Distal colon $(0)$ & 206 & $56(27)$ & $150(73)$ & $12(6)$ & $72(35)$ & $66(32)$ \\
\hline Rectosigmoid (of) & 74 & $18(24)$ & $56(76)$ & $3(4)$ & $14(19)$ & $39(53)$ \\
\hline $\begin{array}{l}\text { Rectum }(\%) \\
\text { DVal wes }\end{array}$ & 151 & $38(25)$ & $\frac{113(75)}{0,}$ & $9(6)$ & $36(24)$ & $68(45)$ \\
\hline & & & & $0.9 \%$ & 0.45 & 0.03 \\
\hline
\end{tabular}

"Information on tumour sub-localisation was avallable for 654 patients

"Fatients without any numbations

c Patients with at least one mutalion

"Patients with at least one silent mutation, but without any missense or nonsense or frameshift mutations

"Patients with at least one missense mutation, but without any nonsense or frameshift mutations

Patients with at least one nonsense or frameshift mutation

g. Values were calculated for parkise comparisons of distribution of sub focalisation for patients with an APC wild type $A P C$ C

the frequency of patients with a sllent, missense or norsiensefframeshift mutation per sublocalisation was

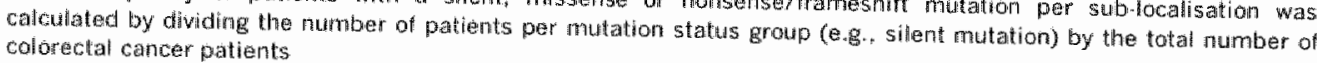

Most mutations that would lead to a truncated APC protein are caused by $\mathrm{C} \rightarrow \mathrm{T}$ transitions, $G \rightarrow T$ transwersions and frameshift mutations. Patients with proximal colon tumours have relatively less $\mathrm{C} \rightarrow \mathrm{T}$ nonsense mufations than patients with a distal colon, rectosigmoid and rectal tumour $17 \%$ versus $12 \%, 22 \%$ and $13 \%$, respectively, $p=0.009$ ) (table 4). Patients with rectosigmoid and rectal tumours have a relatively higher frequency of truncating APC mutations as compared to patients with a proximal or distal colon tumour $\{23 \%$ and $30 \%$ versus $19 \%$ and $16 \%$, respectively, $p=0.045$ ) (table 4). No statistically significant difference in the occurrence of $\mathrm{G} \rightarrow T$ nonsense mutations was observed between patients with tumours at the different sub-localisations (table 4]. With regard to distribution of all $C: G \rightarrow T: A$ transitions over the different sub-localisations, irrespective of their 
putative effect on the APC protein, these seemed to occur relatively more frequently in distal colon. rectosigmaid and rectum as compared the the proximal colon, but this was not statistically significant (data not shown).

Table 4. Characterisation of most common types of truncating APC mutations according to sub localisation of the tumour in 654 sporadic colorectal cancer patients

\begin{tabular}{|c|c|c|c|c|c|}
\hline & Tota & Wild & Worem & (moly & 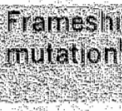 \\
\hline \multicolumn{6}{|l|}{ Sub localisation: } \\
\hline Proximal colon $(\%)$ & 223 & $71(32)$ & $15(7)$ & $12(5)$ & $42(19)$ \\
\hline Distal colon $(9)^{d}$ & 206 & $56(27)$ & $25(12)$ & $7(3)$ & $33(16)$ \\
\hline Rectosigmold $(\%)$ & 74 & $18(24)$ & $16(22)$ & $8(11)$ & $17(23)$ \\
\hline Rectum $(\%)^{\circ}$ & 151 & $38(25)$ & $19(13)$ & $6(4)$ & $46(30)$ \\
\hline
\end{tabular}
pralue $\mathrm{e}^{\mathrm{e}}$

"For one patient $\mathrm{a} \rightarrow \mathrm{C}$ transition and $\mathrm{a} G \rightarrow \mathrm{T}$ transversion was found. This patient was included in both groups.

- For 13 patients frameshift as well as $\mathrm{C} \rightarrow \mathrm{T}$ transitions were found. These patients were included in both groups

r. For 5 patients frameshift as well as $\mathrm{G} \rightarrow \mathrm{T}$ transversions were found. These patients were included in both groups

* The frequency of patients with wild type $A P C, C \rightarrow T$ transitions, $G \rightarrow T$ transwersions or frameshift mutations per tumour sub-localization was calculated by dividing the number of patients per mutation group (e.g. C $\rightarrow T$ Transition) by the total number of colorectal cancer patients

- p.Values were calculated for parwise comparisons af distribution of sub-localization for patients with at least one $c \rightarrow$ T transition $(n=75)$, patients with at least one $G \rightarrow T$ transversion $(n=33)$ or those with at least one frameshift mutation ( $(n=137)$ to patients with wild type APC

" $p$.Value could not be interpreted due to lack of sufficient patients in respective groups

\section{DISCUSSION}

The occurrence and type of somatic mutations in the mutation cluster region of the APC gene was evaluated in 665 tumour samples from an unselected, welldefined group of incident collorectal cancer patients from the Netherlands (age at diagnosis between 57 and 67 years). Seventy-two percent of patients (479/6.65) harboured a total of 978 mutations in the APC mutation cluster region. In particular, we observed a large number $(n=508)$ of missense point mutations. Mutations that would lead to protein truncation were found in $37 \%$ of patients (248/665). Patients with rectosigmoid and rectum tumours relatively more frequently harboured $\mathrm{C} \rightarrow$ T nonsense mutations and deletions and insertions that would lead to protein truncation as compared to patients with proximal and distal colon tumours.

In this study, DNA from archival tumour tissue was used. As this formalin-fixed, paraffin-embedded tissue contains highly fragmented genomic DNA, gene analysis can be difficult. The analysis of APC mutations is based on nested amplification and direct sequencing of purified PCR fragments, a highly sensitive and specific detection method. Using this method on archival tissue yields valid results, as shown in the identical mutations status of fresh tissue and paraffin-embedded tissue. Moreover. most mutations leading to truncation of the APC protein observed in this study were also reported in an APC database (http://www.umd.necker.fr:2008/).

Due to fragmentation of DNA from archival sources, a protein truncation test or similar methods are not feasible, as these techniques require fully intact DNA strands. In other studies, protein truncation test, 7 in vitro synthesised protein / in vitro transcription and translation assay 1\%. ${ }^{24}$ were used, thereby selectively 
identifying truncating mutations. Although these methods provide conclusive information on the functional aberrations in APC, i.e. fruncating mutations, these do not yield information on the occurrence of other than truncating mutations. indeed, the large number of mutations detected in our study is mainly due to the high prevalence of other than truncating mutations.

Techniques used for mutation screening such as single-strand conformational polymorphism, $8.16-18.27$. 30 RNase protection assay? or denaturing gradient gel electrophoresis'31 show differences in sensitivity and/or specificity of mutation detection. In particular, the interpretation of single-strand conformational polymorphism assays is difficult and its sensitivity is relatively low.32 Omission of a screening assay prior to sequence analysis may therefore partially explain the large number of mutations found in this study.

We observed multiple mutations in $40 \%$ of adenocarcinomas, ranging from two to eight mutations per tumour. Possibly, this reflects the occurrence of mutations in both alleles of the APC locus. Since APC is a tumour suppressor gene, more than one inactivating mutation would be necessary to result in loss of APC function in the cell. However, we are unable to distinguish different alleles in our analyses. Another explanation for multiple mutations within a tumour may be that it is a reflection of fumour heterageneity. In a recent study of advanced colorectal tumours, heterogeneity in the mutational status of TP53 and K-ras within the same tumour was demonstraled. 33 We performed macrodissection on the samples that were analysed, as a result of which we may have included different subclones of a fumour that possibly harbour different mutations.

Another plausible cause of multiple mutations is a defect in the DNA repair systems. Inherited variants of the base excision repair gene MYH were found to give rise to $G \rightarrow T$ and $C \rightarrow A$ transversions in a family that is affected with multiple colorectal adenomas and carcinoma. ${ }^{34}$ Recentiy, these inherited variants of MYH have also been observed in a population-based series of colorectal cancer patients, ${ }^{35}$ suggesting that a proportion of the 46 patients that harboured $a \mathrm{G} \rightarrow T$ or $C \rightarrow A$ transversions in our study may be due to inherited MYH mutations. Defects in the mismatch repair genes hMLH1 and hMSH2, resulting in mismatch repair deficiency is found in hereditary non-polyposis coli and is also found in approximately $15 \%$ of sporadic colorectal tumours. However, reported results are inconsistent as to whether mismatch repair deficiency is an alternative pathway in colorectal tumours with intact APC function ${ }^{36 .} 37$ or that it independently gives rise to an increased frequency of APC mutations. $38-40$

The majority of observed mutations were point mutations, $61 \%$ of which give rise to substitution of one amino acid. The relevance of missense mutations in $A P C$ is not yet understood. It is unclear which of these changes would affect the structure and function of the APC protein and whether such an alteration would lead to selective advantage of tumour cells and tumour growth. Intriguingly, $52 \%$ of patients with truncating mutations also had one or more concurrent missense mutation(s). If the occurrence of these missense mutations is the reflection of a biallelic event, this may indicate involvement of missense APC mutations in colorectal tumourigenesis. 
Twenty-three percent of the point mutations would not lead to protein truncation or an altered amino acid. In addition, a polymorphism [G4497 A], which does not result in an altered amino acid was observed in $74 \%(493 / 665)$ of patients. This polymorphism has also been recently described in a series of adenoma samples from Dutch patients, ${ }^{31}$ which suggests that this polymorphism represents a wild type DNA sequence in APC in the Dutch population.

Considering all mutations that are detected in the mutation cluster region, only $28 \%$ (276/978) would lead to a truncated APC protein, half of which are represented by point mutations. This is in contrast with previous reports that up to $98 \%$ of mutations would lead to a truncated APC protein, and only one third of these are caused by point mutations. ${ }^{25}$

Only $37 \%$ of patients (247/665) harboured mutations that would lead to a Iruncated APC protein. Considering the general idea that most colorectal fumours follow a molecular pathway involving APC, our abserved frequency seems low. It is, however, in keeping with the frequency of $3.4 \%$ truncating mutations found in the mutation cluster region in another Dutch populationbased case-control study. ${ }^{21}$ The mutation cluster region spans several 20 amino acid repeats, which form the $\beta$-catenin binding sites and therefore the mutation cluster region represents a functionally important domain of the APC gene. According to several reports 68 to $77 \%$ of the somatic mutations in APC are found in the mutation cluster region, which represents less than $10 \%$ of the APC coding region. $5,7,8$ We are unable to make any predictions of the accurrence of mutations in the complete APC gene, since our mutation analysis was restricted to the mutation cluster region of $A P C$.

Other explanations for the relatively low frequency of truncaling mutations of $A P C$ in the colorectal tumours observed here, are that these tumours may have arisen through other genetic or epi-genetic events. APC is a key player in the Wint pathway. Inactivating mutations that cause loss of $\beta$-catenin binding and degradation sites on the APC protein, would lead to increased levels of intranuclear $\beta$-catenin.\%. 22 However, it has also been shown that activating mutations in the CTNNBI gene can lead to stabilisation and accumulation of the $\beta$-catenin protein, $41, \$ 2$ thereby circumventing the necessity for mutations in $A P C$ to activate the Wnt pathway. Hypermethylation of the promotor region of APC constitutes an alternative mechanism for gene inactivation. This was found to occur in $18 \%$ of primary sporadic colorectal carcinomas, ${ }^{43}$ and in $39 \%$ of a sample of 122 colorectal cancer cases from our study, although these cases were selected on high and low methyl donor intake.44

FAP tumours generally arise at a young age through a germline mutation in the APC gene. Our APC gene mutation analysis is based on a relatively large series of unselected, incident colorectal cancer patients, who were between 55 and 69 years of age at baseline and have developed a first colorectal tumour since. This strongly suggests that the mutations observed in this study are acquired and therefore of somatic nature. Moreover, no significant differences in family history of colorectal cancer between patients without and with APC mutations were abserved, which also argues against germline mutations. The observation that there were no statistically significant differences in occurrence and type of APC mutations with respect to Dukes' stage and tumour differentiation support the 
hypothesis that APC gene mutation is an early event in colorectal tumourigenesis.

The differences in the occurrence of specific types of mutations in colon versus rectosigmoid and recium cancer shown here, suggests a different defiology of tumourigenesis in the different sub-localisations and it may also reflect the exogenous origin of mutations. This is supported by a recent report of $\mathrm{K}$-ras mutations in colorectal cancer tissue of patients from our study, in which mutations in K-ras were also more frequently observed in rectum fumours as compared to rectosigmoid and colon fumours. ${ }^{29}$ The data with respect to the rectosigmoid have to be regarded with some caution as the rectosigmoid is a more clinically applied term rather than an anatomically defined transitional zone between colon and rectum. ${ }^{29}$ When rectosigmoid tumours were excluded from the analyses, both frameshift and $C \rightarrow T$ mutations that would result in protein truncation occurred relatively more frequently in the rectum as compared to proximal and distal colon. However, the asymmetry of $\mathrm{C} \rightarrow T$ nonsense mutations with regard fo tumour sub-localisation was less pronounced.

In conclusion, a large number of mutations was found in the mutation cluster region of the APC gene, in particular, we observed many missense point mutations, more than previously reported. Missense mutations need further exploring with regard to their role in APC function and colorectal tumourigenesis. Patients with a rectosigmoid or rectum tumour relatively more frequently have a truncating $C \rightarrow T$ transition or frameshift mutation as compared to patients with a proximal or distal colon fumour. The pattern of APC mutations abserved in the different sub-localisations of the colorectal tract suggests a different aetiology for tumour site within the large bowel. 


\section{REFERENCES}

1. Fearon ER, Wogelstein B. A genetic madel for colorectal tumorigenesis. Cell $1990 ; 6)(5): 759-67$.

2. Fodde R. The APC gene in colorectal cancer. Eur J Concer 2002,38(7):867-71.

3. Bodmer WF, Bailey CJ, Bodmer J. Bussey HI, Ellis A. Gorman P, Lucibello FC, Murday VA, Rider SH, Scambler $P$, el al. Localisation of the gene for familial adenomatous polyposis on chromosome 5 . Nature 1987:328(6131):614-6.

4. Kinzler KW, Nibert MC, SU LK, Vagelstein B, Eryan TM, Levy DB. Smith KJ, Preisinger AC, Hedge P. Mckechnie D. ef al. Identification of FAP lacus genes from chromosome 5q21. Science $1991: 253(5020): 661-5$.

5. Nagase $H$. Nakamura $Y$. Mutations of the APC (adenomatous polyposis coli) gene. Hum Mutat $1993: 2(6): 42534$.

6. Pollakis P. The adenomatous polyposis coli (APC) tumor suppressor. Blachim Biophys Acto 1997:1332(3): F127-47.

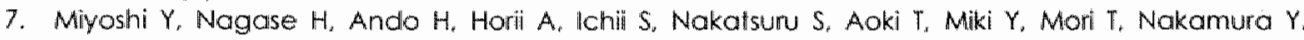
Somalic mutations of the APC gene in colorectal lumors: mutation cluster region in the APC gene. Hum Mol Genet 1992;1/4):229-33.

8. Miyaki M, Konishi M, Kikuchi-Yanoshifa R. Enomoto M. Igari T. Tanaka K. Muraoka M. Takahashi H, Amada $Y$. Fukayama $M$ ef al. Characteristics of somatic mutation of the adenomataus polyposis coli gene in colorectal tumors. Cancer Res 199:4:54(1)1):3011-20.

9. Su LK, Vagelstein $B$, Kinzler KW. Association of the A.PC tumor suppressor protein with catenins. Science $1993 ; 262(5) 40): 1734-7$.

10. Yost $C$, Torres $M$, Miller JR. Huang E, Kimelman D, Moon RT. The axis-inducing activity, stability, and subcelliular distribution of betal-catenin is regulated in Xenopus embryos by glycogen syrithase kinase 3. Genes Dev 1996:10(12):1443-54.

11. Rubinfeld B, Albert I. Portiri E, Fiol C, Munemitsu S, Polakis P. Binding of GSK3beta to the APC-betacatenin complex and regulation of complex assembly. Science 1996:272(5264):1023-6.

12. Rubinfeld B. Albert 1, Porfiri E. Munemitsu S. Polakis P. Loss of beta-Catenin regulation by the APC tumor suppressor protein correlates with lass of structure due to common somatic mutations of the gene. Concer Res 1997:57(20):4624-30.

13. Fearnhead NS, Britton MP, Brodmer WF. The abc of apc. Hum Mol Genel 2001:10171:721-33.

14. Morin P., Vogelstein B, Kinzler KW. Apoptosis and APC in colorectal tumorigenesis. Proc Natl Acad Sci U S A 1998:93[15]:7950-4.

15. Powell SM, Zilz N, Beazer-Barclay $Y$, Bryan TM, Hamilton SR, Thibodeau SN, Vogelstein B, Kinzler $K W$. APC muttations occur early during colorectal tumorigenesis. Nature 1992:359(6392]:235-7.

16. Cottrell S, Bicknell D, Koklamanis L, Bodmer WF. Molecular analysis of APC mutations in familial adenomatous polyposis and sporadic colon carcinomas. Lancel 1992;340;88201:626-30.

17. Yashima K. Nakamori S. Murakami Y, Yamaguchi A. Hayashi K, Ishikawa O. Konishi Y, Selkiya T. Mutations of the adenomatous polyposis coli gene in the mutation cluster region: comparison of human pancreatic and colorectal cancers. Int $\mathbb{J}$ Cancer 1994:59:11:43-7.

18. Konishi M. Kikuchi-Yanoshita R. Tanaka K. Muraoka M. Onda A, Okumura Y, Kishi N, Iwama T, Mori T. Koike M. Ushio K. Chiba M. Nomizu S, Kanishi F. Utsunomiya J. Miyaki M. Molecular nature of colon tumors in hereditary nonpolyposis colon cancer. familial polyposis, and sporadic colon cancer. Gastroenterology 1996:1111(2):307-17.

19. De Filippo C, Luceri C, Cademi G. Pacini M, Messerini L, Biggeri A, Mini E, Tonelli F, Clanchi F. Dalara P. Mutations of the APC gene in human sporadic colorectal cancers. Scand I Gastroenterol 2002:37(9):10:48-53.

20. Kim Sh St: Kaminker P. Campisi J. Telomeres, aging and cancer: in search of a happy ending. Oncogene 2002;21 (4):503-11

21. Diergaarde B, van Geloof WL, van Muijen GN, Kok FJ, Kampman E. Dietary factors and the occurrence of truncating APC mutations in sporadic colon carcinomas: a Dutch populationbased study. Carcinogenesis 2003:24121:283-90.

22. Smith KJ. Johnson KA. Bryan TM, Hill DE, Markowillz S, Willson JK, Paraskeva C. Petersen GM. Hamilton SR, Vogelstein $B_{\text {r }}$ et al. The APC gene product in normall and fumor cells. Proc Nati Acad SCI USA 1993:90171:2846-50.

23. Rowan AJ. Lamlum H. llyas $M$, Wheeler J. Stroub J. Papadopoulou A. Bicknell D. Badmer WF Tarnlinson IP. APC mutations in sporadic collorectal tumors: A mutational "hotspot" and interdependence of the "fwo hits". Proc Noll Acad Sci U S A 2000;97(7):3352-7. 
24. Goyet J, Zhou XP, Duval A, Rolland S. Hoong MM. Coth P. Hamelin R. Extensive charactenzation of genetic alferations in a series of human colorectol cancer cell hines. Oncogene 2001.20(36):502532 .

25. Beroud C. Souss T. APC gene: database of germline and sornatic mutations in human tumors and cell ines. Wucleic Acids Res $1996 ; 24: 11: 121-4$

26. Larnlum H. llyas M, Rowan A, Clark S. Johnson W. Bell J. Froyling I. Efstathiou J. Pack K, Payne S. Roylance $R$, Gorman P. Sheer D. Neale K. Phillips $R$, Talbot I, Bodmer $W$. Tomilison 1 . The type of somatic mutotion at APC in familial adenomatous polyposis is detemined by the site of the gemline mutation: a new facet fo Krudson's "fwo-hif" hypothesis. Nat Med 1999:5191:1071-5.

27. van den Brandi PA, Goldbohm RA, van "I Veer P. Volovics A, Hermus R.J. Sturmans F. A Iarge-scale prospective cohort study on diet and concer in The Nefherlands. J Clin Epidemiol 1990;43/31:28595

28. van den Brandt PA, Schouten LJ. Goldbohm RA, Dorant E. Hunen PM. Development of a record linkage protacol for use in the Dutch Cancer Registry for Epidemiological Research. Int J Epidemiol 1990;19(3):553-8.

29. Brink M. De Goeij AF, Weijenberg MP. Roemen GM, Lentjes MH. Pachen MM. Smits KM, De Bruine AP, Goldbohm RA, Van den Brandt PA, K-ras oncogene mutations in sporadic colorectal cancer in The Nefheriands Cohort Study. Carcinogenesis 2003;24(4):703-10.

30. Kim JC, KoO KC. Roh SC. Cho YC. Kim HC, YU CC, Cho MC. Genetic and epigenetic changes in the APC gerie in sporadic calorectal carcinoma with synchronous adenoma. Int $\mathrm{J}$ Colorectal Dis 2003:18(3):203-9.

31. Mulkens J, Poncin J. Arends JW, De Goeif AF. APC mutations in human colorectal adenomas: analysis of the mutation cluster region with temperature gradient gel electrophoresis and clinicopathological features. $\Downarrow$ Fathol 1998; $85(4): 360-5$.

32. Grompe $M$. The rapid detection of unknown mutations in mucleic acids. Nat Genet 1993;5(2):111 7 .

33. Baisse B. Bouzourene H. Saraga EP. Bosman F., Benhattar J. Intratumar genefic theterageneify in adwanced human colorectal adenocarcinoma. Inf J Cancer $2001 ; 93(3): 346-52$.

34. Al-Tassan N. Chmiel NH. Maynard J. Fleming N. Livingston AL. Williams GT, Hadges AK, Davies DR, David SS, Sarnpson JR, Cheadle JP. Inherited variants of MYH associated with somalic G:C- $\rightarrow$ I:A mutations in colorectal fumors, Nat Genet 2002;30(2):227-32.

35. Enhalm S, Hienonen T, Suomalainen A, Lipton L, Tomlinson I, Karja V, Eskelinen M, Mecklin JP, Karhu A, Jarvinen HJ, Aaltonen LA. Proportion and phenotype of MYH-associated colorectal neoplasio in a population-based series of Finnish colorectal cancer patients. Am J Pathol 2003; 163/3/:827-32.

36. Shitoh K. Konishi F. Miyaki M. lijima T. Furukawa T. Tsukamoto T. Nagai H. Pathogenesis of namfamilial colarectal carcinomas with high microsateilite instability. J Clin Pathol 2000:53(1) 1):841-5.

37. Olschwang S, Hamelin R. Laurent-Puig P. Thuille B. De Rycke Y, Li YJ. Muzeau F, Girodet J, Salmon R.J, Thomas $G$. Altemative genetic pathways in colorectal carcinogenesis. Proc Natl Acad Sci U S
A 1997:94:(22):12122-7.

38. Homlray TF. Cottrell SE, llyas M. Rowan A. Talbot IC. Bodmer WF. Tomilnson P. Defects in mismatch repair occur after APC mutations in the pathogenesis of sporadic colorectal tumaurs. Hum Mutat $1998: 1112): 114-20$

39. Huang I. Papadopoulos $N$, Mckinley AJ, Farrington SM, Curtis $L$. Wyllie AH, zheng S, Willson JK, Markowitz SD. Morin P. Kinzler KW, Wogelstein B. Dunlop MG. APC mutations in colorectal tumors with mismalch repoir deficiency. Proc Nall Acad Sci U S A 1996:93(17):9049-54.

40. Salahshor S. Kressiner U. Pahiman L. Glimelius B. Lindmark G. Lindblom A. Colorectal cancer with and without microsalellite instability involves different genes. Genes Chromosomes Cancer
$1999: 26(3): 247-52$.

41. Morin P.J. Sparks AB, Korinek V. Barker N. Clevers $H$. Vogetstein B. Kinzler KW. Activation of betccatenin- 1 ch signaling in colon cancer by mutations in beta-catenin or APC [see comments]
Science 1997:275(5307):1787-90.

42. Sparks AB. Morin PJ. Vogelstein B, Kinzler KW. Mutational analysis of the APC/beta-catenin/TCF pothway in colorectall cancer. Cancer Res 1998:58(6):1130-4.

43. Esteller $M$. Relevance of DNA methylation in the management of cancer Lancel oncol 2003:416):351-8.

44. wan Engeland $M$, Weijenberg MP. Roemen GM. Brink M. de Bruine AP. Goldbohm RA, van den Brandi PA. Baylin SB. de Goeil AF. Herman JG. Effects of dietary folote and alcohol intake on cancer. Cancer Res 2003:63(12):3133-7. 

$\begin{array}{llllllll}C & H & A & P & T & E & R & \end{array}$ 


\section{MUTATIONS IN APC, CTNNBI, AND $K$-RAS GENES AND EXPRESSION OF HMLH 1 IN SPORADIC COLORECTAL CANCER}




\section{A B STR ACT}

In calorectal carcinogenesis several pathways have been identified. The majority of colorectal fumours are thought to be driven by a sequential accumulation of mutations in the APC, K-ras and TP53 genes. A smaller proportion of cancers displays microsatellite instability.

In a group of 656 unselected incident colorectal cancer patients, the accurrence of mutations in the APC. K-ras, and CTNNBI genes as well as expression of $\mathrm{hMLHI}$ was investigated. Additionally. tumours were divided in groups on the basis of molecular features and compared with respect to age at diagnosis, sex, family history of colorectal cancer, fumour sub-lacalisation. Dukes' stage and tumour differentiation.

Mutations at the phosphorylation sites in the CTNNBI gene were observed in tumours from only five of 464 patients. Tumours with truncating APC mutations and activating $K$-ras mutations in codons 12 and 13 occurred at similar frequencies $(37 \%, 245 / 656)$ and $36 \%$ (235/656), respectively). Seventeen percent of fumours harboured both an APC and a K-ras mutation (109/656). Nine percent of all tumours (58/656) lacked hMLHI expression. Patients harbouring a tumour with absent hMLHI expression were older, more often women, more often had proximal colon tumours that showed poorer differentiation when compared to patients harbouring tumours with an A.PC and/or Kuras mutation.

From data of a large, unselected group of sporadic colorectal cancer patients, we conclude that several pathways in colorectal cancer can be identified, but that the main differences in tumour and patient characteristics are found between groups of patients based on mismatch repair deficiency. 


\section{INTRODUCTION}

Carcinogenesis is a multi-step process that involves the accumulation of numerous genetic and epigenetic changes in cells.' These genetic aberrations affect a limited number of identified pathways that are involved in (colorectal) carcinogenesis. ${ }^{2}$ In colorectal cancer a number of specific genetic alterations have been identified. A genetic model for sporadic colorectal cancer has been proposed, which describes the sequential accumulation of specific genetic alterations in various pathways, involving tumour suppressor genes (e.g. APC, SMAD4. TP53) and oncogenes (e.g., CTNNB., K-ras). $\hat{s}^{4}$ Two important molecular pathways that upon activation affect the early and intermediate stages of colorectal carcinogenesis are the Wnt and Ras signalling pathways.

Activation of the Wnt pathway plays a central role in the aetiollogy of most colorectal cancers and is often the result of mutations in the central domain of the adenomatous polyposis coli (APC) gene, that lead to partial or complete loss of this region and thereby to loss of the $\beta$-catenin regulating function. ${ }^{5,6}$ Conversely, activating missense mutations at one of the phosphorylation sites in exon 3 of the CTNNBI gene, encoding the $\beta$-catenin protein, can render it stable as it can no longer be tagged for cellular degradation. ${ }^{7}$ Activation of the Ras pathway in cancer is marked by the loss of the intrinsic GTPase activity of the Ras protein, which can be ascribed to missense mutations in codons 12 and 13 of exon 1 of the Kirsten ras (K-ras) gene in $90 \%$ of cases. ${ }^{8}$

According to the paradigm for colorectal cancer development, mutations in the APC, K-ras and TP53 genes are all thought to contribute to the aetiology of colorectal cancer. ${ }^{3}$ However, a recent study based on the analysis of APC, Kras and TP53 genes concluded that simultaneous occurrence of all three genetic alterations is rare and that multiple genetic pathways may be relevant to colorectal cancer. ${ }^{9}$

Genetic instability is seen in most types of cancer. ${ }^{10}$ Two distinct types of genetic instability appear to occur in colorectal cancer:"1 chromosomal and microsatellite instability. Chromosomal instability results in gains or losses of entire chromosomes or parts of them, and gives rise to aneuploid tumours and occurs in the majority of cancers. A smaller proportion of colorectal cancers displays microsatellite instability, represented by diploid cells acquiring high mutation rates, and was found to be associated with defective mismatch repair.12 These tumours are less likely to harbour mutations in genes associated with chromosomally instable and generally aneuploid tumours, such as APC, K-ras and TP53,13-21 suggesting that these tumours form a distinct group. Moreover, microsatelite instable tumours are found predominantly in the proximal colon, 22. 23 are more likely to occur in patients with a positive family history of colorectal cancer, ${ }^{22,23}$ are often less differentiated than microsatellite stable tumours, ${ }^{23}$ and occur more frequently in women ${ }^{2 A}$ and at older age. ${ }^{25}$

Considering the aforementioned issues, there is a need for studies addressing the helerogeneity of affected genes involved in colorectal cancer development in large groups of patients. We have previously studied the accurrence of $A P C$ and K-ras mutations separately. ${ }^{26,27}$ In the current study, in addition to investigating mutations in the APC, CTNNBI and $K$-ras genes als well 
as mismatch repair deficiency and combinations of these aberrations, their relation with various fumour and patient characteristics were studied in a large, unselected group of incident colorectal cancer patients.

\section{MATERIALS AND METHODS}

\section{STUDY POPULATION}

The prospective Netherlands Cohort Study on diet and cancer was initiated in September 1986. The study design has been described in delail elsewhere. 28 At baseline, a total of 58,279 men and 62,573 women, between the ages of 55 and 69 years, completed a self-adminisfered food frequency and lifestyle questionnaire. The study population originated from 204 municipal population registries throughout The Netherlands.

Incident cancer cases are identified by monitoring of the entire cohort for cancer occurrence through annual record linkage to the Netherlands Cancer Registry, i.e. nine regional cancer registries throughout the Netherlands, and to PALGA, a nationwide network and registry of histo- and cytopathology.29 Together, the NCR and PALGA provide a near 100\% coverage of the municipalities included in the NLCS. The first 2.3 years of follow up were excluded because of possible pre-clinical disease affecting exposure status and because of incomplete nationwide coverage of PALGA in some of the municipalities included in the NLCS in that period. From 1989 until 1994, 929 incident cases with histologically confirmed colorectal cancer were identified within the cohort, of whom 819 could also be linked to a PALGA report of the lesion.

The PALGA reports were used to identify and locate tumour fissue from eligible colorectal cancer patients in Dutch pathology laboratories. Colon and rectal cancer were classified according to site as follows, colon: cecum through sigmoid colon (ICD-O codes 153:0, 153.1, 153.2, 153.3. 153.4, 153.5, 153.6, 153.7). rectosigmoid (ICD-O code 154.0), and rectum (ICD-O code 154.1).

\section{TISSUE SAMPLES}

Tumour material of colorectal cancer patients was collected after approval by the Ethical Review Board of Maastricht University, PALGA and the NCR. Tissue samples from 819 colorectal cancer patients were localised in 54 pathology laboratories throughout The Netherlands. Forty-four (5\%) fumour tissue samples could not be retrieved from the pathology archives. Of 775 available tissue samples, $737(95 \%)$ contained sufficient tumour material for molecular analyses. Tissue sections were cut from each sample, which were used for DNA isolation and immunohistochemical analysis.

\section{DNA ISOLATION}

DNA isolation was described in detail elsewhere. ${ }^{26}$ Briefly, a $4 \mu \mathrm{m}$ section, cut from each paraffin-embedded tumour tissue block, was stained with haematoxylin and eosin (HE) for histopathological examination by a pathologist. Five $20 \mu \mathrm{m}$ sections of tumour tissue were cut from each sample for DNA isolation. Tumour tissue was separated from normal colon epithelium using the HE section as a reference. Genomic DNA was extracted from 
compare as different methods of detecting mutations in APC have been used and different regions of the APC gene have been studied.

In the current report, the frequency and type of APC gene mutations are assessed in a large series of unselected, incident colorectal cancer patients from The Netherlands identified in a prospective cohort study. The occurrence and type of APC gene mutations in the mutation cluster region are reported with regard to age at diagnosis, sex, family history of colorectal cancer. Dukes" stage, fumour differentiation and sub-localisation.

\section{MATERIALS AND METHODS}

\section{STUDY POPULATION}

A prospective cohort study on diet and cancer was initiated in the Netherlands in September 1986. The study design has been described in detail elsew/here, ${ }^{27}$ Briefly, at baseline a total of 58,279 men and 62,573 women, between the ages of 55 and 69 years, completed a self-administered food frequency and lifestyle questionnaire. The study population originated from 204 municipal population registries throughout the country. Incident cancer cases are identified by monitoring of the entire cohort for cancer occurrence through annual record linkage to the Netherlands Cancer Registry (NCR), nine regional cancer registries throughout The Netherlands, and to the Pathologisch Anatomisch Landelijk Geautomatiseerd Archief (PALGA), a nationwide database of pathology reports.28 The PALGA database was used to identify and locate tumour tissue in Dutch Pathology laboratories. The first 2.3 years of follow up were excluded due to incomplete nationwide coverage of PALGA. From 1989 until 1994, 819 incident cases with histologically confirmed colorectal cancer were identified. Colorectal cancer was classified according to site as follows, proximal colon: cecum through transverse colon (ICD-O codes 153:0, 153.1. $153.4,153.5,153.6$ ); distal colon: splenic flexure through sigmoid colon (ICD-O codes 153.2, 153.3. 153.7): rectosigmoid (ICD-O code 154.0) and rectum (ICD-O code 154.1). Information about age at diagnosis, sex and family history of collorectal cancer (at baseline) was retrieved from the Netherlands Cohort study on diet and cancer (NLCS) database. Information about tumour sublacalisation. Dukes' stage and differentiation was retrieved from the NCR database.

\section{TISSUE SAMPLES}

Tumour material of colorectal cancer patients was collected after approval by the Ethical Review Board of Maastricht University, PALGA and the NCR. Tissue samples from 819 colorectal cancer patients were retrieved from 54 pathology laboratories throughout the Netherlands. Tumour tissue specimen collection started in August 1999 and was completed in December of 2001. Forty-four tumour tissue samples (5\%) could nof be traced. Of 775 eligible tissue samples 737 (90\%) contained sufficient tumour material as confirmed by a pathologist (A.d.B.) for molecular analyses. 
Tabile 1. Description of pattent, tumour and molecular characteristics of tumours harbouring a CTNNE 1 mutation from a total of 464 tumours analysed

\begin{tabular}{|c|c|c|c|c|c|}
\hline Patsol & sex & 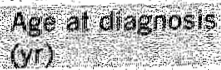 & Sublocals adion & dernes stoge & Tumour dif ferentation \\
\hline 1 & M & 65 & Proximal colon & $B$ & Moderate \\
\hline 2 & $M$ & 67 & Proximal colon & A & Moderate \\
\hline 3 & $M$ & 69 & Proximal colon & $B$ & Good \\
\hline 4 & $M$ & 61 & Proximal colon & $c$ & Maderate \\
\hline 5 & $f$ & 69 & Proximal colon & A & Undifferentiated \\
\hline 6 & M & 69 & Distal colon & $B$ & Moderate \\
\hline 7 & $\mathrm{~F}$ & 65 & Proximal colon & A & Moderate \\
\hline
\end{tabular}

$(\mathrm{pH} 8.0)$ and incubated with $10 \%$ normal horse serum for ten min at room temperature. Then, sections were incubated overnight at $4^{\circ} \mathrm{C}$ with mouse monoclonal antibodies against hMLH 1 protein (clone G168-15. PharMingen, San Diego. CAl at a 1:100 dilution. Antibody binding was detected by incubating the sections at room temperature with the peroxidase-labelled DAKO Envision System (DAKO, Carpiriteris, CA), using diaminebenzidine as a chromogen. Sections were counterstained with diluted haematoxylin.

Lesions were considered to lack hMLHI protein expression when unequivocal absence of nuclear staining of the tumour epithelial cells was observed. Nuclear staining of normal epithelial and stromal cells or lymphocytes served as an internal positive control. Staining was scored independently by at least two abservers and in case of discordant results discussed with a pathologist untit consensus was reached. hML.H1 expression could be determined in 724 of 737 patients.

\section{B A T - 26}

Analysis of the BAT-26 mononucleotide repeat was performed in tumour samples from 162 patients to determine the correlation between the microsatellite instability marker BAT-26 and hMLH1 expression including 48 of 61 tumours that lacked hMLHI expression. The primer sequences and PCR conditions for the BAT-26 mononucleotide repeat were used as described previously, a.

\section{STATISTICAL ANALYSIS}

In the statistical analysis data from 656 patients for whom information on APC and $\mathrm{K}$-ras mutation status as well as hMLHI expression was complete were included.

Characteristics of patients (age at diagnosis, sex, family history of colorectal cancer) and fumours (tumour sub-localisation, Dukes' stage and tumour differentiation) were compared between patients with and without an activating Kuras or a truncating APC mutation as well as patients harbouring tumours with and without hMLHI expression, using Student's t test lage at diagnosis) and $\chi^{2}$ tests (sex, family history of colorectal cancer, tumour sublocalisation. Dukes' stage and differentiation). Additionally, patient and tumour characteristics of tumours with an activating K-ras and/or a fruncating APC mutation were compared to tumours lacking hMLH1 expression. All p-values are 
Tablle 1. Continued

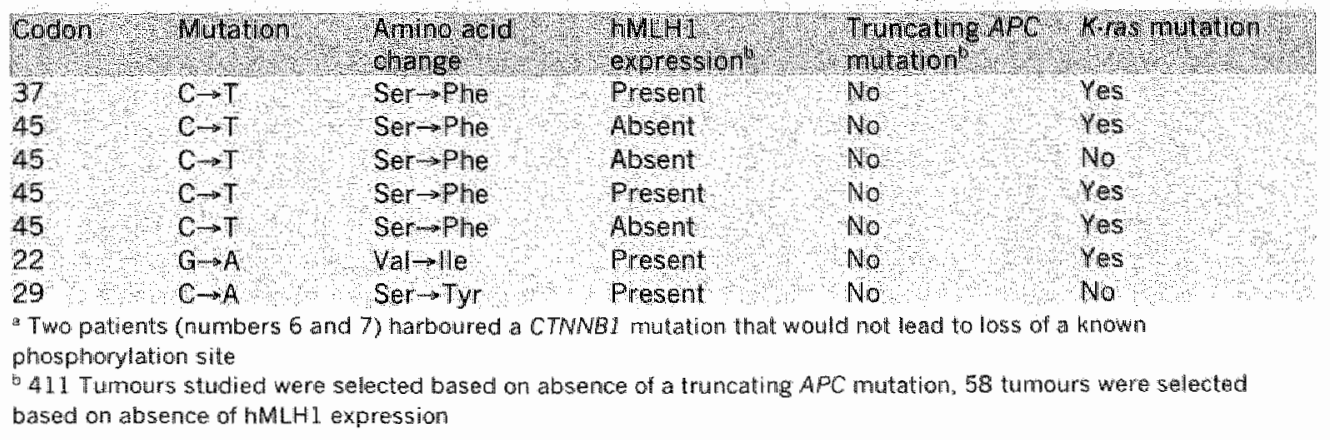

reported for a two-sided test; $p$-values of less than 0.05 were considered to be statistically significant.

\section{RES ULTS}

464 Tumours without a truncating APC mutation and/or lacking hMLH expression, were analysed for mutations in exon 3 of the CTNNBI gene. Table 1 describes the patient, tumour, and molecular characteristics of seven colorectal tumours that harboured a mutation in CTNNBI exon 3. Five colorectal cancers with a CTNNBI mutation that would lead to loss of one of the Ser/Thr phosphorylation sites and subsequent stabilisation of the protein, all accurred at codons 37 and 45 , all were $C \rightarrow T$ transitions, leading to Ser $\rightarrow$ Phe amino acid changes and all occurred in the proximal colon. All bar one also had an activating mutation in the $K$-ras gene. Three of the five tumours showed hMLHI deficiency. Two colorectal cancer patients harboured a mutation in the CTNNBI gene, that did not occur at the Ser/Thr phosphorylation sites, but would result in an amino acid alteration at codons 22 and 29 , the effects of which are unknown. Because of the very low frequency of fumours harbouring a CTNNBI mutation. these mutations were not included in further analyses. Moreover. mutation analysis of the remaining samples was abandoned since this was deemed irrelevant.

Of all tumours for which the other molecular alterations, i.e. mutations in the APC and K-ras genes and hMLH1 expression, were successfully analysed, 103 colorectal tumours did not harbour a truncating or missense APC mutation, an activating $\mathrm{K}$-ras mutation or showed lack of $\mathrm{hMLH} 1$ expression, as depicted in figure 1.

Truncating as well as missense APC mutations and activating $K$-ras mutations were relatively common. Truncating APC mutations alone and activating $K$-ras mutations in codons 12 and 13 only. occurred at similar frequencies $(20 \%$ $(130 / 656)$ and $18 \%(121 / 656)$, respectively). A combination of a truncating mutation in APC and an activating mutation in K-ras occurred less often than the sole occurrences of mutations in both genes. However, as shown in table 2. 


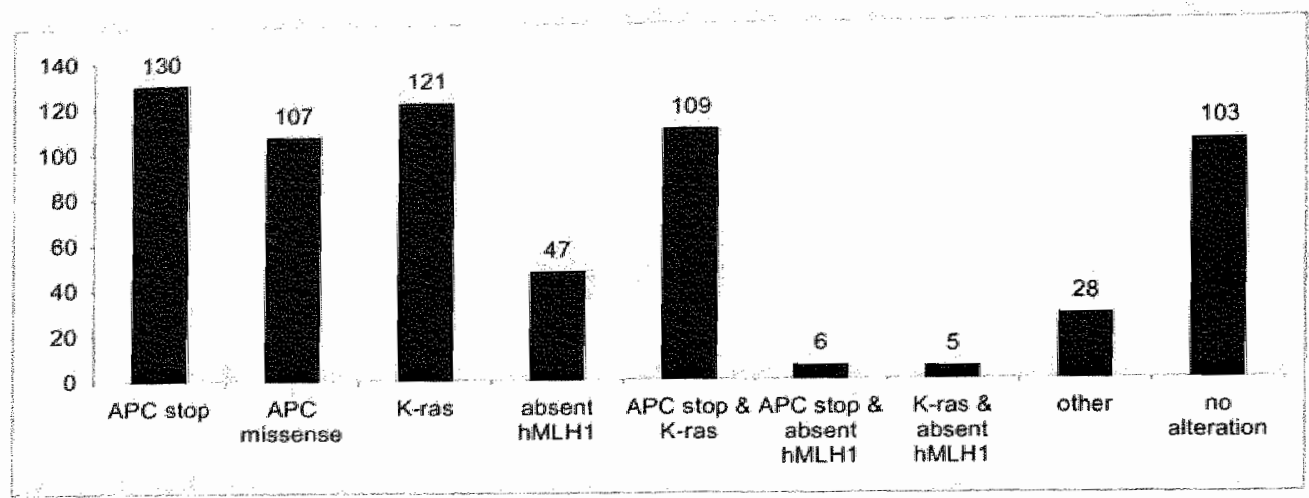

Figure 1. Distribution of (Combinations off genetic aberrations in the APC and Kras genes and hMLH expression in tumours from 656 sporadic colorectal cancer patients. The bars represent the different molecular alterations present in mutually exclusive groups of tumours.

the simultaneous occurrence of mutations in both genes accurred more frequently than expected on the basis of chance alone.

A $x^{2}$ test for the occurrence of a truncating APC mutation and an activating $K$ ras mutafion, revealed that the occurrence of these mutations was not independent $(p<0.001)$, but the correlation was weak (Cramers $V=0.138$ ). Finally, although 11 fumours that harboured a mutation in the APC or K-ras gene also lacked hMLHI expression, hMLHI deficiency occurred more frequently in fumours that did not harbour these mutations $\left(x^{2}=36.6, p<0.001\right)$

Table 2. Crosstabulation of colorectai carcinomas with and without activating $K$-ras and truncating $A P C$ multation(s)

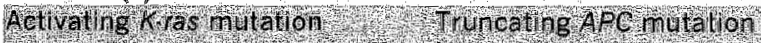

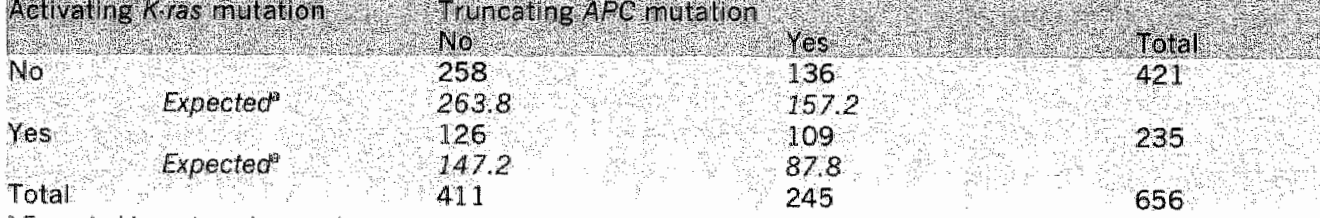

Expected based on chance alone

With respect to localisation in the colorectal tract, fumours of the rectosigmoid and rectum more frequently harboured truncating APC mutations when compared to colon tumours $[p=0.001$, as shown in table 3 . Rectosigmoid and rectal tumours have a relatively higher frequency of $K$-ras mutations in codons 12 and 13 when compared colon tumours $(\rho=0.05$ ) (table 3). Tumours lacking hMLH1 expression occur almost exclusively in the proximal colon $(p<0.001)$ and relatively more frequently show poor differentiation or are undifferentiated $(p<0.001)$ when compared to tumours with hMLHl expression (table 3$)$.

Next, we compared the patient and tumour characteristics of tumours harbouring a truncating APC and/or an activating K-ras mutation mutation to those of tumours without hMLHI expression, and these results are presented in table 4. Patients with a hMLH] deficient tumour were slightly older when diagnosed with colorectal cancer $169.3 \pm 4.3 \mathrm{yr}$ versus $67.8 \pm 4.2 \mathrm{yr}$, 
Table 3. Comparisons between colorectal cancer patients with or without a Kras and APC gene mutation and with or without hMLHI expression, according to patient and fumour characteristics

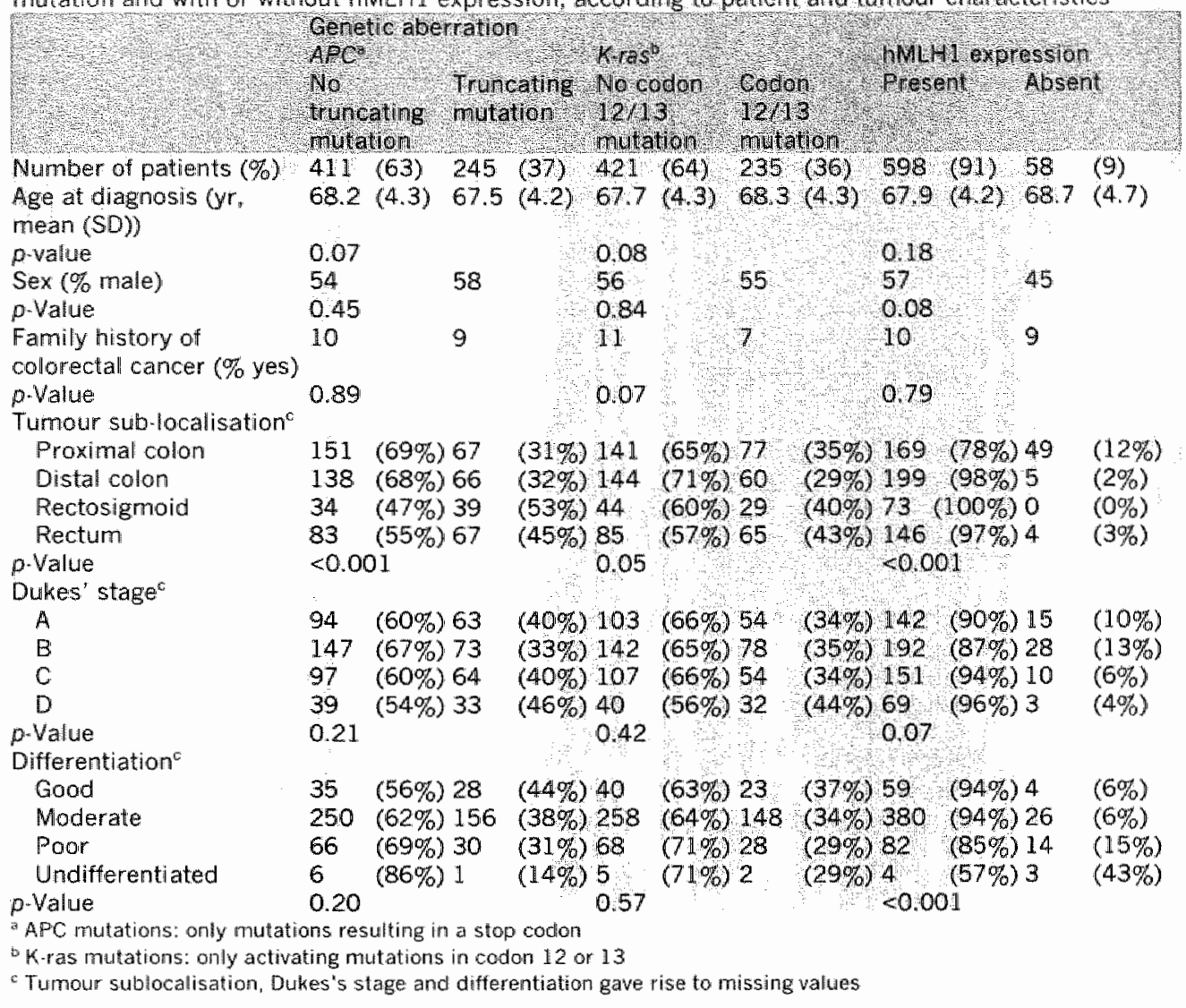

$p=0.03)$. were relatively less frequently men $[40 \%$ versus $58 \%, p=0.02]$ than patients with a fumour harbouring a truncating APC and/or activating $K$-ras mutation. Compared to tumours with an APC and/or K-ras mutation, lumours without hMLHI expression occurred relatively more frequently in the proximal colon $(p<0.001)$ and relatively more frequently showed poor differentiation or are undifferentiated $(p<0.001)$.

When comparing tumours with a missense (but not a truncating) mutation in $A P C$ to tumours with a truncating mutation in the APC gene, missense mutations occurred relatively more frequently in the colon $(0=0.002)$ less often also harboured an activating $K$-ras mutation $(p=0.004)$, and more often also lacked hMLHI expression $(p<0.001)$. No differences were observed with regard to age at diagnosis, sex, Dukes' stage or tumour differentiation (data not shown).

Finally, to assess agreement between hMLHI expression and microsatellite instability, for 162 tumours both $h M L H I$ expression and BAT-26 were analysed. All tumours that had normal BAT-26, also showed hMLHI expression. Fourteen tumours with unstable BAT-26 also lacked hMLHI expression, and two tumours 
with unstable BAT-26, were found to express hMLH1, which demonstrates a high agreement between these molecular features of mismatch repair deficiency.

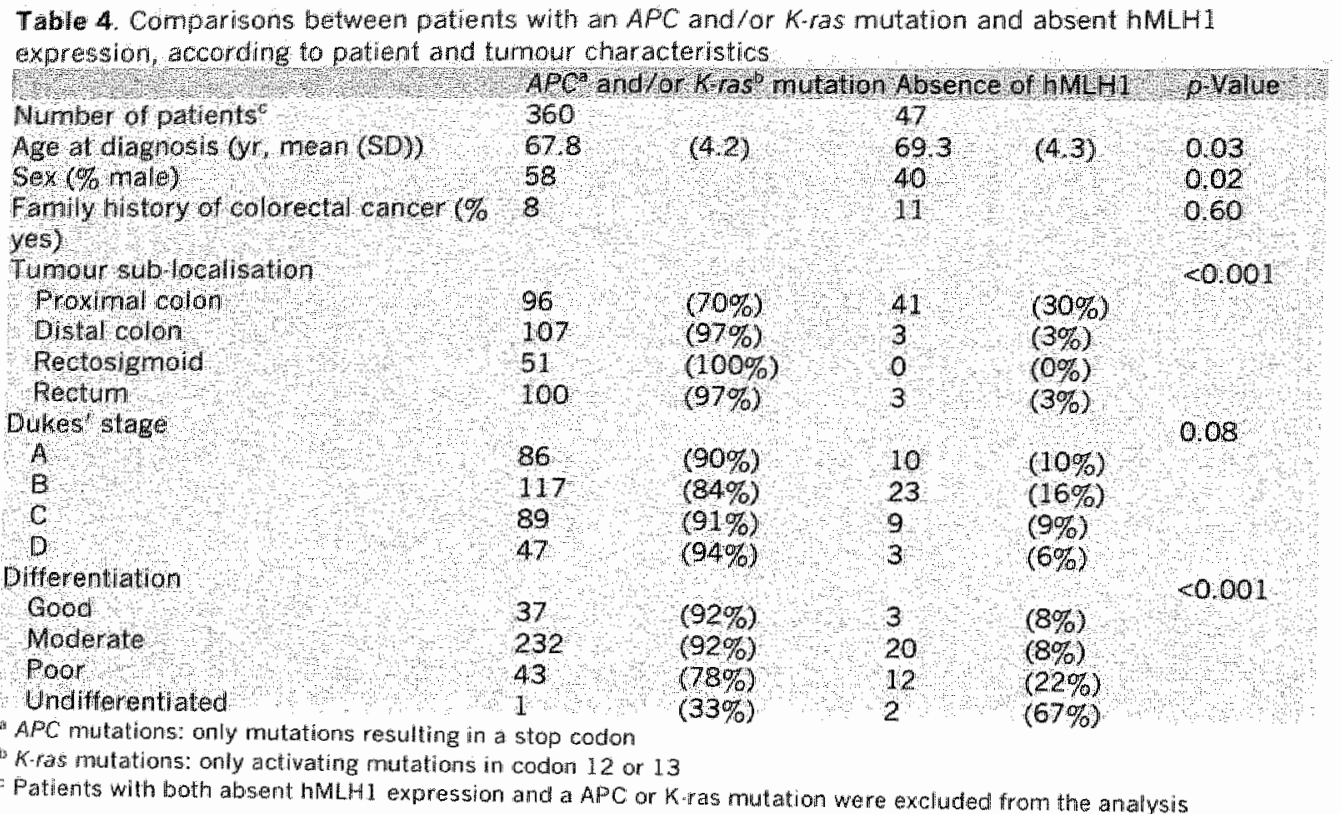

\section{DISCUSSION}

In this study, the occurrence of mutations in the APC, CTNNBI and K-ras genes as well as expression of the $\mathrm{hMLHI}$ protein in tumour tissue of 656 sporadic colorectal cancer cases was investigated. The occurrence of mutations in the CTNNB1, which codes for $\beta$ mcatenin, was rare: only five of 464 tumours analysed were found to have a mutation at one of the phosphorylation sites in exon 3 . Truncating mutations in APC and activating mutations in $K$-ras appeared to occur at similar frequencies. Although tumours harbouring both mutations were relatively rare, mulations in $A P C$ and $K$-ras may occur co-dependently. Nine percent of all tumours (58/656) lacked hMLHI expression, and in these tumours generally no APC or K-ras mutation was detected. Patients harbouring a tumour with absent hMLHI expression were older, more often women, more often had proximal colon tumours that showed poorer differentiation when compared to mutation.

The selection of patients included in this study was based on the completeness of analyses of both APC and K-ras genes and hMLLHI expression and this led to a considerable reduction in the number of cases included in the analyses incompleteness study. The largest reduction (72 cases) was due to mutation cluster of the analysis of all four fragments comprising the APC history of colorectalion. However, characteristics of patients lage, sex, family differentiation) of the group und tumours (sub-localisation. Dukes' stage and 
fumour material was available and all 819 patients initially recognised within the cohort (data not shown). Moreover, the Kras and hMLHI data presented here. are similar to the data for $K$-ras and hMLHI based on the complete groups 1737 and 724 cases, respectively) (data not shown).

Mutations in exon 3 of the CTNNBI gene that would lead to loss of one of the phosphorylation sites were rare. Strikingly, all five of these mutations occurred in the proximal colon and three of these also had absent hMLHI expression. This may indicate that these proximal colon tumours, which often also show mismatch repair deficiency, are more likely to harbour CTNNBI mutations. This was also found in a study of microsatellite instable colorectal tumours. 30 WAVE screening technique has not previously been used for formalin-fixed, paraffinembedded tissue, and therefore it seems plausible that samples harbouring a CTNNBI mutation have escaped detection. However, all $58 \mathrm{hMLHI}$ deficient samples were analysed by direct sequencing without a prior screening step, and only three of these samples harboured a CTNNBI mutation.

The model describing the accumulation of genetic alterations of the APC, K-ras, TP53 and SMAD4 genes that drive the development of a carcinoma, has become generally accepted as a paradigm for the genetic basis of colorectal carcinogenesis. ${ }^{3}$, 32 The relatively low frequency of simultaneous occurrence of mutations in both APC and K-ras observed in this study seems to argue against this synergy. This contention is in accordance with observations from another cohort study, in which APC. K-ras and IP53 gene mutations were studied in 109 tumours and these mutations were found to rarely occur together in the same tumour.9 However, the simultaneous occurrence of APC and K-ras mutations observed in our study accurs more frequently than expected based on chance alone and therefore mutations in the APC and K-ras genes do not seem to occur independently. When data on APC and K-ras mutations were derived from the study by Smith et al., ${ }^{9}$ similar results, although not statistically significant. could be obtained.

Of the microsatellite instable tumours, approximately $90 \%$ show absence of hMLHI expression. ${ }^{24}$ In most sporadic colorectal cancers, the promoter region of hMLHI is hypermethylated, resulting in absence of the protein. $33-35$ BAT-26 was previously shown to identify microsatellite instability in sporadic colorectal cancer ${ }^{36}$ and results from our study showed a goad agreement belween unstable BAT-26 and absent hMLHI expression.

Several studies have shown that microsatellite instability and mutations in APC. TP53 and K-ras occur almost mutually exclusively, ${ }^{17,18,21,37}$ suggesting that these characteristics represent separate pathways. However, others have observed aberrations in both pathways, but these studies have been performed in relatively small groups of HNPCC and sporadic colorectal cancer patients and this may have given rise to a relative overrepresentation of mutation detection in both pathways. ${ }^{19.20 .38}$ Although in our study the simultaneous occurrence of hMLHl deficiency as well as an APC or K-ras mutation was observed in a small number of tumours, the mutually exclusive occurrence of hMLHI deficiency and mutations in APC and/or $K$-ras seemed to predominate.

Moreover, after exclusion of tumours displaying this overlap, a striking difference between occurrences of APC and/or K-ras mutations versus absence of hMLH 1 
expression was observed. The differences were most pronounced with regard to tumour sublocalisation and differentiation. hMLHI deficient fumours occur almost exclusively in the proximal colon and are relatively more frequently poorly differentiated, which is in accordance with previous reports from other studies.22-2s

In conclusion, this study shows that mutations in the CTNNBI gene seem to be of minor importance in sporadic colorectal cancer. Although APC and K-ras mutations are often observed seperately in a tumour, these mutations appear to aiso occur in a co-dependent manner. Tumours that display mismatch repair deficiency, seem to form a distinct sub-group as they differ from fumours with $A P C$ and/or K-ras mutations with regard to age and sex of the patient, fumour sub-localisation and differentiation. 


\section{REFERENCES}

1. Hanaham D, Weinberg RA. The hallmarks of cancer. Cell 2000:100/1/:57 70.

2. Vogelstein B. Kinzler KW. Cancer genes and the pathways they control. Not Med 2004:10181:789. 99.

3. Fearon ER, Vogelstein 8. A genetic model for colorectal tumorigenesis. Cell 1990:61(5):759-67.

4. Fodde R, smits R. Clewers H. APC, signal transduction and genetic instability in colorectal cancer. Nature Rev Cancer 2001:1111:55-67.

5. Bienz M. Clewers H. Linking colorectal cancer to Wnt signaling Cell 2000; 103(2):311-20.

6. Rubinfeld B. Alberk 1. Porfini E. Munemitsu S. Polakis P. Loss of beta-catenin regulation by the APC fumor suppressor protein correlates with loss of structure due to common somatic mulations of the gene. Concer Res $1997 ; 57(20): 4624-30$.

7. Sparks AB. Morin PJ. Vogelstein B. Kinzler KW. Mutational analysis of the APC/belawCatenin/Tci pathway in colorectal cancer. Cancer Res 1998;58/61:1" 30-4.

8. Bos JL. ras oncogenes in human cancer: a review. Cancer Res 1989;49(17):4682-9\%,

9. Smith G. Carey FA, Beatte J, Wikie MJ, Lightfoot TJ, Coxhead J. Garner RC. Steele RJ. Wolf CR. Mutations in APC. Kirsten-ras, and P53-alternative genetic pathways to colorectal camcer. Proc Nall Acad Sci U S A 2002;99| 14:94:433-8.

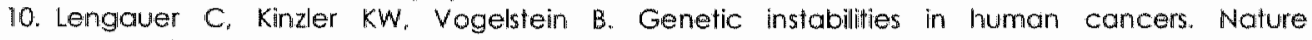
$1998: 396(6712): 643-9$.

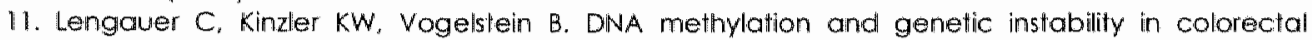
cancer cells. Proc Natl Acad Scil U S A 1997:94(6):2545-50.

12. Kolodner RD, Marsischky GT. Eukaryotic DNA mismatch repair, Curr Opin Genet Dev 1999:9[1]:8996.

13. Aaltonen LA, Peltomaki P, Leach FS, Sistionen P. Pyllkkanen L. Mecklin JP, Jarwinen H. Powell SM, Jen I. Hamilton SR, et al. Clues to the pathogenesis of familial colorectal cancer. Sicience $1993: 260(5109): 812-6$.

14. Heinen CD. Richardsom D. White $R$, Groden J. Microsatellite instability in calorectall ademacarcinoma cell lines that hawe full-length adenomatous polyposis colli protein. Cancer Res: $1995: 55(21): 4797-9$.

15. Konishi M, Kikuchi-Yanashita R. Tanaka K, Muraoka M. Onda A, Okumura Y, Kishi N, Iwama T, Marl T. Koike M. Ushio K. Chiba M. Nomizu S, Konishi F, Utsunomiya J, Miyaki M. Molecular nature of colon tumors in hereditary nonpolyposis colon cancer, familial polyposis, and sporadic calon cancer. Gastroenterology 1996;111:(2):307-17.

16. Huang J. Papadopoulos N. MaKiniey AJ, Farrington SM. Curtis LJ. Wyllie AH, Zheng S, Willson JK. Markowiz SD. Morin P. Kinzler KW, Vogelstein B. Dunlop MG. APC mutations in colorectall tumors. with mismotch repair deficiency. Proc Natl Acad Sci U S A 1996:93117):9049-54.

17. Oischwang S, Hamelin R. Laurent.Pulg P. Thuille B, De Rycike Y, Li YJ. Muzeau F, Girodel J, salmon RJ. Thomas G. Altermative genetic pathways in colorectal carcinogenesis. Proc Natl ACad SEU U A $1997 ; 94: 22): 12122-7$.

18. Salohshor $\mathrm{S}$, Krewsner U, Pahlman L, Glimelius B, Lindmark G, Lindblom A. Colorectal concer will and without microsatelite instability irvolves different genes. Genes Chromosiomes Cancer $1999: 26|3|: 247-52$

19. Shitoh K. Konismi F. Myaki M. lijma T. Furukawa T. Tsukamoto T. Nagai H. Pathogenesis of nonfamilial calorectal carcinomas with hight microsatellite instability. J Clin Palhol 2000;53:11):841:5.

20. Fujwara T, Staker JM, Watanabe T, Rashid A. Longo P. Eshteman JR, Booker $S$, Lynch HT, Jas's JR. Green JS, Kim H. Jen J. Wogelstein B. Hamilton SR. Accumulated clonal genetic alterations in familial and sparadic colarectal carcinamas with widesphead instability in milcrosallellite sequences. Am J Pathol 1998: 153(4):1063-78.

21. Slattery ML, Curtin K, Anderson K. Ma KN. Ballard L. Edwards S, Schaffer D, Potter J, Lepperl M. Samowitz WS. Assaciations between cigarelte smoking. lifesfyle factors, and microsatellite instability in colon fumors. J Nall Cancer Inst 2000;92(22): $183 \|-6$.

22. Thibodeau $\$ N$. Bren G. Scmaid D. Microsatellte instability in cancer of the proximal colon. Schence $1993 ; 260151091: 816-9$

23. Lothe RA. Peltamaki P. Meling Gl, Aaltonen LA. Nystrom-Lathi M. Pylkkanen L, Heindal K, Andersen TI. Maller P. Rognum TO, et al. Genomic instability in colorectal cancer: relationship to cilinicopathological wariables and family thistory. Cancer Res 1993;53(24):5849-52.

24. Thibodeau SN. Fench A.J. Cunningham JM. Tester D. Burgart LJ, Roche PC, McDonnell SK, Schaid DJ. Vockley CW, Michels WV, Farr GH. Jr., O'Connell MJ. Micrasatellite instability in colorectal 
cancer: different mulator phenotypes and the princlpal involvement of hMLHI. Cancer Res $1998.58181 .1713-8$.

25. Aeltonen LA, Salowadra R, Kristo P. Canzian F. Hemminki A, Peltomaki P. Chadwick RB, Kaoriainen

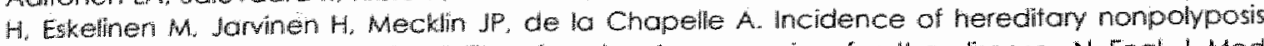
colorectal cancer and the feasibility of moleculor screening for the disease. N Engl I Med $1998338121): 1481-7$.

20. Brink M. De Goeil AF. Weijenberg MP. Roemen GM. Lentjes MH, Pachen MM. Smits KM, De Brüne A. G, Goldbonm RA, Van den Brandi PA. K-ras oncogene mutations in sporadic colorectal cancer in The Netheriands Cohor Study, Carcinogenesis 2003;24(4):703-10.

27. Luchtenborg M, Weijenberg MP. Roemen GM, de Bruine A. van den Brandt PA. Lentjes MH. Brink M. won Engeland M, Goldbohm RA, de Goell AF. APC mutations in sporadic colorectal carcinomas from the Netherlands Cohort Study. Carcinogenesis 2004;25(7):1219-26

28. wan den Brandt PA, Goldbohm RA, van "f Weer P. Volovics A. Hermus RI. Sturmans F. A large-scale prospective cohort study on diet and concer in the Wetherlands. J Clin Epidemiol 1990;43/31:28595.

29. wan den Brandt PA, Schovten LJ, Goldbohm RA, Darant E. Hunen PM. Development af a record linkage protocol for use in the Dutch Cancer Registly for Epidemiological Research. Int J Epidemiol 1990:19(3):553-8.

30. Mirabelli-Primdahl L, Gryfe R. Kim H, Millar A, Luceri C. Dale D, Holowaty E, Bapat B. Gallinger S. Redsion M. Beta-catenin mutations are specific for colorectal carcinomas with microsatellite imstability but occur in endometrial carcinomas irrespective of mulator palhway. Cancer Res $1999: 59(14): 3346-51$.

31. Hoang JM. Cottu PH. Thuille B. Salmon RJ, Thomas G. Hamelin R. BAtT-26, an indicator of the replication error phenotype in colorectal cancers and cell lines. Cancer Res $1997 ; 57$ (2):300-3.

32. Kinzler KW, Vogelstein B. Lessons from hereditary colorectal cancer. Cell 1996;87(2:159-70.

33. Herman JG, Umar A, Polyak K. Graff JR. Ahuja N, Issa JP, Markowitz S. Willson JK. Hamiltan SR, Kinzler KW. Kane MF, Kolodner RD. Vogelstein B. Kunkel TA, Baylin SB. Incidence and functional consequences of hMLHH promoter hypermethylation in colorectal carcinoma. Proc Nall Acad Sci US A. 1998:951121:6870-5.

34. Kane MF, Lada M, Gaida GM, Lipman J, Mishra R, Goldman $H$, Jessup JM Kolodner $R$. Methylation of the hMLHI promoter correlates with lack of expression of $\mathrm{MMLHI}$ in sporadic colon fumors and mismatch repair-defective human fumor cell lines. Cancer Res 1997:57151:808-11.

35. Miyakura Y, Sugano K, Konishi F, Ichikawa A. Maekawa M, Shitoh K, lgarashi S, Katake K, Kayama $Y$. Nagai $\mathrm{H}$. Extensive methylation of WMLHI promoter region predaminates in proximal colon cancer with microsatellite instabillty. Gastroenterology 2001:121(6):1300-9.

36. Cravo M. Lage P. Albuquerque C. Chaves P. Claro I. Gomes T. Gaspar C. Fidalgo P. Soares J, Nobre-Leitao C. BAT-26 identifies sporadic colorectal cancers with mutator phenolype: a correlative study with clinico-pathological features and mutations in mismatch repair genes. I Pathol 1999:18813:252-7.

37. Samowitz WS, Holden JA, Curtin K. Edwards SL. Walker AR, Lin HA, Robertson MA. Nichols MF. Gruenthal KM. Lynch BJ. Leppert MF. Slattery ML. Inverse Relationship between Microsatellite Instabilly and Kwas and $p 53$ Gene Alterations in Colon Cancer. Am J Pathol 2001; 1 58:41:1517-24.

38. Shimizu $Y$. tkeda $S$. Fujimori $M$. Kodama S. Nakahara $M$. Okajima $M$. Asahara $T$. Frequent alterations in the wht signaling pathway in colorectal cancer with microsatellite instability. Genes Chromosomes Cancer 2002:33(1):7381. 

$\begin{array}{lllllll}C & H & A & P & T & E & R\end{array}$

4 


\section{MEAT AND FISH CONSUMPTION, APC GENE MUTATIONS AND HMLH 1 EXPRESSION IN COLON AND RECTAL CANCER: A PROSPECTIVE COHORT STUDY}

MARGREET LUCHTENBORG MATYY P WEIJENBERG ANTON FPM DE GOEIJ PETRA A WARK MIRIAN BRINK GUIDO MJM ROEMEN MARJOLEIN HFM LENTJES ADRIAAN P DE BRUIME R ALEXANDRA GOLDBOHM PIETER VAN "T VEER PIET A VAN DEN BRANDT 


\section{A B STR ACT}

The aim of this study was fo investigate the associations between meat and fish consumption according to adenomatous polyposis coli (APC) mutation status and human mut-L homologue 1 (hMLHI) expression in colon and rectal cancer.

The associations were investigated in the Netherlands Cohort Study on diet and cancer, and included 434 colon and 154 rectal cancer patients on whom casecohort analyses (subcohort $n=2,948$ ) were performed.

Total meat consumption was not associated with the endpoints studied. Meat product (i.e., processed meat) consumption showed a positive association with colon tumours harbouring a truncating APC mutation, whereas beef consumption was associated with an increased risk of colon tumours without a truncating APC mutation (incidence rate ratio (RR) for highest versus lowest quartile of intake 1.61, 95\% confidence interval (C) $0.96-2.71, p$-trend $=0.04$ and $1.58,95 \% \mathrm{Cl} 1.10-2.25$, p-trend $=0.01$, respectively). Consumption of other meat (horsemeat, lamb, mutton, frankfurters and deep-fried meat rolls) was associated with an increased risk of rectal cancer without a truncating APC mutation ( $R R$ intake versus no intake $1.79 .95 \% \mathrm{Cl} 1.10-2.90$ ). No associations were observed for meat consumption and tumours lacking hMLHI expression.

Our data indicate that several types of meat may contribute differently to the aetiology of colon and rectal cancer, depending on APC mutation status but not hMLHI expression of the tumour. 


\section{INTRODUCTION}

Epidemiological studies have led to the current understanding that a significant proportion of colorectal cancer cases may be explained by dietary habits.' Although results from epidemiological studies on the risk of diet on colorectal cancer are inconsistent, meat consumption has been associated with an increased risk of colorectal cancer in several studies. According to the WCRF/AICR report on cancer prevention, evidence from previous studies shows that red meat (fresh meat excluding poultry) probably increases isk of colorectal cancer, and processed meat possibly increases risk. ${ }^{2}$ Poultry consumption data are inconsistent and there may be no relationship with colorectal cancer risk. ${ }^{2}$ Fish consumption possibly also has no relationship with the risk of colorectal cancer. ${ }^{2}$ A recent meta-analysis of 34 case-control and 14 cohort studies, investigating the risk of meat consumption on colorectal cancer concluded that total meat consumption was not significantly associated with colorectal cancer, but high intake of red meat (beef, veal, pork, mutton, and lambl, and in particular processed meat, was associated with a moderate but significantly increased risk of colorectal cancer. ${ }^{3}$

Most epidemiological studies investigating the consumption of meat as a risk factor have not made a distinction between colon and rectal cancer, or included only colon cancer but not rectal cancer. Previous studies have suggested differences in aetiology between the subsites of the collorectal tract.* The duration of exposure to and the composition of bowel content differ between colon and rectum. Moreover, molecular aspects of tumourigenesis also seem to differ between subsites of the large bowel.5.6

Most sporadic colorectal cancers are thought to arise through genetic pathways, which involve aberrations in a number of genes, as described by Fearon and Vogelstein. Inactivation of the adenomatous polyposis coli (APC) gene is thought to be a key event early in colorectal tumourigenesis. Somatic mutations in the mutation cluster region of APC have been found in 34 to $70 \%$ of sporadic fumours in colorectal cancer patients, which underscores the importance of APC gene mutation in sporadic colorectal carcinogenesis. ${ }^{8-16}$ The large majority of mutations observed in different studies would lead to a truncated and therefore inactivated APC protein. In our study, using a sensitive mutation detection technique, we found $72 \%$ of patients to have mutations in the APC gene, but only 37\% of patients had a mutation that would lead to truncation of the APC protein. ${ }^{6}$ A considerable proportion of patients (29\%) had a colorectal tumour that did not harbour truncating but missense mutations in the APC gene. ${ }^{5}$

In contrast with the majority of sporadic colorectal tumours being chromosomally instable and harbouring mutations in APC. tumour protein 53 (TP53) and Kirsten ras (K-ras). a smaller subset (approximately 10 to $15 \%$ of tumours) exhibits loss of mismatch repair manifested by microsatellite instability. Studies have shown that microsatellite instability and mutations in APC. TP53 and K-ras occur almost mutually exclusively. ${ }^{17-19}$ suggesting that these characteristics represent separate pathways. In approximately $90 \%$ of 
microsatellite instable tumours, absence of the mismatch repair enzyme human mut-L homologue 1 (hMLHI) expression was observed.20

The arimal fat and haem iron content of meat as well as meat preparation have been proposed as explanations for meat consumption as a risk factor for colorectal cancer. High temperature cooking of meat proteins generates heterocyclic aromatic amines (HCAs). The most abundant HCA in cooked meat, 2-amino-1-methyl-6-phenylimidazo[4.5-b]pyridine (PhiP), was shown to cause site-specific mutations in the APC gene in rats after induction of colon fumours with PhiP. ${ }^{21} \mathrm{~N}$-Nitrosamines and their precursors are compounds that can be formed endogenously ${ }^{22}$ but are also found in red and processed meat. ${ }^{23}$ Through their alkylating action they can be carcinogenic. $N$-nitroso compounds could induce $G \rightarrow A$ transitions that have been observed in codons 12 and 13 of the $K$-ras gene in human colonic tissue.22 Similarly. meat consumption may be associated with specific mutations in the APC gene.

To our knowledge, only ane study has addressed the issue of studying an assaciation between dietary factors and truncating mutations of the APC gene in sporadic colon cancer in humans. In this case-control study, meat consumption was associated with colon carcinomas harbouring a truncating mutation in APC.16 In another report from that study, an inverse relation between red meat and microsatellite instability was found. ${ }^{24}$

Here, we investigated the associations between fresh meat, meat products (i.e.. processed meatl and fish consumption and the risk of colon and rectal tumours harbouring truncating mutations, missense mutations and specific types of point mutations in the mutation cluster region of the APC gene in cancer as well as colon tumours with absent $\mathrm{hMLH}$ l expression in a large prospective cohort study in the Netherlands.

\section{MATERIALS AND METHODS}

\section{STUDY POPULATION}

The prospective Netherlands Cohort Study on diet and cancer (NLCS) was initiated in September 1986. The study design has been described in detail elsewhere. ${ }^{25}$ Briefly, at baseline a total of 58,279 men and 62.573 women. between the ages of 55 and 69 years, completed a self-administered food frequency and lifestyle questionnaire. The study population originated from 204 municipal population registries throughout the country. For data processing and analysis, the case-cohort approach was used: the cases were enumerated for the entire cohort, while the person years at risk accumulating in the cohort were estimated from a random sample (subcohort). This subcohort of 3,500 men and women was randomly sampled from the cohort after baseline exposure measurement and was followed for migration and vital status by contacting the participants and the municipalities biennially to calculate accumulated persontime in the cohort.26 154 Cases with prevalent cancer other than nonmelanoma skin cancer were excluded, resulting in a subcohort of 3.346 men and women. During the first 2.3 years of follow-up, 83 subcohort members deceased or were diagnosed with cancer other than non-melanoma skin 
cancer, leaving 3,263 subcohort members for analysis. No subcohort members were lost to follow-up.

Incident cancer cases are identified by monitoring of the entire cohort for cancer occurrence through annual record linkage to the Netherlands Cancer Registry (NCR), nine regional cancer registries throughout the Netherlands, and to the Pathologisch Anatomisch Landelijk Geautomatiseerd Archief (PALGA), a nationwide network and registry of histo- and cytopathology reports. ${ }^{26}$ The NCR and PALGA together provide a near 100\% coverage of the municipalities included in the NLCS. The first 2.3 years of follow up were excluded because of possible pre-clinicall disease affecting exposure status and because of incomplete nationwide coverage of PALGA in some of the municipalities included in the NLCS. From 1989 until 1994, 929 incident cases with histologically confirmed colorectal cancer were identified within the cohort, of whom 819 could also be linked to a PALGA report of the lesion. The PALGA reports were used to identify and locate tumour tissue from eligible colorectal cancer patients in Dutch pathology laboratories. Colon and rectal cancer were classified according to site as follows, colon: cecum through sigmoid colon (ICD-O codes 153:0, $153.1,153.2,153.3,153.4,153.5,153.6,153.7$ ), rectosigmoid (ICD-O code 154.0), and rectum (ICD-O code 154.1).

\section{TISSUE SAMPLES}

Tumour material of colorectal cancer patients was collected after approval by the Ethical Review Board of University Maastricht, the NCR and PALGA. Tissue samples from 819 colorectal cancer patients were distributed among 54 pathology laboratories throughout the Netherlands. From 95\% (775/819) of patients, tissue samples could be retrieved. Tissue samples from nine patients registered in one pathology laboratory could not be retrieved due to administrative inconsistencies. From 34 patients, tumour tissue blocks were not available in the archive of pathology laboratories. One patient had a gastric instead of a colorectal carcinoma. Of 776 tissue samples available, from 20 patients only normal mucosa was available, 10 tissue samples were revised as being a benign adenoma instead of a carcinoma by a pathologist (A.d.B.), from six patients. DNA yield was insufficient for molecular analyses, and from three patients the available tissue did not include malignant colorectal cancer tissue. Hence, tumour tissue from 737 colorectal cancer patients was available for APC mutation analysis and hMLHI inmmunohistochemistry.

\section{APC MUTATION ANALYSIS}

The majority of somatic mutations in APC occurs within the mutation cluster region. Mutation analysis of this region (codons 1,286-1,520) was performed on archival adenocarcinoma specimens, using macrodissection to extract tumour DNA, followed by nested polymerase chain reaction (PCR) of the mutation cluster region in four overlapping DNA fragments and direct sequencing of purified fragments. This procedure has been described in detail elsewhere in brief, in a first round of PCR, two overlapping fragments were generated, that served as templates for a second round of PCR to amplify four overlapping biotin-labelled PCR fragments that were subsequently used for direct sequencing. The sequence profile was analysed on ALFexpress. DNA Analysis System using ALFwin software (Amersham Biosciences, Roosendaal, The 
Netherlands). Evaluation of the sequence patterns and data entry was performed independently by two observers. The detection limit was $5 \%$ of mutated DNA. Duplicate experiments reveded good reproducibility (85\%).

From 72 of the 737 patients, one or more fragments of the mutation cluster region could not be amplified and these patients were not included in this study. Since the rectosigmoid can be considered as a clinically applied term rather than an anciomically defined transitional zone between the colon and rectum, patients with a rectosigmoid tumour were excluded from data analysis. Moreover, the group of patients with a rectosigmoid tumour was too small for adequate stratified analysis. After exclusion of the 74 patients with a rectosigmoid tumour, 440 colon and 151 rectal cancer patients remained available.

\section{HMLH 1}

Formalin-fixed, paraffin-embedded tissues were sectioned at $4 \mu \mathrm{m}$ and included tumour tissue with normal adjacent mucosa. Endogeneous peroxidase activity was blocked with $3 \% \mathrm{H}_{2} \mathrm{O}_{2}$. Slides were submitted to microwave antigen retrieval in $1 \mathrm{mM}$ EDTA buffer $(\mathrm{PH} 8.01$ and incubated with $10 \%$ normal horse serum for ten $\mathrm{min}$ at room temperature. Then, sections were incubated overnight at $4^{\circ} \mathrm{C}$ with mouse monoclonal antibodies against hMLH1 protein (clone G168-15. PharMingen, San Diego. CA) at a 1:100 dilution. Antibody binding was detected by incubating the sections at room temperature with the peroxidase-labelled DAKO Envision System (DAKO. Carpinteris, CA) Using diaminebenzidine as a chromogen. Sections were counterstained with diluted haematoxyline.

Lesions were considered to lack hMLHl protein expression when unequivocal absence of nuclear staining of the tumour epithelial cells was observed. Nuclear staining of normal epithelial and stromal cells or lymphocytes served as internal positive control. Staining profiles were scored independently by at least two observers and in case of discordant results discussed with a pathologist until consensus was reached. hMLHI expression could be determined in 724 of 737 patients, for whom tumour DNA was available. With the exclusion of 84 patients with a reclosigmoid fumour, 468 calon and 172 rectal cancer cases were available for the analysis.

\section{EXPOSURE ASSESSMENT}

The dietary section of the questionnaire, a 150 -item semi-quantitative food frequency questionnaire, concentrated on habitual intake of food and beverages during the year preceeding the start of the study. Questionnaire data were key-entered twice and processed for all incident cases in the cohort and for all subcohort members in a manner blinded with respect to case/subcohort status in order to minimise observer bias in cading and interpretation of the data.

Subjects whose dietary data were incomplete or inconsistent, were excluded from the analysis, leaving 484 colon cancer patients of whom 13 were also subcohort members and 160 rectal cancer patients of whom one was also a subcohort member, and 3.048 subcohort members. Criteria used for this selection were (a) 60 or more questionnaire items left blank and 35 items that 
were eaten less than once per month and/or (b) one or more item blocks (groups of items, e.g. beverages) left blank.

The questionnaire contained 14 items on the consumption of meat with the hot meal "mainly fresh meat, including chicken), five items on the consumption of meat products, which are used as sandwich filling, and three items on fish consumption. ${ }^{27}$ As for serving sizes, a question was included on the quantity of fresh meat usually purchased (per person, per meal). For meat products; the number of sandwiches filled with a product was asked and a standard serving size per sandwich filling of $15 \mathrm{~g}$ was used. For chicken and fish standard serving sizes were also used. Fresh meat is defined as meat that has not undergone any form of preservation, such as smoking, fermentation, and/or treatment with nitrate and/or nitrite salt ("curing"?. which is consumed during the main (hot) meal. Meat products are defined as meat items that have undergone preservation as described above. The questionnaire was validated against a nine-day diet record. ${ }^{28}$ The Spearman correlation coefficients for meat, meat products and fish were $0.46,0.54$ and 0.53 , respectivelly.

Quartiles of intake of fresh meat, beef, pork, minced meat and meat products were computed separately for men and women based on the distribution of intake in subcohort members. For liver and other meat eaten with main meal, categories of intake were a non-user and a user group (>0 g/day). For poultry. categories of intake were classified into a non-user and three user categories $(0-13.2,13.2-22.8$ and $\geq 22.8 \mathrm{~g} /$ day $)$. For fish, categories of intake were a non-user group and three user groups $(0-10,10-20$ and $\geq 20 \mathrm{~g} / \mathrm{day})$.

\section{STATISTICAL ANALYSIS}

The data analysis was conducted separately for overall colon and rectal cancer, colon and rectal cancer with or without a truncating APC mutation, described here as APC+ and APC- tumours, and colon cancer lacking hMLHI expression. In addition, in colon and rectal cancer without a truncating APC mutation, separate analyses were conducted for tumours harbouring a missense APC mutation and fumours that did not have such a mutation. Finally, tumours with a specific $C: G \rightarrow T: A$ or $G: C \rightarrow T: A$ point mutation, irrespective of their putative effect were analysed. Truncating APC mutations lead to intraduction of a stop codon and would result in a truncated and therefore inactive APC protein. Missense mutations lead to alteration of a single amino acid at the protein level. In the data analysis, associations with missense mutations in APC were studied in patients with at least one missense mutation, but without a truncating mutation.

Mean values of the intake of fresh meat, beef, pork, minced meat, liver, other meat, poultry, meat products, fish (all $\mathrm{g} /$ day), and possible confounding variables including age at baseline (years), intake of vegelable (g/day), fruit (g/day), alcohol (g/day), fat (g/day), dietary fibre (g/day), calcium (mg/day). energy ( $\mathrm{kJ} /$ dayl, and body mass index $\mathrm{BMI}(\mathrm{kg} / \mathrm{m} 2)$, as well as distributions of the variables sex, family history of colorectal cancer (yes/no), smoking status (never/ex/current smoker) and physicall activity in leisure time $<30,30-60,60-90$. $>90 \mathrm{~min} / \mathrm{day}$ ) were evaluated for subcohort members, colon and rectal cancer patients with or without a truncating APC mutation and colon cancer patients lacking hMLHI expression. Differences in distribution of the continuous variables 


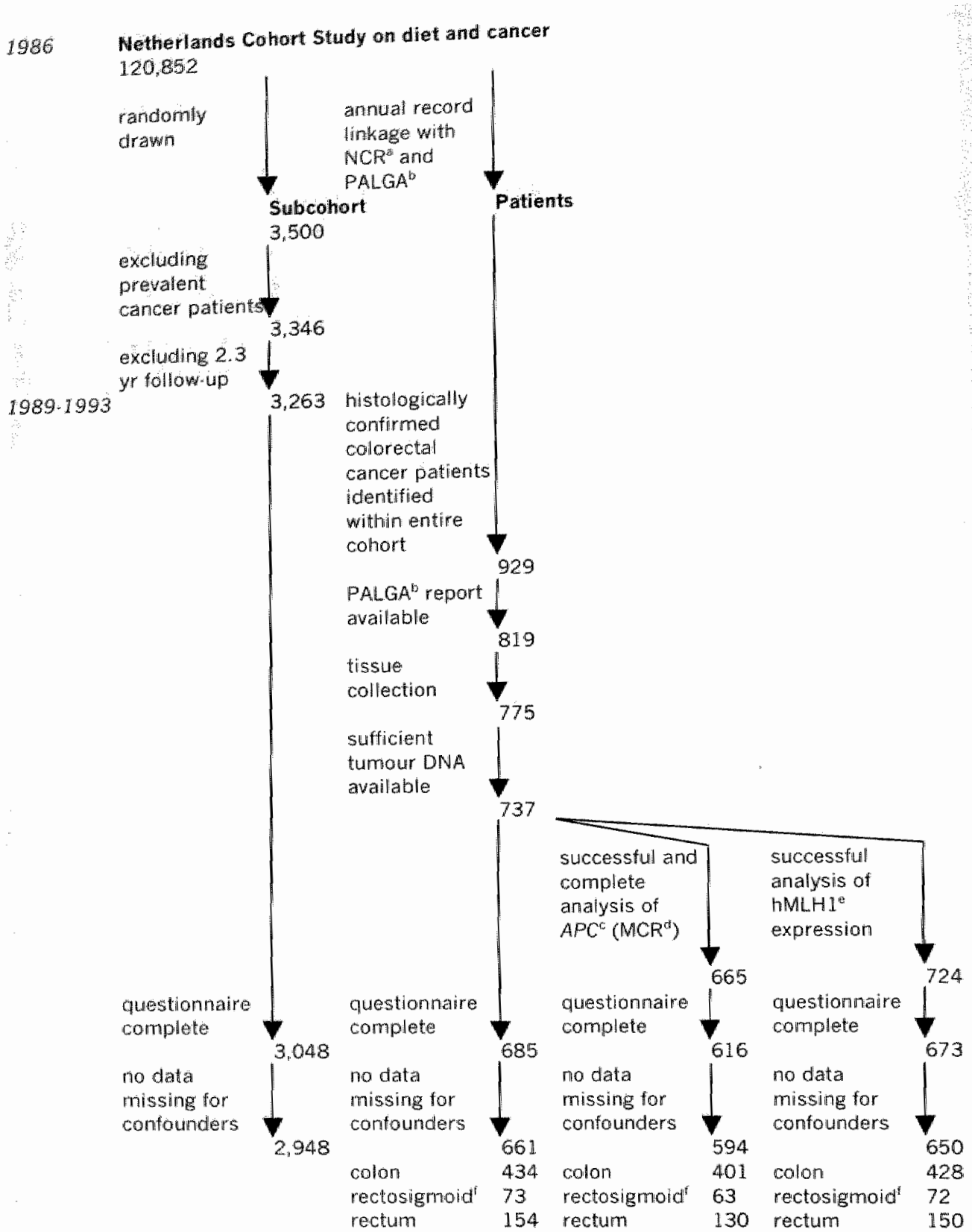

Figure 1. Flow diagram of subcahort members and colorectal cancer patients on whom the analyses were based.

"Netherlands Cancer Registry

- Pathologisch Anatomisch Landelijk Geautomatiseera Archief

"Adenomatous polyposis coli

Mutation cluster region

* human nut L homologue 1

"Patients with rectosigmoid tumours were not included in the analysis 
between patients with or withoul truncating nonsense or frameshift mutations in the mutation cluster region of the APC gene were tested with the Student"s t test or the Mann-Whitney $U$ test if the variables were not normally distributed. The distributions of the categorical variables between patients with and without truncating APC mutations were compared with the $\chi^{2}$ test.

Incidence rate ratios (RR) and corresponding $95 \%$ confidence interval (Cl) for colon and rectal cancer patients according to quartiles or categories of intake of fresh meat. meat products and fish intake and one standard deviation increment of intake were estimated using Cox proportional hazards regression models. In addition, associations were estimated for specific molecular endpoints of the tumours.

Standard errors were estimated using the robust Huber-White sandwich estimator to account for additional variance introduced by sampling from the cohort. ${ }^{29}$ The proportional hazards assumption was tested using the scaled Schoenfeld residuals. ${ }^{30}$ Tests for dose response trends over the different quartiles and categories of meat and fish intake were estimated by fitting the ordinal exposure variables as continuous variables using the Wald test.

Age at baseline, sex, intake of vegetables, fruit, alcohol, fat dietary fibre, calcium, body mass index, smoking status, family history of colorectal cancer, energy intake, and physical activity in leisure time were considered as potential confounders. Those variables that were found to statistically significantly $(p<0.05)$ contribute to the multivariate model for colon and/or rectal cancer lage at baseline, sex, body mass index, family history of colorectal cancer, and smoking status), as well as energy intake, were included as covariates in the multivariate analyses. None of the above-mentioned variables influenced the risk estimates by more than $10 \%$.

\section{RES ULTS}

The flow diagram of patients and subcohort members available for the analysis. is depicted in figure 1. 434 Colon and 154 rectal cancer patients from whom tumour material was available were included in the analysis of meat and fish consumption as a risk factor for colon and rectal cancer. Of the colon tumours, 220 were localised in the proximal colon, 204 in the distal colon and from 10 localisation was unspecified. With regard to Dukes stage, 77 colon tumours were graded Dukes' A, 154 Dukes' B, 112 Dukes' C, 59 Dukes' D, and 32 were unspecified, 59 rectal tumours were graded Dukes' A, 32 Dukes' B, 40 Dukes' C, and 11 Dukes' D, and 12 were unspecified.

Of the 401 colon and 130 rectal cancer patients, for whom APC mutation analysis was complete, $35 \%(188 / 535)$ had one or more mutations in the mutation cluster region of the APC gene that would lead to introduction of a stop codon and hence to a truncated and therefore inactive APC protein. In addition to these nonsense and frameshift mutations, a large number of silent and missense mutations were observed. When considering all mutations, regardless of their putative effect, $81 \%(431 / 535)$ of patients harboured at least one mutation in the APC gene. 


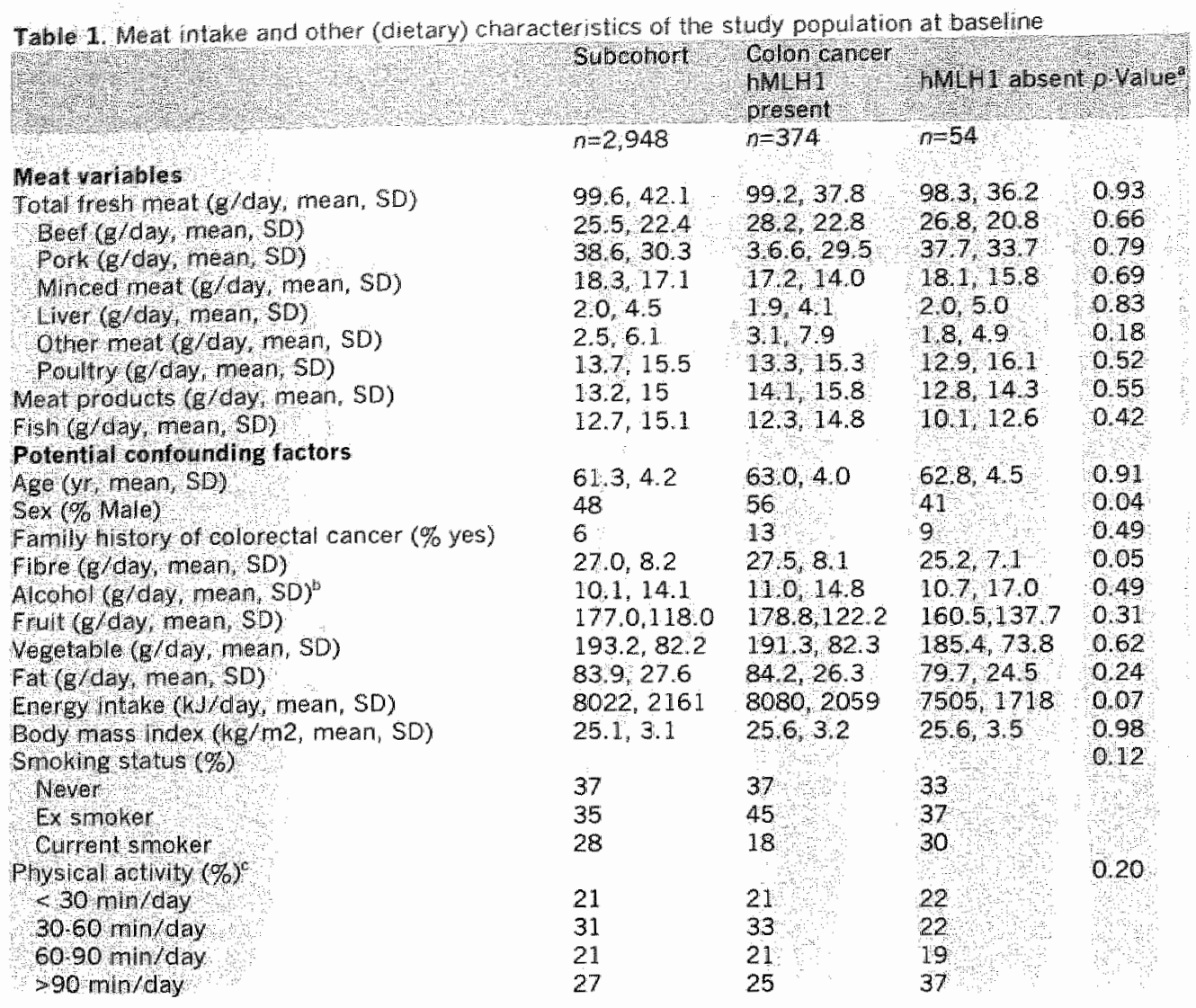

Multiple mutations in the APC gene were observed in tumours from $44 \%$ $(236 / 535)$ of patients. These figures are similar to the results that were obtained for the all patients, including rectosigmoid cancer patients that were analysed for the occurrence of APC mutations.

In 428 colon and 150 rectal cancer patients hMLH1 expression was determined. Of the colon tumours 54 were hMLHI deficient, 49 of which were located in the proximal colon. Two rectal tumours lacked hMLHI expression. Therefore, associations between meat and fish consumption and hMLHI deficiency were investigated for colon cancer only.

The baseline characteristics of the patients and subcohort members are presented in table 1. Colon and rectal cancer patients were older, more often men, more often had a family history of colorectal cancer and were more often ex-smokers as compared to the subcohort (data not shown). Rectal cancer 
Table 1. Cantinued

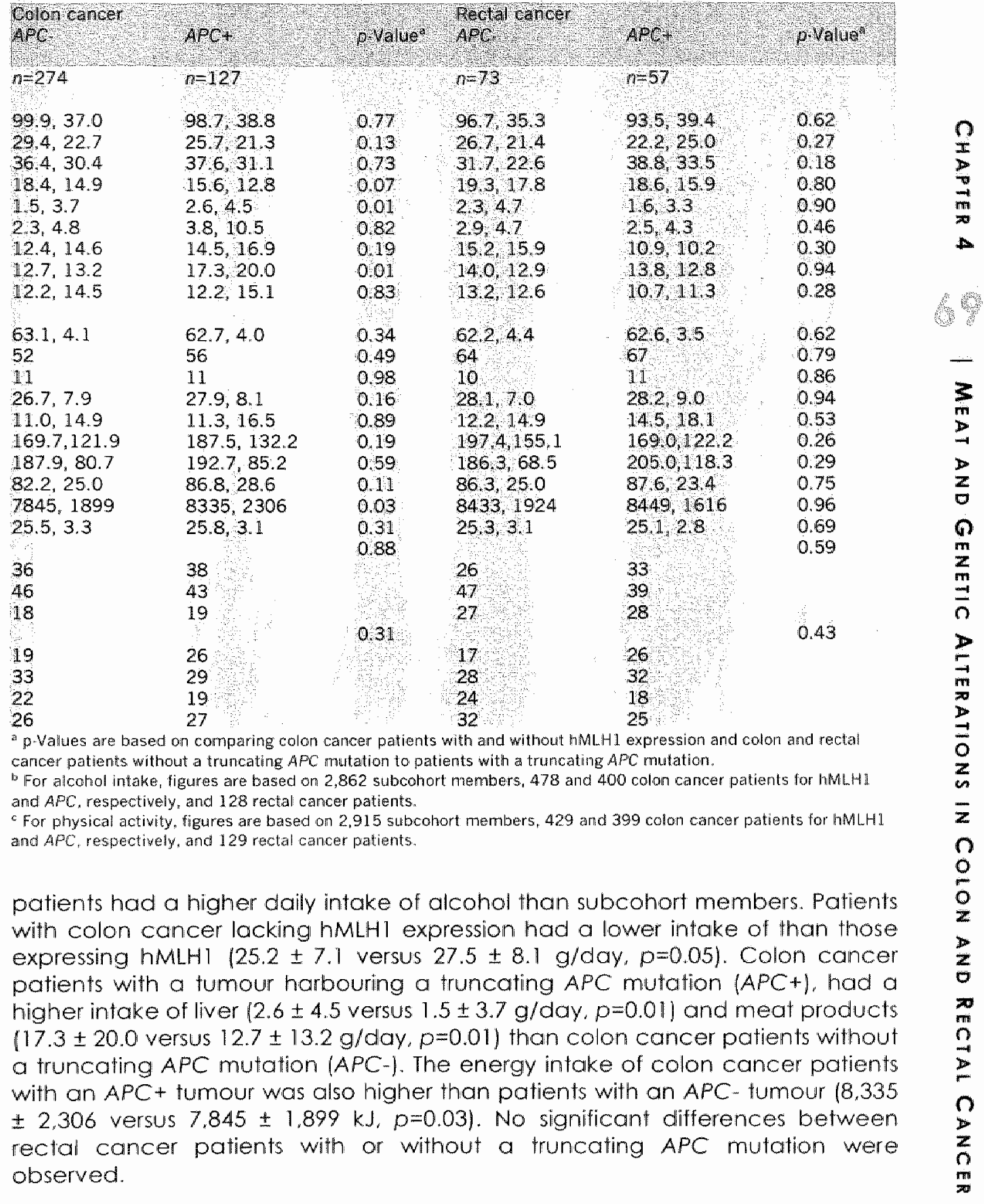




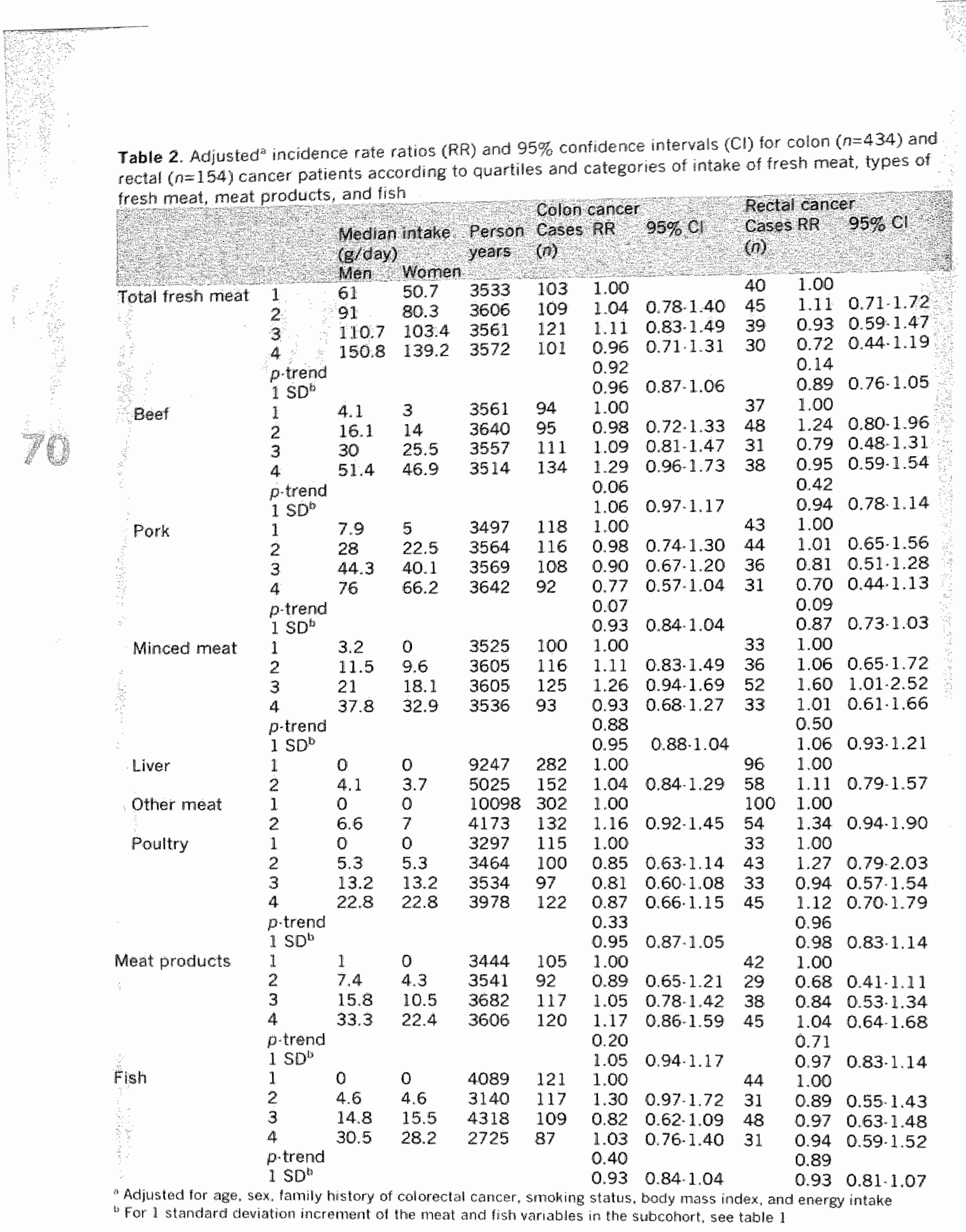


Associations between the consumption of several types of meat, meat products and fish with the risk of colon or rectal cancer are presented in table 2. RR and 95\% $\mathrm{Cl}$ for colon and rectal cancer were adjusted for age and sex only as well as for age, sex, smoking. BMl, energy intake and family history of colorectal cancer. The age and sex adjusted RR and the multivariate RR were similar (data not shown). A high consumption of beef seemed associated with an increased risk of colon cancer (RR for highest versus lowest quartile of intake $1.29 .95 \% \mathrm{Cl}$ 0.96-1.73, p-trend 0.06). However, pork consumption seemed associated with a decreased risk of both colon cancer (RR for highest versus lowest quartile of intake $0.77 .95 \% \mathrm{Cl} 0.57-1.04$, p-trend 0.07 ) and rectal cancer (RR for highest versus lowest quartile of intake $0.70 .95 \% \mathrm{Cl} 0.44 \% 1.13$, p-trend 0.09 ). Total fresh meat consumption was not associated with the overall risk of colon or rectal cancer.

Associations of several types of meat, meat products and fish with tumours without truncating APC mutations (APC-) and fumours with a truncating APC mutation (APC+) of colon and rectum are shown in table 3. Total fresh meat consumption was not associated with risk of APC+ or APC - colon tumours. A high consumption of beef was associated with an increased risk of colon tumours without an APC nonsense or frameshift mutation (RR for highest versus lowest quartile of intake $1.58,95 \% \mathrm{Cl} 1.10-2.25$, p-trend 0.01). Because the APCcolon tumours consisted of tumours that harboured a missense mutation ( $n=130$ ) and tumours that did not harbour such a mutation $(n=144)$, these groups were analysed separately. The risk estimates for both groups were similar (RR for highest versus lowest quartile of intake $1.64,95 \% \mathrm{Cl} 0.99-2.71, p$-trend=0.03 and $1.52,95 \% \mathrm{Cl} 0.95-2.45$, p-trend $=0.09$, respectively]. The risk of an APC+colon cancer was increased by high meat product consumption (RR for highest versus lowest quartile of intake $1.61,95 \% \mathrm{Cl} 0.96-2.71$, p-trend $=0.04$ ).

For rectal cancer, consumption of total fresh meat and beef seemed to be associated with a decreased risk of APC+ tumours (RR for highest versus lowest quartile of intake 0.48 and $0.53,95 \% \mathrm{Cl} 0.20-1.12$ and $0.24-1.19$, respectively, $p$ trend 0.05 for bothl. Consumption of other meat showed a statistically significant increased risk of APC-rectal tumours (RR for intake versus no intake $1.79 .95 \% \mathrm{Cl} \quad 1.10-2.90)$. When incidence risk ratios were calculated for fumours that harboured a missense mutation $(n=32)$ and tumours that did not harbour such a mutation $(n=41)$, these were similar, but did not reach statistical significance [RR for intake versus no intake $1.99,95 \% \mathrm{Cl} 0.95-4.16$ and $1.64,95 \%$ Cl 0.88-3.08, respectively).

When considering colon and rectal tumours that harboured o $C \rightarrow T$ or $G \rightarrow A$ mutation, irrespective of its putative effect, no clear associations were observed for any of the meat variables and 214 colon cancer patients with such a mutation (data not shown). Other meat consumption was associated with an increased risk of rectal cancer with $a C \rightarrow T$ or $G \rightarrow A$ mutation $(n=70$ ) (RR for intake versus no intake $1.75,95 \% \mathrm{Cl} 1.06-2.891$. but is similar to the risk observed for rectal cancer without a truncating APC mutation. No associations were abserved for any of the meat variables with colon tumours lacking hMLH1 expression (table 4). 
Table 3. Adiusted incidence rate ratios (PR) and $95 \%$ confidence interwal (C) for colon and rectai cancer patients without and with a trunceting $A P C$ gene mutations $(A P C$ - and $A P C+)$ according to quartiles and categories intake of fresh meat types of fresh meat, meat products, and ish

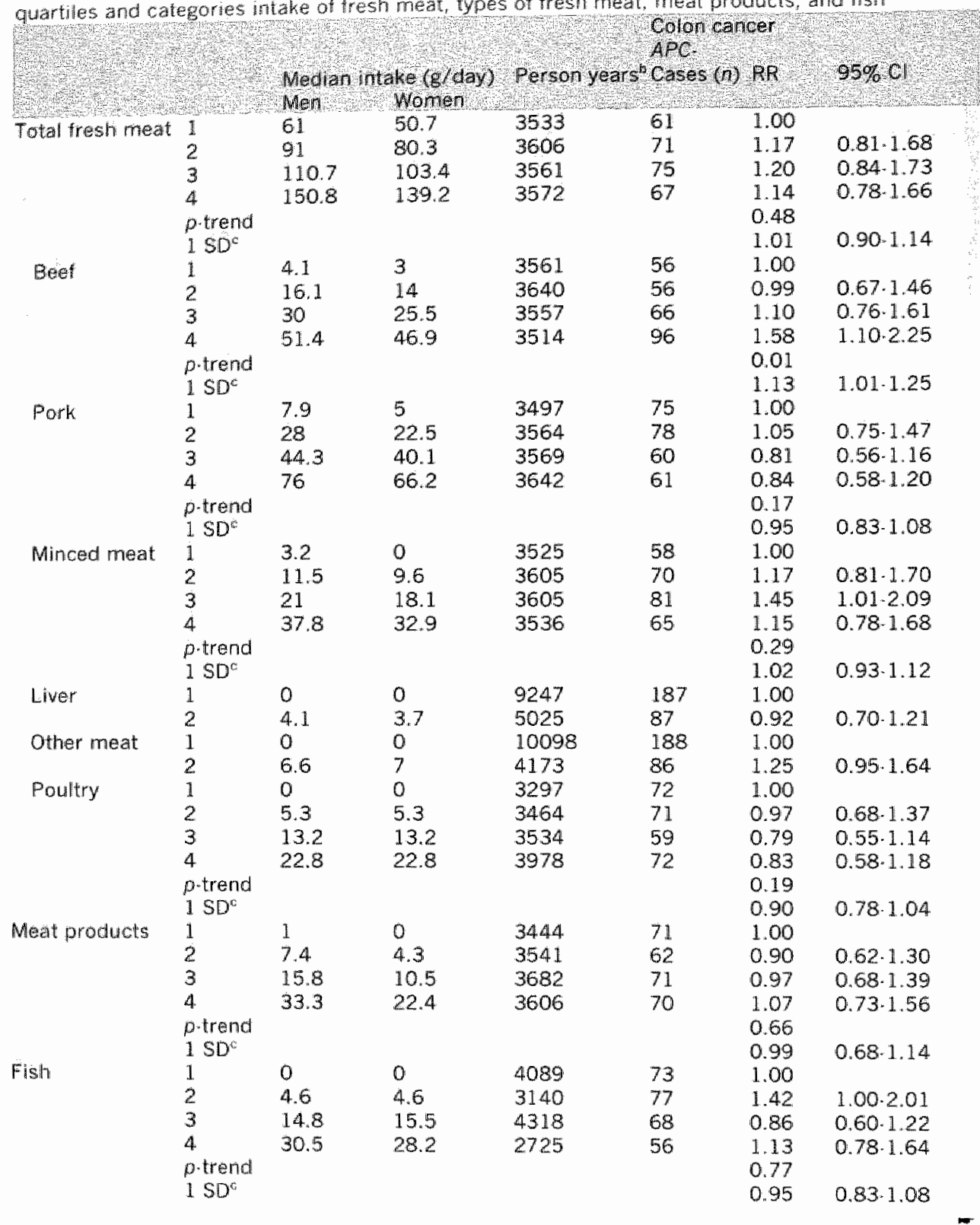


Table 3. Continued

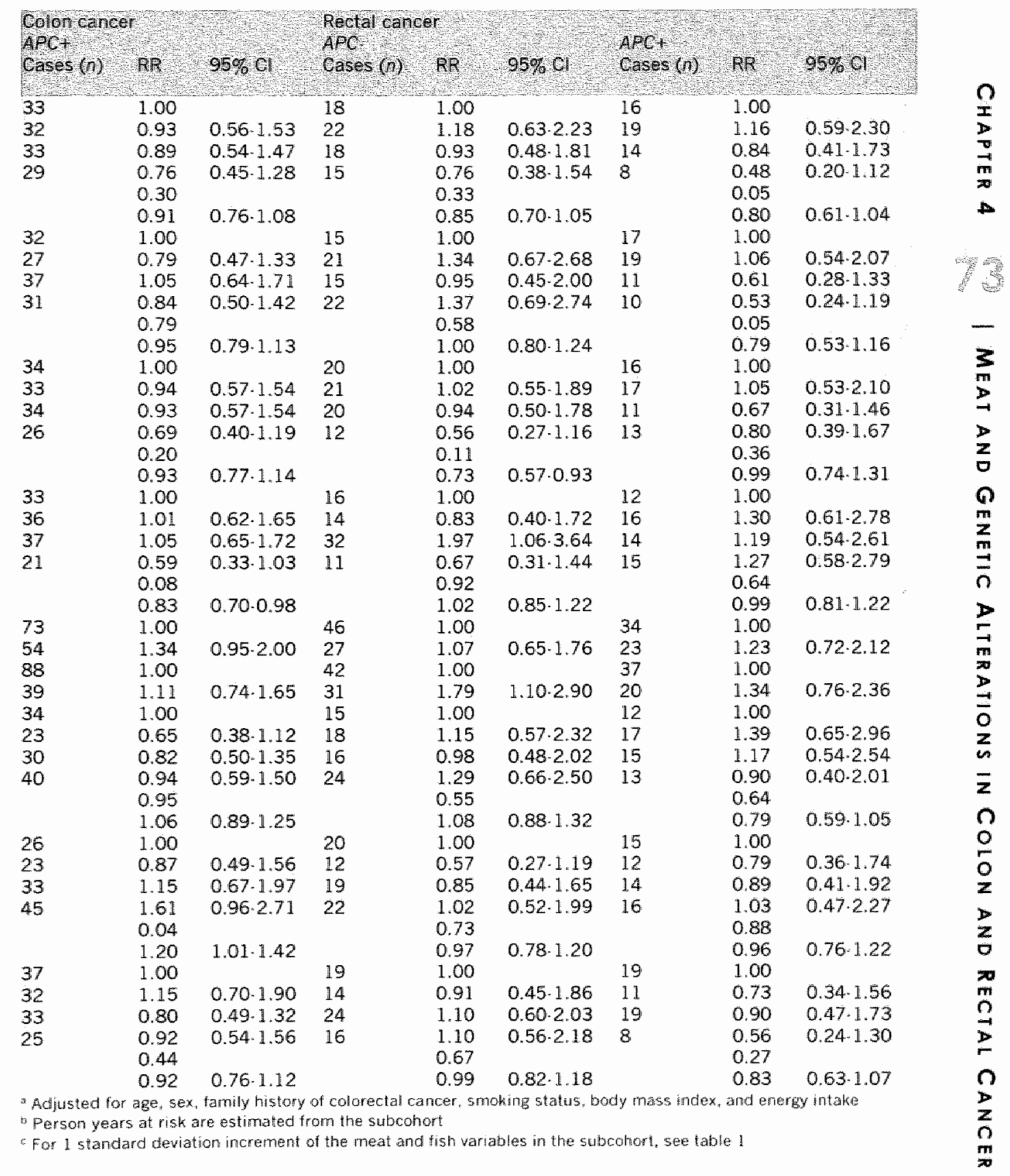




\title{
DISCUSSION
}

\begin{abstract}
Although colorectal cancer has often been studied as a single endpoint in epidemiologic studies, several differences between colon and rectal cancer have been described, such as differences in aetiology of tumour formation. ${ }^{4}$, in if has aiso been suggested that the molecular profile of fumours varies along the colorectal tract. We previously found asymmetry with respect to APC mutation status, more fruncating APC mutations were observed in rectal than in colon cancer. 6 In the present study, we evaluated the associations between meat. meat products, and fish intake and the risk of colon and rectal cancer with and without mutations in the mutation cluster region of the APC gene and the expression of the mismatch repair enzyme hMLHI.
\end{abstract}

For colon cancer, 401 patients could be included in this study, which gave rise to reasonable power to perform sub-group analyses for APC mutation status of the Humours. The limited number of 130 rectal cancer patients included in this study provided limited power, especially when estimating risk of rectal cancer with or without an APC mutation. It should be noted that patients with fumours in the rectosigmoid were excluded from the analyses, to make a clear distinction between colon and rectum tumours. Moreover, because we have run several analyses to estimate risk ratios for different subsets of colon and rectal tumours based on APC mutation status, the associations observed in this study need to be treated with some caution and would need confirmation in a larger study. The loss of patients initially recognised within the cohort, due to irretrievable tumour material, incomplete analysis of the APC gene and incompleteness of the food frequency questionnaire, may have influenced the observed results. However, risk estimates for meat and fish consumption for the group under study here, were similar to the results obtained for all 819 patients originally recognised within the cohort (data not shown).

Previous studies have not always taken into account possible differences between sub-localisations along the colorectal tract. Risk factors for colon and rectal cancer seem to differ, although in a recent study by Wei et al. ${ }^{4}$ the risks associated with servings of beef, pork or lamb or processed meats were not found to differ for colon and rectum. We found some differences between colon and rectal cancer. The risk of colon cancer seemed to be increased with high intake of beef, whereas for rectal cancer total fresh meat consumption
was found to be protective.

We observed no significant association between meat or fish consumption and overall risk of colon cancer, although there seemed to be a positive association with beef consumption. The associations seemed stronger for rectal than for colon cancer. A recent meta-analysis including 34 case-control and 14 cohort studies also found no risk of colorectal cancer associated with total meat intake, but a moderately increased risk associated with red meat and particularly processed meat consumption. ${ }^{3}$ In a recent systematic review of

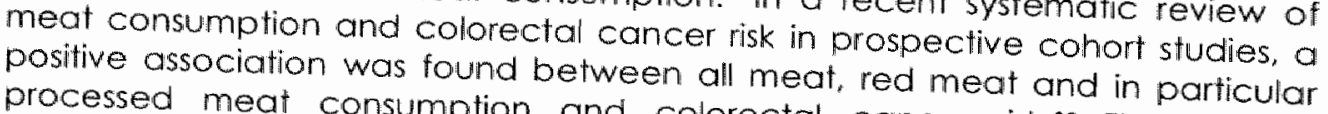
processed meat consumption and colorectal cancer risk. ${ }^{32}$ The positive association between all meat consumption and colorectal cancer risk in the 
Table 4. Adjusted incidence rate ratios (RF) and $95 \%$ Cl for colon cancer patients lacking thMHI expression $(n=54)$ according to quartiles and categories intake of fresh meat, types of fresh meat, meat products, and fish

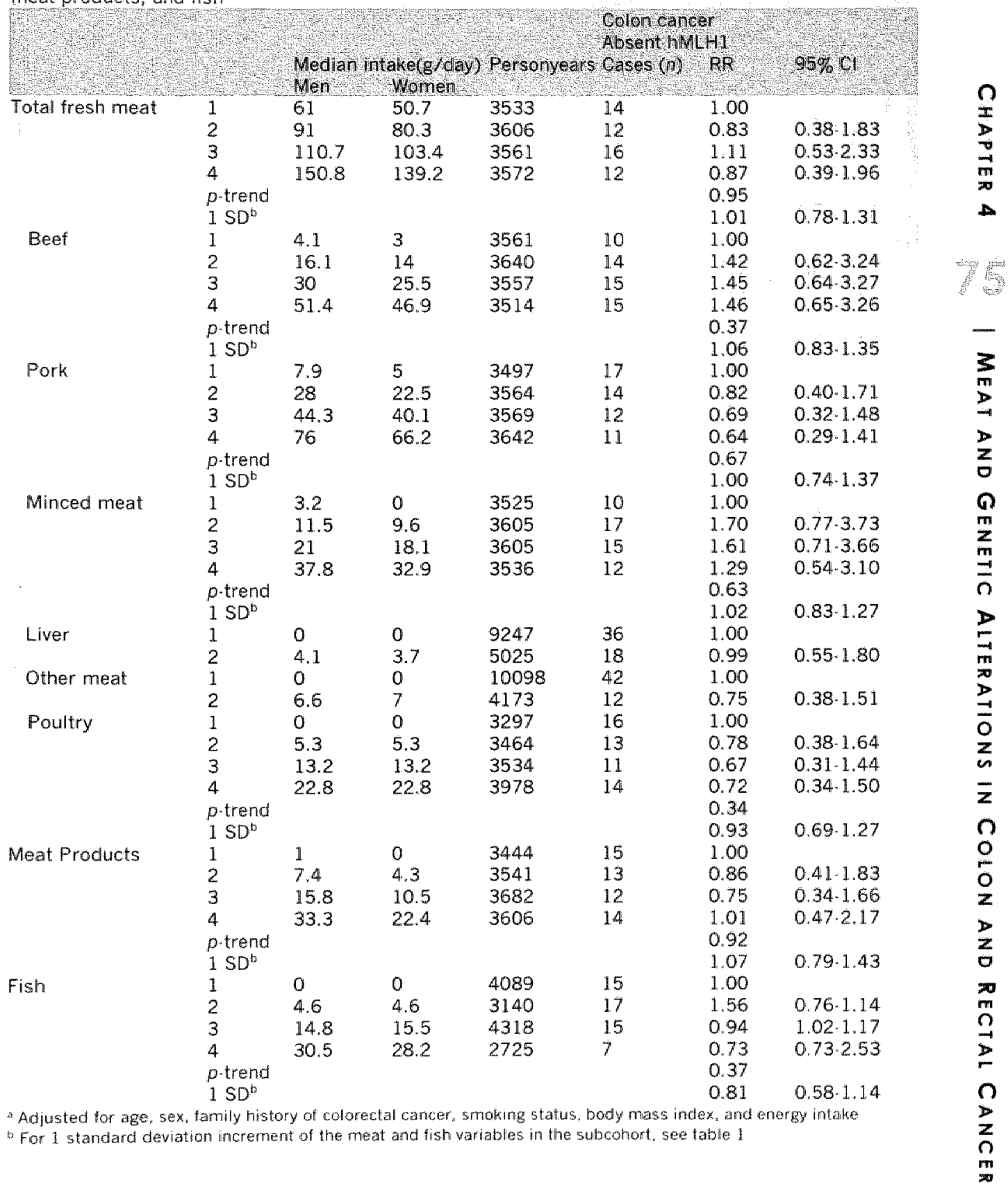


latter study may be due to inclusion of processed meat in the analysis of the "all meat" variable and differs from the "total fresh meat" variable used in our study in that respect, and residual confounding may be present in the systemic rewiew.

Whereas we found beef consumption to be positively associated with risk of colon cancer, pork consumption was inversely associated with colon cancer risk. Confounding of the associations of consumption of beef or pork by pork or beef, respectively, seems unlikely, as mutually adjusting the analysis for beef and pork consumption did not influence risk estimates. An explanation of the observed difference in risk may lie in the differences in preparation and haem iron content of beef and pork.

The differences between colon and rectal cancer are more complex as these also involve a variety of genetic aberrations. Microsatellite instability is most frequently observed in the proximal colon, whereas mutations in the APC and Kras gene occur more frequently in the distal colon and rectum. ${ }^{17-19}$ When taking into account the APC gene mutation status, we found specific associations between meat variables and colon and rectal cancer. Differences in associations between colon and rectal cancer and meat consumption may be explained by APC gene mutation status rather than by differences in exposure of the colon or rectum to meat. Consumption of meat products, i.e.. processed meat, significantly increased risk of $A P C+$ colon tumours. Beef intake was associated with an increased risk of APC-colon cancer. Total meat intake and in particular beef intake appears to be associated with a decreased risk of $A P C+$ rectall cancer. No associations for poultry or fish were observed. In a casecontrol study of dietary intake and risk of colon cancer with or without truncating APC mutations, moderate positive associations for colon tumours that harbour a truncating APC mutation were found with red meat and fish consumption. ${ }^{16}$ The discrepancy between the results from the case-control study and from our study may be attributable to a different exposure assessment of meat consumption in the case contral study (e.g., red meaf): alternatively, information bias may have played a role while the limited number of subjects in the case-control study (184 cases, 259 controls) may have resulted in chance findings.

$N$-nitroso compounds found in processed meats could induce $G \rightarrow A$ transitions that have been observed in codons 12 and 13 of the K-ras gene in human colonic tissue. ${ }^{22}$ In one of our previous studies, meat product consumption was found to be associated with $G \rightarrow A$ transitions in the $K$-ras gene, but only in rectal cancer.3 We found a positive association for meat product consumption with $\mathrm{APC}+$ colon tumours. Since a $\mathrm{G} \rightarrow \mathrm{A}$ transition may occur on the non-coding strand, this would give rise to detection of a $C \rightarrow T$ transition of the coding strand of the APC gene and vice versa. However, when we analysed tumours with a specific $C: G \rightarrow T: A$ mutation that leads to introduction of a stop codon, no significant association with meat products was found. This may be due to the limited group size. Moreover, we abserved a large proportion of fumours to have multiple mutations, which further complicates analysis on specific types of mutations. 
Consumption of other meat was associated with an increased risk of colon and rectal cancer. Other meat consisted of other meat eaten with the main course. i.e., horsemeat, lamb, mutton, frankfurters and deep-fried meat rolls. The association was most pronounced in rectal tumours, and in both colon and rectal tumours without a truncating APC mutation. Although consumption of other meat was also positively associated with rectal fumours with $C: G \rightarrow \pi: A$ transitions, irrespective of their putative effect, the observed associations were similar to rectal cancer without a truncating APC mutation, and may be due to chance. Although the intake of other meat is low, it seems that consumption of other meat is associated with an increased risk of colon and rectal cancer without a truncating APC mutation.

Beef consumption was associated with an increased risk of APC-colon tumours. In previous analyses on beef and K-ras mutation status within the same cohort, beef was also positively associated with $K$-ras-colon tumours. ${ }^{33}$ A proportion of the APC-tumours harbour missense APC mutations. Analysis of tumours without a truncating mutation, but with a missense mutation and tumours that harboured neither of these mutations yieldled similar results. When fumours with missense mutations and those without show similar incidence risk ratios, but different from tumours harbouring a truncating mutation This suggest fumours with missense mutations may not be similar to fumours with impaired APC function. Possibly, the risk of beef consumption involves a pathway that does not involve inactivation of APC or activation of K-ras.

It has been suggested that the majority of colorectal cancer arises through the genetic pathway as described by Fearon and Vogelstein. ${ }^{7}$ which involves inactivation of the APC protein, generally followed by activation of the K-ras protein. Tumours that harbour mutations in the APC gene are generally chromosomally instable tumours. ${ }^{34}$ A proportion of colorectal fumours may develop through different lepi-jgenetic aberrations. Microsatellite instability is such an alternative pathway and tumours showing microsatellite instability accur almost exclusively in the proximal colon. In a case-control study that addressed associations between dietary factors and microsatellite instability based on 40 microsatellite instable patients, an inverse association of red meat with micrasatellite instable tumours was observed. ${ }^{24}$ In 54 patients with hMLHI deficient tumours in our study, no association with meat consumption was observed. This may indicate that the differences in observed associations may be due to the limited number of patients in both studies.

To our knowledge, this study is the first to have investigated the associations between meat, meat products and fish consumption and the occurrence of different types of APC mutations as well as expression of $\mathrm{hMLHI}$ in a prospective cohort. Although most associations between meat, meat products and fish consumption are weak, our data suggest that several types of fresh meat and meat products seem to contribute differently to the aetiology of colon and rectal cancer, depending on the APC mutation status of the fumour, but lnot its hMLHI expression status. 


\section{REFERENCES}

1. Potter JD. Nutrition and colorectal cancer. Cancer Causes Control 1996:71 11:127-46.

2. World Cancer Research Fund. American Institutte for Cancer Reseorch. Food, nutrition and the prewention of cancer: A global perspective, ed. 1st. Washington. DC: WCRF/AIRC. 1997.

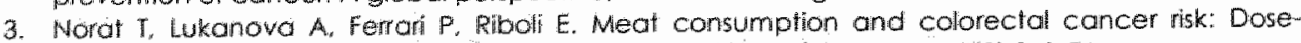
response mela- analysis of epidemiological studies. Int I Cancer 2002:98(2):241-56.

4. Wei EK, Giovannucei $E$. Wu K. Rosner B. Fuchs CS, Willeft WC, Colditz GA. Comparison of risk factors for colon and rectal cancer, Int J Cancer 2004:108(3):433m.42.

5. Brink M, De Goeij AF, Weijenberg MP. Roemen GM, Lentjes MH, Pachen MM, Smits KM. De Bruine AP. Goldbohm RA, Von den Brand PA, K-ras oncogene mutations in sporadic colorectal concer in the Netherlands Cohort Study. Carcinogenesis 2003:24(4):703-10.

6. Luchtenborg $M$, Weijenberg MP, Roemen $G M$, de Bruine AP, van den Brandt PA, Lentjes MH, Brink $M$, wan Engeland M, Goldbohm RA, de Goeif AF. APC mutations in sporadic colorectal corcinomas from the Netherlands Cohort Study. Carcinogenesis 2004:25(7):1219-26.

7. Fearon ER, vogelstein B. A genetic model for colorectal tumorigenests. Cell 1990;6:(5):759-67.

8. Powell SM, Zilz N, Beazer-Barcloy Y. Bryan TM. Hamilton SR, Thibodeau SN, Vogelstein B, Kinzler KW. APC mutations occur early during colorectal tumorigenesis. Nature 1992;359/6392]:235-7,

9. Miyoshi Y, Nagase H. Ando H, Horli A, Ichi S, Nakatsuru S, Aaki T. Miki Y, Mori T. Nakamura Y. Somatic mulations of the APC gene in colorectal tumors: mutation cluster region in the APC gene. Hum Mol Genet 1992:1/4):229-33.

10. Cottrell 5. Bicknell D, Kaklamanis L. Bodmer WF. Molecular analysis of A.PC mutations in familial adenomatous polyposis and sporadic colon carcinomas. Lancet 1992,340(8820),626-30.

11. Myaki M. Kanishi M. Kikuchi-Yanoshita R. Enamoto M. Igari T. Tanaka K, Muraoka M, Takahashi $H$. Amada $Y$. Fukayama $M$, ef al. Characteristics of somatic mutation of the adenomatous polyposis coligene in colorectal tumors. Cancer Res 1994:54[11]:3011-20.

12. Yashima K. Nakamori S, Murakami Y, Yamaguchi A, Hayashi K. Ishikawa $O$. Konishi Y, Sekiya T. Mutations of the adenomatous polyposis call gene in the mutation cluster region: camparison of human pancreatic and colorectal cancers. Int J Cancer 1994:59(1):43-7.

13. Konishi M, Kikuchi-Yanoshita R. Tanaka K, Muraoka M. Onda A, Okumura Y. Kishi N. Iwama T. Mori T. Koike $M$. Ushio $K$. Chiba M, Nomizu S, Konishi $F$, Utsunomiya J. Miyaki M. Molecular nature of colon tumors in hereditary nonpolyposis colon cancer, familial polyposis, and sporadic colon cancer. Gastroenterology 1996:111 [2]:307-17.

14. De Filippo C, Luceri C. Caderni G. Pacini M, Messerini L. Biggeri A. Mini E. Tonelli F, Cianchi F. Dolara P. Mutations of the APC gene in human sporadic colorectall cancers. Scand $J$ Gastroenterol 2002:37/9):1048-53.

15. Kim Sh SH. Kaminker P. Campisi J. Telomeres, aging and cancer: in search of a happy ending. Oncogene 2002;21(4):503-11.

16. Diergaarde B, van Geloof WL, van Nulien GN. Kok FJ Kampman E. Dietary factors and the occurrence of truncating APC mutations in sporadic colon carcinomas: a Dutch populationbased study. Carcinogenesis 2003:24(2):283-90.

17. Olschwang S, Hamelin R, llaurent-Puig P. Thuille B, De Rycke Y, Li YJ, Muzeau F. Girodet J, Salmon RJ. Thomas G. Alternative genelic pathways in colorectall corcinogenesis. Prac Nall Acad Sci U S A $1997,94(22): 12122-7$.

18. Salahishor S, Kressner U. Pohiman L. Glimelius B, Lindmark G, Lindblom A. Colorectal cancer with and without microsatellite instability involves different genes. Genes Chromosomes Cancer $1999: 26(3): 247-52$

19. Samowitz WS, Holden JA, Curtin K, Edwards SL, Walker AR, Lin HA, Robertson MA, Nichols MF, Gruenthal KM, Lymch BJ. Leppent MF. Slattery ML. Inverse Relationship between Microsatellife Instability and K-ras and p53 Gene Alterations in Colon Cancer. Am J Pathol 2001:158(4):1517-24.

20. Thibodeau SN. French A.J. Cunningham JM. Tester D. Burgart LJ, Roche PC. MCDonnell SK. Schaid DJ Vockley CW, Michels VV. Farr GH. Jr. O'Comnell MJ. Microsatellite instability in colorectal cancer: different mutator phenotypes and the principal involvement of hMLHI. Cancer Res $1998 ; 58(8): 1713-8$.

21. Toyota M. Ushijima T. Kakiuchi H. Canzian F. Watanabe M. Imai K, Sugimura $T$, Nagao M. Genetic alterations in rat colon tumors induced by heterocyclic amines. Cancer 1996:77 (8 Suppl):1593-7.

22. Binghan $S A$, Hughes $R$, Cross AJ. Effect of white versus red meat on endogenous N-nitrosation in the human colon and further evidence of a dose response. J Nutr 2002:132/111 Suppll:3522S-25S. 
23. Mirvish S5, thoorah J. Zhou L, Clapper ML, Harrison KL. Povey AC. Total Nhitroso compounds and their precursors in hot dags and in the gastrointestinal tract and feces of rats and mice: possible etiologic agents for colon cancer. J Nutr 2002:132(1) Supply:3526\$-29S.

24. Diergaarde B. Braam H. van Muijen GN, Ligtenberg MJ. Kok FJ. Kampman E. Dietany factors and microsatellite instability in sporadic colon carcinomas. Cancer Epidemiol Biomankers Prev 2003; 12:111 P1 11:1130-6.

25. van den Brandt PA, Goldbohm RA, van 't Veer P. Volovics A, Hermus R.J. Stumans F. A llarge-scale prospective cohort study on diet and cancer in The Wetherlands. J Clin Epidemiol 1990:43/31:28595.

26. wan den Brandt PA, Schouten LJ, Goldbohm RA, Dorant E. Hunen PM. Development of a record linkage protocot for use in the Dutch Cancer Registry for Epidemiological Research. Int I Epidemial 1990:119 (3):553-8.

27. Goldbohm RA, van den Brandt PA, van 't veer P, Brants HA, Dorant E, Sturmans F, Hermus RJ. A prospective cohort sludy on the relation between meat consumption and the risk of colon cancer. Cancer Res 1994;54(3):718-23.

28. Galdbohm RA, van den Brandt PA, Brants HA, van'f Veer $P$, Al M, Sturmans $F$, Hermus $R$ J. Validation of a dietary questionnaire used in a large-scale prospective cohort study on diet and cancer. Eur \Clin Nutr 199:4;48:4):253-65.

29. Lin DY. Wei $U$. The rabust inference for the Cox Proportional Hazards Model. JASA 1989;84[408]:1074-78.

30. Schaenfeld D. Partial residuals for the proportional hazards regression madels. Biometrika $1982 ; 69(1): 239-41$.

31. Iacopetta B. Are there two sides to colorectal cancer? Int J Cancer 2002:101(5):403-8.

32. Sandhu MS, White IR, MCPherson K. Systematic review of the prospective cohort studies on meat consumption and colorectal cancer risk: a meta-analytical approach. Cancer Epidemiol Biomarkers Prev 2001;10(5):439-46.

33. Brink $M$, Wejenberg MP, de Goelj AF, Roemen GM, Lentjes MH, de Bruine AP, Goldbohm RA, Brandt.P.A. va. Meat consumption and K-ras mutations in sporadic colorectal cancer in The Netherlands Cohort Study. Br J Cancer 2005:92(4):13110-20.

34. Fodde R. Smits R. Clevers H. A.PC, signal transduction and genetic instability in calorectal cancer. Nature Rev Cancer 2001:1 (11:55-67. 
$\begin{array}{lllllll}C & H & A & P & T & E & R\end{array}$ 5 


\section{DIETARY FAT AND RISK OF COLORECTAL CANCER WITH ABERRANT HMLHI EXPRESSION, APC OR K-RAS GENES}

\footnotetext{
MATTY P WEIJENBERG MARGREET LUCHTENBORG ANTON FPM DE GOEIJ MIRIAN BRINK GOOS NP VAN MLIJEN ADRIAAN P DE BRUIINE R ALEXANDRA GOLDBOHM PIET A VAN DEN BRANDT
} 


\section{A B STR A C T}

Sporadic colorectal cancers arise through pathways characterised by specific genefic aberrations.

We investigated baseline fat intake and the risk of colon and rectal tumours lacking expression of the hMLHI repair gene and with or without mutations in the mutation cluster region of the APC tumour suppressor gene and in codons 12 and 13 of the K-ras oncogene in the Netherlands Cohort Study on diet and cancer $(n=120.852)$. After 7.3 years of follow-up, excluding the first 2.3 years. adjusted incidence rate ratios (RR) and $95 \%$ confidence intervals (C) were computed. using 2,948 subcohort members (55-69 years at baseline) and 401 colon and 130 rectal cancer patients.

Total, saturated and monounsaturated fat were not associated with the risk of colon or rectal cancer or the different molecular subgroups, nor were associations observed between polyunsaturated fat and risk of rectal cancer. Linoleic acid was significantly associated with increased risk of colon tumours with a $K$-ras mutation and no additional truncating APC mutation or lack of hMLH1 expression (RR=6.74,95\% Cl 2.36-19.51 for the highest versus the lowest quartile of intake, $p$-trend $<0.0011$. Linoleic acid intake was neither associated with risk of colon tumours without any of the gene defects, with tumours only lacking hMLHI expression, nor with tumours only harbouring an APC mutation.

Our data suggest that linoleic acid intake is associated with colon fumours with an aberrant $K$-ras gene, but an intact APC gene and hMLHI expression, suggesting a unique aetiology of tumours with specific genetic aberrations. 


\section{INTRODUCTION}

Although dietary fat has been implicated in the aetiology of colorectal cancer, results from epidemiological studies are inconsistent ${ }^{2,3}$ and often do not support an association, as observed recently in the Women's Health Study. ${ }^{4}$ Fortunately, current efficient molecular techniques to detect DNA alterations on a large scale offer possibilities of studying molecular endpoints in colorectal cancer, characterised by acquired (epilgenetic defects in tumour DNA. ${ }^{5}$ This approach may improve our ability to observe associations between dietary factors and cancer that may otherwise remain undetected.

A multistep model linking sporadic colorectal carcinogenesis to molecular aberrations has been proposed and is still considered valid.6-8 Currently, three classes of genes are thought to be involved, i.e. tumour suppressor genes, ancogenes, and DNA repair genes, that operate in multiple genetic pathways leading to collorectal cancer. In most types of cancer, including colon and rectum cancer, two distinct forms of genomic instability have been identified, $\%$ 10 microsatelite instability, resulting in varying sizes of short tandem repeats in the genome, and chromosomal instability, characterized by partial or complete loss of chromosomes and genes. Ten to $15 \%$ of sporadic colon carcinomas are characterised by microsatellite instability, predominantly due to promoter methylation of the human MUt-L homologue 1 (hMLHI) DNA mismatch repair gene, which prevents expression of the enzyme." Up to 90 percent of colon and rectum carcinomas are chromosomally instable ${ }^{10.12}$ and are associated with mutations in the adenomatous polyposis coli (APC) and tumour protein 53 (TP53) tumour suppressor genes and in the Kirsten ras ( $K$-ras) oncogene. ${ }^{13}$ However, simultaneous occurrence of mutations, in these three genes is rare, which suggests that (even in this group of chromosomally instable tumours) different genetic pathways to colorectal cancer exis 14 "Mutations in the APC gene are found to occur relatively early in colorectal tumourigenesis and are observed in up to $80 \%$ of bath adenomas and carcinomas. ${ }^{8}$. 5 Mutations in the $K$-ras gene are observed in approximately 10 to $20 \%$ of small adenomas and 40 to $50 \%$ of larger adenomas and carcinomas suggestive of it being an important event in the progression of adenoma to carcinoma. ${ }^{15}$ Mutations in the TP53 gene are postulated to affect relatively late stages of colorectal carcinogenesis. ${ }^{15}$

Several epidemiological studies on the relation between dietary factors and molecular features of colon and rectum cancer have been published previously. Two of three studies on diet and hMLH1 expression in colon carcinomas do not report on dietary fat intake ${ }^{16,17}$ and one study reports no association between total fat intake and colon fumours either with or without hMLHI expression, and does not report on specific types of fat. Regarding truncating APC mutations, one study shows an association between tatal fat intake, and especially unsaturated fat intake, and increased risk of colon carcinomas with a truncating $A \cdot P C$ mutation, 19 whereas in another study an association between total fat intake and increased risk of colon adenomas

\footnotetext{
- Lüchtenborg M. Weijemberg MP. Wark PA, ef al Mutations in APC. CTNNBI and K-ros genes and
} expression of $\mathrm{hMLH}\}$ in sporadic colorectal cancer, see chapter 3 
without a truncating APC mutation was observed.20 The studies on fat intake and risk of fumours with or without mutations in the K-ras gene have shown conflicting results. No associations were observed for total fat intake and colon or rectal fumours with or without mutations in the $K$-ras gene. ${ }^{21-24}$ except for a positive association of intake of total, saturated and mono-unsaturated fat with colon tumours harbouring specific $G \rightarrow T$ mutations at the second position in codon 12.25 A case-control study in Spain showed an inverse association between monounsaturated fat intake and risk of colon cancer with wild type $K$ ras. ${ }^{21}$ We previously reported a significant association between the intake of linoleic acid and increased risk of colon carcinomas with a mutated $K$-ras gene. ${ }^{24}$

Breivik and Gaudernack proposed that the type of genetic instability in cancer cells reflects the selection pressures exerted by specific carcinogens. Bardelli et al. ${ }^{26}$ subsequently tested this hypothesis in immortalised, genetically stable human cells and concluded that exposure to specific carcinogens can indeed select for tumour cells with distinct forms of genetic instability. In particular, cells resistant to the methylating agent $N$-methyl- $N^{\prime}$-nitro- $N$-nitrosoguanidine (MNNG) exhibited microsatelite instability associated with mismatch repair defects, whereas cells resistant to the bulky-adduct-forming agent 2-amino-1-methyl-6phenylimidazo [4,5-b]pyridine (PhIP) exhibited chromosomal instability. In line with this reasoning. DNA adducts derived from fat metabolism could also be associated with colorectal tumours exhibiting chromosomal instability. This is supported by the observations that malondialdehyde (MDA), generated during lipid peroxidation and arachidonic acid metabolism, can form DNA adducts and induce $G \rightarrow T$ transversions and $G \rightarrow A$ transitions in DNA.27.28 In addition. higher levels of MDA-DNA adducts have been observed in colorectal tissue of adenoma patients than in tissue of controls.29 MDA levels are modulated by dietary factors, i.e. n-6 polyunsaturated fatty acids presumably increase MDA levels, whereas dietary antioxidants and n-3 polyunsaturated fatty acids seemingly decrease MDA levels. 29

These observations and hypotheses prompted us to investigate the associations between the intake of total fat and different types of fat and the risk of colon and rectal fumours lacking KMLHI expression, with and without APC and K-ras gene mutations within the Netherlands Cohort Study on diet and cancer (NLCS).

\section{MATERIALS AND METHODS}

\section{STUDY POPULATION}

The prospective NLCS was initiated in The Netherlands in September 1986. The study design has been described in detail elsewhere. 30 Briefly, at baseline a total of 58,279 men and 62,573 women, between the ages of 55 and 69 years, completed a self-administered food frequency and lifestyle questionnaire. The study population originated from 204 municipal population registries throughout the country. Incident cancer cases are identified by monitoring of the entire cohort for cancer accurrence through annual record linkage to the 
Netherlands Cancer Registry (NCR), consisting of nine regional cancer registries throughout the Netherlands, and to the Pathologisch Anatomisch Landelijk Geautomatiseerd Archief (PALGA), a nationwide network and registry of histoand cytopathology. ${ }^{31}$ The NCR and PALGA together provide a near 100\% coverage of the municipalities included in the NLCS.

Accumulation of person-time in the cohort was estimated through biennial vital status follow-up of a subcohort of 3.500 men and women who were randomly selected after baseline exposure measurement." Cases with prevalent cancer other than non-melanoma skin cancer were excluded from the subcohort. which left 3,346 men and women for analysis. No subcohort members were lost to follow-up.

The first 2.3 years of follow up were excluded because of possible pre-clinical disease affecting exposure status and because of incomplete nationwide coverage of PALGA alone (i.e., not in combination with the NCR) in some of the municipalities included in the NLCS. Within this period, 83 subcohort members deceased or were diagnosed with cancer other than non-melanoma skin cancer, leaving 3,263 subcohort members for analysis. From 1989 until 1994, 929 incident cases with thistologically confirmed collorectal cancer were identified within the cohort, of whom 819 could also be linked to a PALGA report of the lesion. The PALGA reports were used to identify and locate tumour tissues from eligible colorectal cancer patients in Dutch pathology laboratories. Colon and rectal cancer were classified according to site as follows, colon: cecum through sigmoid colon (ICD-O codes 153:0, 153.1, 153.2, 153.3, 153.4, 153.5, 153.6, 153.7). rectosigmoid (ICD-O code 154.0), and rectum (ICD-O code 154.1).

\section{TISSUE SAMPLES}

Tumour material of colorectal cancer patients was collected after approval by the Ethical Review Board of University Maastricht, the NCR and PALGA. Archival, paraffin embedded tissue samples from 819 colorectal cancer patients were distributed among 54 pathology laboratories throughout The Netherlands. The tissue specimen collection started in August 1999 and was completed in December of 2001 . For five percent of patients, tissue samples could not be retrieved (44/819), nine of which were due to administrative inconsistencies in one pathology laboratory, and 34 of which were due to the unavailability of the paraffin blacks in the archives of pathology laboratories. One patient furned out to have a gastric instead of a colorectal tumour. Of 775 tissue samples available, only normal mucosa was available from 20 patients, 10 tissue samples were revised as being a benign adenoma instead of a carcinoma by a pathologist, from six patients the DNA yield was insufficient for molecular analyses, and from three patients the available tissue did not include malignant colorectal cancer tissue but cancer tissue from another site. Hence, fumour tissue from 737 colorectal cancer patients was available for hMLHI expression analysis and for APC and K-ras mutation analysis.

Since the rectosigmoid can be considered as a clinically applied term rather than an anatomically defined transitional zone between the colon and rectum, 85 patients with a rectosigmoid tumour were excluded from data analysis. Moreover, the group of patients with a rectosigmoid fumour was too small for adequate stratified analysis. 


\begin{abstract}
HMLH1 EXPRESSION ANALYSIS
Formalin-fixed, paraffin-embedded tissues were sectioned at $4 \mu \mathrm{m}$ and contained tumour tissue and normal adjacent mucosa. Endogeneous peroxidase activity was blocked with $3 \%$ hydragen peroxide. Slides were submitted to microwave antigen retrieval in $1 \mathrm{mM}$ EDTA buffer $(\mathrm{pH} 8.0)$ and incubated with $10 \%$ normal horse serum for ten minutes at room femperature. Then, sections were incubated overnight at $4^{\circ} \mathrm{C}$ with mouse monoclonal antibodies against hMLHI protein (clone G168-15. PharMingen, San Diego, CA) at a 1:100 ditution. Antibody binding was detected by incubating the sections at room temperature with the peroxidase-labelled DAKO Envision System (DAKO, Carpinteris, CA) and using diaminebenzidine as a chromogen. Sections were counterstained with diluted haematoxylin.

Lesions were considered to lack hMLHI protein expression when unequivocal absence of nuclear staining of the tumour epithelial cells was observed. Nuclear staining of normal epithelial and stromal cells or lymphocytes served as internal positive control. Staining profiles were scored independently by at least two observers and in case of discordant results discussed with a pathologist until consensus was reached. hMLHI expression status could be determined in 724 of 737 patients.
\end{abstract}

\title{
APC MUTATION ANALYSIS
}

The majority of somatic mutations in APC occur within the mutation cluster region. Mutation analysis of the mutation cluster region (codons $1,286-1,520$ ), was performed on archival adenocarcinoma specimens, using macrodissection followed by extraction of tumour DNA. Then nested PCR was used to amplify the mutation cluster region in four overlapping DNA fragments and the purified fragments were sequenced. This procedure has been described in detail elsewhere. ${ }^{32}$ In brief, in a first round of PCR, two overlapping fragments were generated, that served as templates for a second round of PCR to amplify four overlapping biotin-labelled PCR fragments that were subsequently used for direct sequencing. The sequence profile was analysed on ALFexpress DNA Analysis System using ALFwin software (Amersham Biosciences, Roosendaal, The Netherlands). Evaluation of the sequence patterns and data entry were independently performed by two observers. The detection limit was $5 \%$ mutated DNA. Duplicate experiments revealed good repraducibility $(85 \%)$.

From 72 of the 737 patients, one or more fragments of the APC gene mutation cluster region could not be amplified and these patients were not included in this study.

\section{K-RAS MUTATION ANALYSUS}

Mutation analysis of the exonl fragment of the K-ras oncogene, spanning codons 8-29. was performed on archival colorectal adenocarcinoma specimens of 737 patients, using nested PCR, followed by direct sequencing of purified fragments. ${ }^{33}$ The detection limit was $5 \%$ mutated DNA and duplicate experiments revealed good reproducibility (88\%). ${ }^{33}$

\section{EXPOSURE ASSESSMENT}

The dietary section of the questionnaire consisted of a 150 -item semiquantitative food frequency questionnaire, which concentrated on habitual 
consumption of food and beverages during the year preceding the start af the study. Mean individual nutrient intakes per day were computed using the computerized Dutch food composition table of $1986^{34}$ by cumulating the multiplied frequencies and portion sizes of all food items with their tabulated nutrient contents. The questionnaire was validated against a nine-day diet record. ${ }^{35}$ Crude and energy-sex-adjusted (in parentheses) correlation coefficients were $0.72(0.52)$ for total fat, $0.73(0.58)$ for saturated fat and 0.73 (0.75) for polyunsaturated fat. ${ }^{35}$ For energy intake the correlation coefficient was 0.74 . On average, the questionnaire covered $91 \%$ of the energy intake assessed by the recard intake. Questionnaire data were key-entered wwice and processed for all incident cases in the cohort and for all subcohort members in a manner blinded with respect to case/subcohort status. This was done in order to minimise observer bias in coding and interpretation of the data.

For $7 \%$ of all subjects (either cases or subcohort members), dietary data were incomplete or inconsistent, and they were excluded from the analyses. Questionnaires were considered incomplete when either: (a) more than 60 items were left blank and less than 35 items were eaten at least once a month; or (b) one or more item blocks (groups of items, e.g., beverages) were left blank. Additional details are given elsewhere. ${ }^{35}$ This resulted in the availability of 3,048 subcohort members, 441 colon cancer cases for whom hMLHI expression status was known, and 414 colon and 136 rectal cancer cases for whom APC and K-ras mutation status was known. No data-analyses were conducted for lack of hMLHI expression in rectal cancer cases since there were only two such cases in the cohort.

Intake of specific fatty acids was based on a food composition database with specific fatty acids derived from the TRANSFAIR study. ${ }^{36}$ For this database, the hundred foods that contributed most to fat intake in the Dutch dietary pattern were sampled and analysed as methyl esters of the fatty acids present in the foods. In the database, total fat includes triglycerides and other lipids such as phospholipids and sterols. The percentage of triglycerides in total fat is assumed to be $93 \%$ on average, but varies across food sources. Daily intakes of rotal fat (g/day), saturated fat (g/day). monounsaturated fat (g/day), polyunsaturated fat (g/day), and linoleic acid (C) 8:2, C9, 12) (g/day) and inolenic acid (C) 8:3, C9. 12,15$)$ (g/day) as the main constituents of polyunsaturated fat, were used as exposure variables. Linoleic and linolenic acid were used as the most abundant sources of $n-6$ polyunsaturated fatty acids and $n-3$ polyunsaturated fatty acids in the diet. In all analyses, the values for fat intake variables are adjusted for energy intake by the residual method. ${ }^{37}$ For data analyses, quartiles of the intake of fat and different types of fats were computed based on the distribution among subcohort members. Daily intake of dietary fibre (g/day). alcohol (g/day). fruit ( $g /$ day), vegetables (g/day) and total energy (kJ/day) and age at baseline (years), sex (men/women). body mass index $(\mathrm{kg} / \mathrm{m} 2)$, nonoccupational physical activity $<<30 \mathrm{~min} /$ day, 30-60 min/day, 60-90 min/day, $>90$ min/day). family history of colorectal cancer (yes/no) and smoking status (never/ex/current) were regarded as potential confounders. 


\section{STATISTICAL ANALYSIS}

Data analyses were based on study participants for whom data on fat intake and confounding variables were complete, i.e., 2,948 subcohort members, 428 colon cancer patients for whom hMLHI expression status was known, and 401 colon cancer and 130 rectal cancer patients for whom APC and K-ras mutation status was known (figure 1).

Data analyses were conducted separately for overall colon and rectal cancer, colon cancer lacking hMLHI expression, colon and rectal cancer with or without a truncating APC mutation, described here as APC+ and APC-tumours, respectively. Truncating APC mutations lead to the introduction of a stop codon and result in a truncated and therefore inactive APC protein. The analyses with truncating APC mutations were also conducted separately for the most common point mutations that result in the introduction of a stop codon, i.e. $C: G \rightarrow T: A$ or $G: C \rightarrow T: A$ point mutations. As indicated previously, associations between fat intake and $K$-ras mutated fumours have been described in this population previously, and a positive association between the intake of linoleic acid and K-ras mutated colon tumours was observed. ${ }^{24}$

Since tumours may harbour multiple mutations, it is difficult to assess whether observed associations are specific for tumours with a particular gene defect. We therefore conducted additional analyses when (borderline) significant associations were observed. In these, subgroups of tumours were analysed separately, based on either the absence of either of the three gene defects, or on defects in a single gene, i.e. either only lack of hMLH1 expression, only a truncating APC mutation or only an activating K-ras mutations. Activating $K$-ras mutations are defined as mutations in codons 12 and 13 of the Kwas gene that would lead to an altered amino acid.

Mean values of the intake of fat variables $(\mathrm{g} / \mathrm{day})$, and possible confounding variables including age at baseline (years). dietary fiber ( $g / d a y)$, alcohol (g/day), intake of fruil $(\mathrm{g} / \mathrm{dav})$, vegelable $(\mathrm{g} / \mathrm{day}$ ), energy $(\mathrm{kJ} / \mathrm{day})$, and $\mathrm{BM}$ $(\mathrm{kg} / \mathrm{m} 2)$, as well as distributions of the variables sex, family history of colorectal cancer (yes/no), smoking status (never/ex/current smoker) and physical activity in leisure time $(<30,30-60,60-90,>90 \mathrm{~min} /$ day $)$ were evaluated for subcohort members, colon and rectal cancer patients with or without a truncating APC mutation and colon cancer patients lacking $h \mathrm{MLH}$ l expression. Differences in mean values of the continuous variables between patients with or without truncating nonsense or frameshift mutations in the mutation cluster region of the APC gene, and between patients with and without hMLHI expression, were tested using the Mann-Whitney $U$ test since the variables were not normally distributed among cases. We used the $\chi^{2}$ test to test for differences in the distributions of the categorical variables between patients with and without truncating APC mutations, and between patients with and without hMLH 1 expression.

Cox proportional hazards regression models were used to estimate incidence rate ratios $(R R)$ and corresponding $95 \%$ confidence intervals $(C \mid)$ of colon and rectal cancer according to quartiles of intake of (types of) dietary fat and according to one standard deviation increment of fat intake. In addition. associations were estimated for specific molecular endpoints of the tumours. 


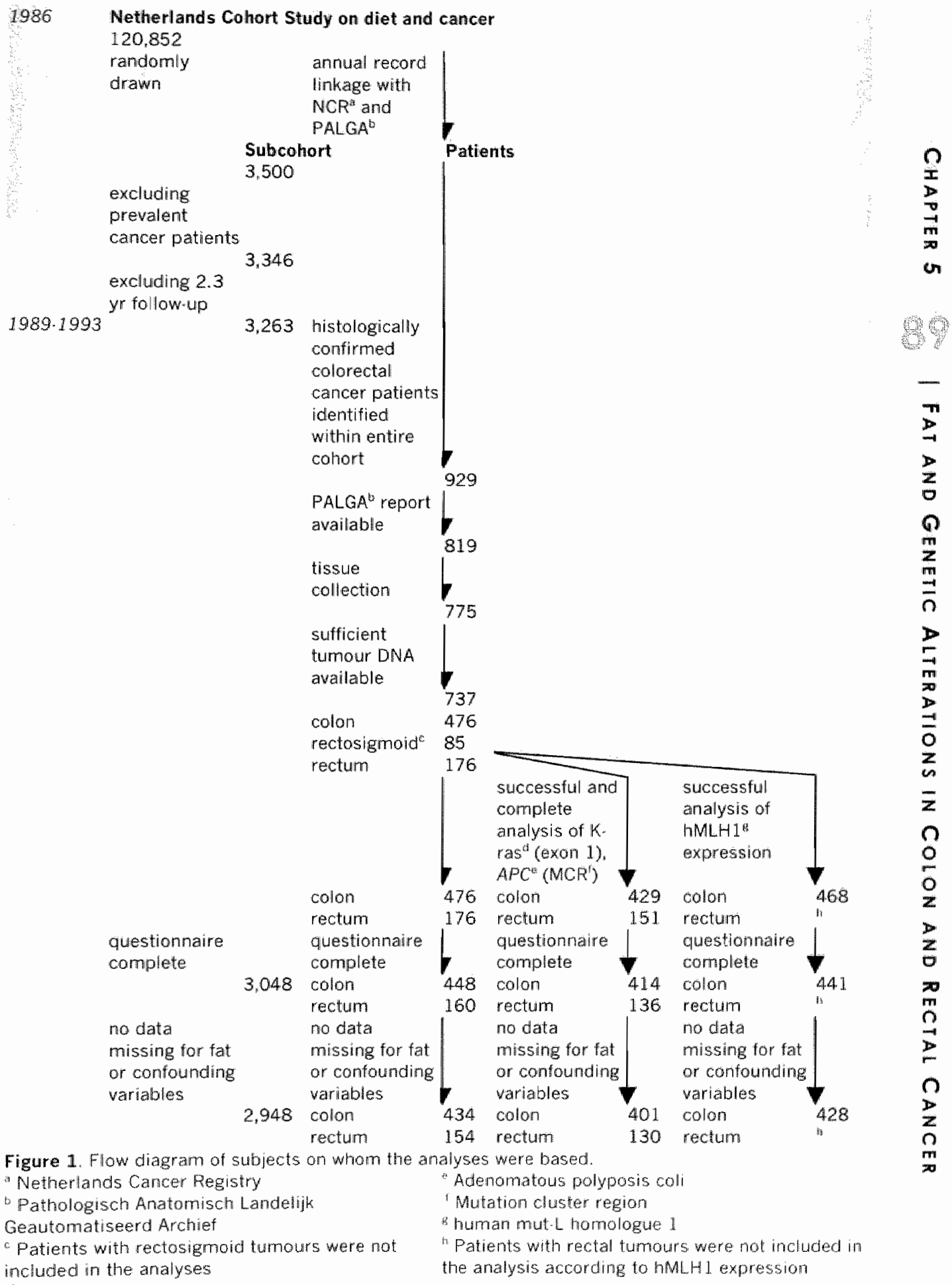


Standard errors were estimated using the robust Huber-White sandwich estimator to account for additional variance intraduced by sampling from the cohort. ${ }^{35}$, 39 The proportional hazards assumption was tested using the scaled Schoenfeld residuals. 40 Tests for dose response trends over the different quartiles and categories of fat intake were estimated by fitting the ordinal exposure variables as continuous variables and evaluated using the Wald test.

Age at baseline, sex, intake of fiber, alcohol, fruits and vegetables, body mass index, smoking status, family history of colorectal cancer, energy intake, and physical activity in leisure time were considered as potential confounders. Those variables that were found to statistically significantly $(p<0.05)$ contribute to the multivariate model for colon and/or rectal cancer (age at baseline, sex, bady mass index, family history of colorectal cancer, and smoking status), or to influence the RR by more than 10\%, as well as energy intake, were included as covariates in the multivariate analyses.

Table 1 Baseline dietary intake and other characteristics of the subcohort and colon and rectum cancer patients

\begin{tabular}{|c|c|c|c|c|}
\hline \multirow{2}{*}{ 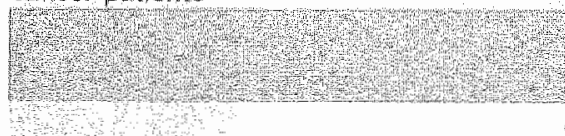 } & subsorids & \multirow{2}{*}{\multicolumn{3}{|c|}{ 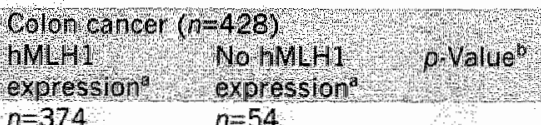 }} \\
\hline & $n=2,948$ & & & \\
\hline Sex (\%men) & 48 & 56 & 41 & 0.04 \\
\hline Age (y nean,so) & $61,3,4.2$ & $630,4,0$ & $62.8,4.5$ & 0.91 \\
\hline \multicolumn{5}{|l|}{ Fat variables (g/day, mean, SD) } \\
\hline Total fat & $83,8,158$ & $85,1,14.7$ & $84.1,17.5$ & 0.57 \\
\hline Saturated fat & 332,75 & $33.5,6.6$ & $33,3,7,6$ & 0.64 \\
\hline MUIFAd & $31,4,7,0$ & $31,9,6,5$ & $31.1,7.5$ & 0.45 \\
\hline PUFA: & $17.3,75$ & $179,7.5$ & $17.4,6.8$ & 0.85 \\
\hline Linoleic acid & $16.0,7.5$ & $167,7.5$ & $16,6,7.0$ & 0.76 \\
\hline Linolenic acid & $1.3,0.6$ & $1.2,0: 5$ & $1.3,0.6$ & 0,98 \\
\hline \multicolumn{5}{|l|}{ Other dietary factors } \\
\hline Fibre (g/day, mean, SD) & $27.0,8.2$ & $24.5,8.1$ & $25.2,7.1$ & 0.13 \\
\hline Alcohol (g/day, mean, SD) & $10.1,14.1$ & $110,14,8$ & $10.7,17.0$ & 0.49 \\
\hline Fuit (g/day mean, SD) & $177.0,118.0$ & 1788,1221 & $160.5,137.7$ & 0.07 \\
\hline Vegetables (g/day, mean, SD) & $193.8,82.2$ & $191,3,82.3$ & $185.4,73.8$ & 0.80 \\
\hline Energy (w/day, mean, SD) & 8028,2164 & 8080,2059 & 7505,1718 & 0.07 \\
\hline \multicolumn{5}{|l|}{ Other characteristics } \\
\hline Body mass index (kg/m", mean, SD) & $25.1,3.1$ & $25.6,3.2$ & $25.6,3.5$ & 0.57 \\
\hline Family history of colorectal cancer (\% yes) & 6 & 13 & 9 & 0.49 \\
\hline \multicolumn{5}{|l|}{ Smoker (\%) } \\
\hline Never & 37 & 37 & 33 & \\
\hline Ex-smoker & 35 & 45 & 37 & 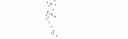 \\
\hline Curirent smoker & 28 & 18 & 30 & 0.12 \\
\hline \multicolumn{5}{|l|}{ Physical activity $(\%)^{\prime}$} \\
\hline <30 min/day & 21 & 21 & 22 & \\
\hline $30.60 \mathrm{~min} / \mathrm{day}$ & 32 & 33 & 22 & \\
\hline $6090 \mathrm{mn} / \mathrm{day}$ & 21 & 21 & 19 & \\
\hline$>90 \mathrm{~min} / \mathrm{day}$ & 27 & 25 & 37 & 0.20 \\
\hline
\end{tabular}




\section{RESULTS}

Lack of expression in hMLH1 was observed in $13 \%(54 / 428)$ of fumours from colon cancer patients (table 1). APC truncating mutations were observed in tumours of $32 \%$ of colon cancer patients $(127 / 40)\}$ and $44 \%$ of rectal cancer patients $(57 / 130$ ) (table 1). $\mathrm{C}: \mathrm{G} \rightarrow \mathrm{T}: \mathrm{A}$ transitions or $\mathrm{G}: \mathrm{C} \rightarrow \mathrm{T}: \mathrm{A}$ transversions that would result in a stop codon were abserved in $10 \%$ and $5 \%$ of colon cancer patients and $12 \%$ and $5 \%$ of rectal cancer patients, respectively. These figures are similar to the percentages reported for the total group of colon and rectal cancer patients for whom APC mutation status was available but for whom dietary intake data were not always complete. ${ }^{32}$

Colon and rectal cancer patients were generally older and more frequently men than subcohort members (table 1). Patients with collon cancer lacking

Table 1. Continued

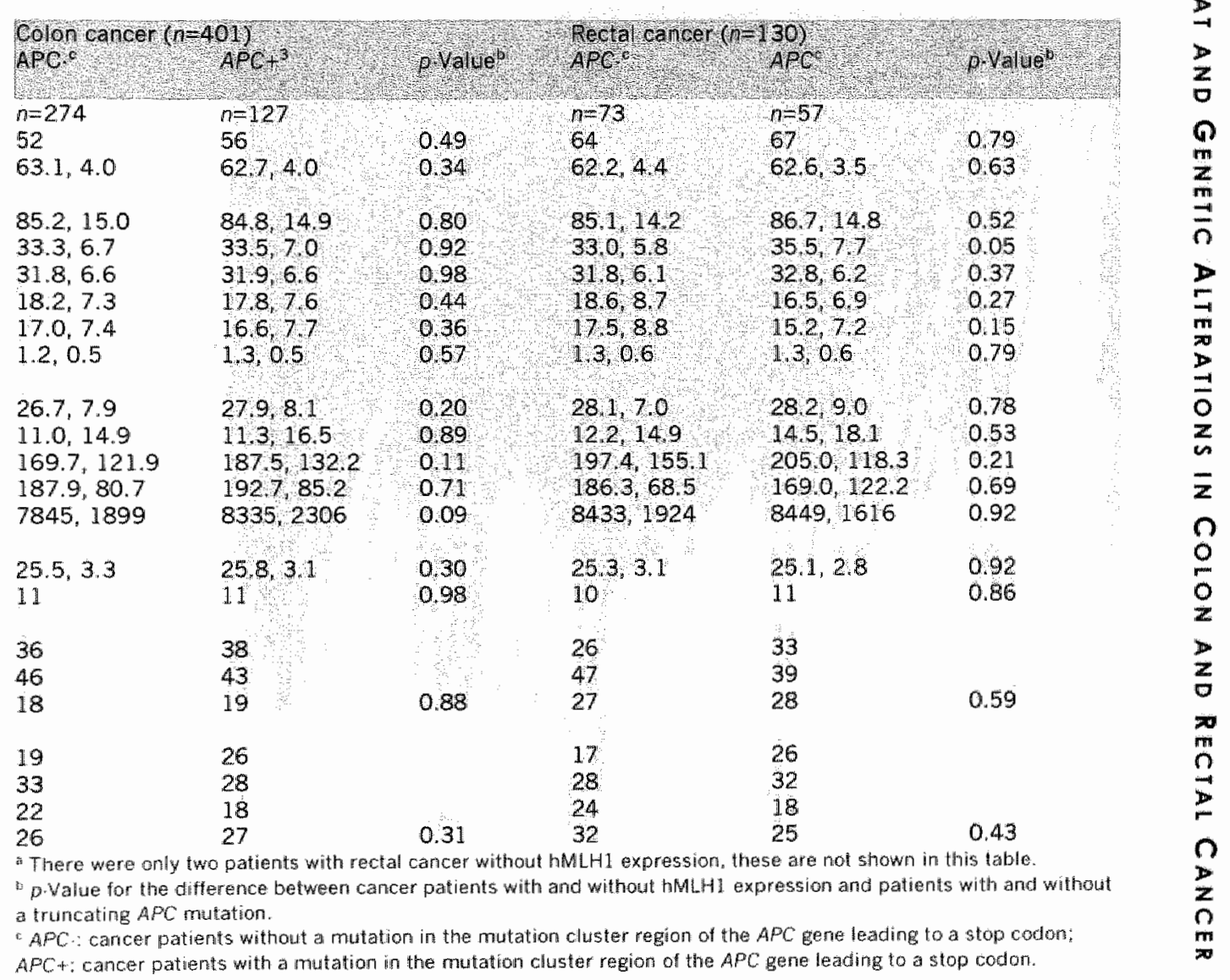

2 Pothunsaturated fat.

"For alcohol intake and physical activity the mean levels in the subcohort are based on 2,86.2 and 2,915 subjects respectively. Four and six colon cancer cases had missing walues for alcohol intake and physical activity respectively. Two and one rectal cancer case had missing values for alcohol intake and physical activity respectively. 


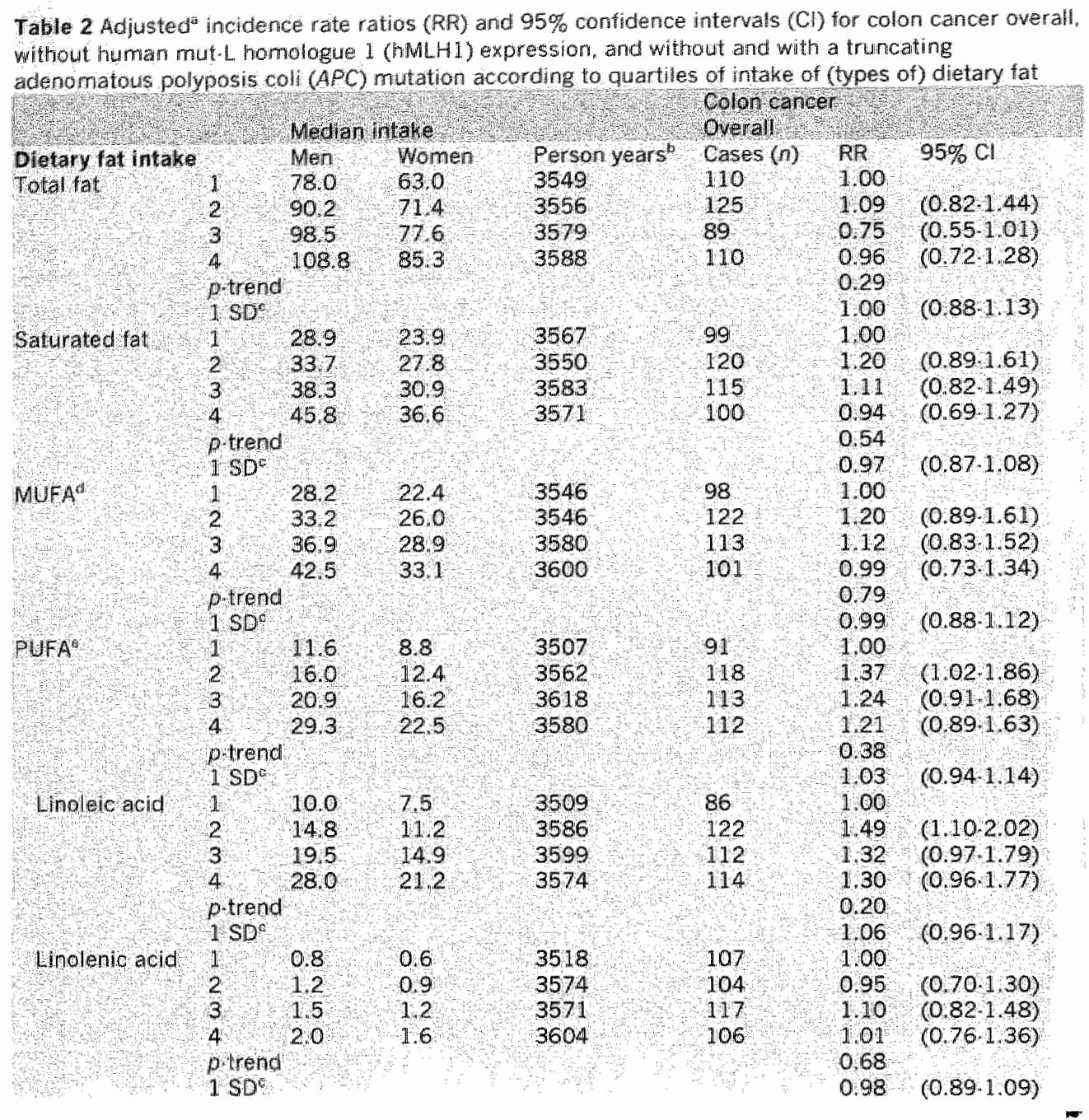

hMLHI expression were significantly less often men than patients with expression of the gene 141 versus $56 \%$ ). There were no striking differences in dietary fat intake between patients and subcohort members or between patients with and without hMLHI expression or APC mutations in their fumours. Only patients with rectal cancer that had a truncating APC mutation appeared to have a higher intake of saturated fat than rectal cancer patients without a truncating APC mutation $|p=0.05|$. For the other food intake variables, only fruit intake appeared to be lower among the colon cancer patients without hMLHI expression in their tumour as compared to those whose tumours presented expression of the gene $(p=0.07)$. Total energy intake appeared to be lower 
Table 2. Continued

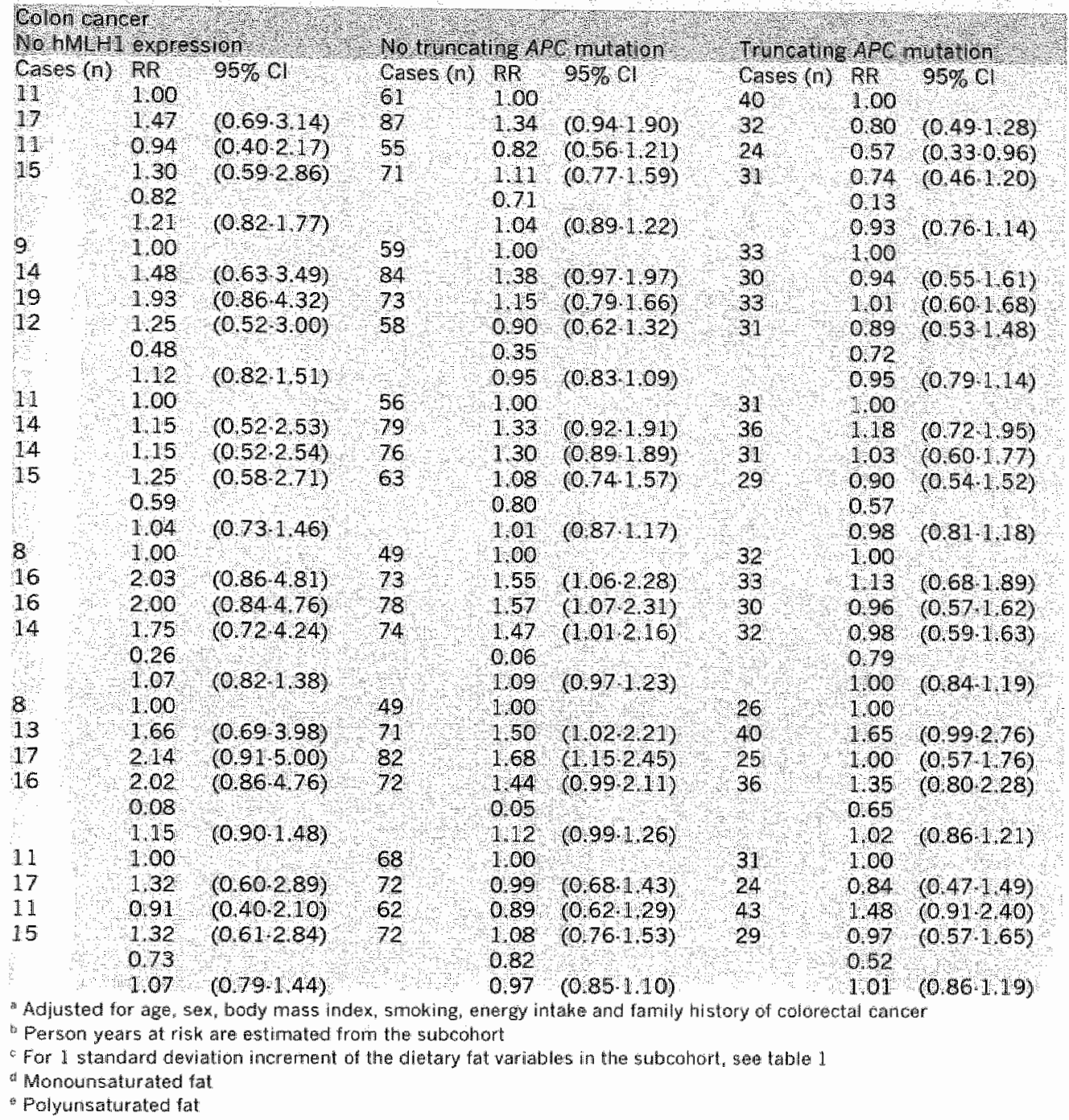

among colon cancer patients without hMLHI expression in their tumours $(p=0.07)$ in comparison with patients with colon cancer expressing the gene, and colon cancer patients with a truncating APC mutation appeared to have a higher intake of energy than patients without such a mutation $(p=0.09)$. Body mass index, a family history of colorectal cancer, smoking and physical activity did not differ significantly between subgroups of patients or between patients and subcohort members.

Neither total fat nor the different types of fat appeared to be associated with overall colon cancer risk in this population (table 2). For different subgroups of colon cancer based on absence of hMLH1 expression or absence or presence 
Table 3 Adjusted incidence rate ratios (RBy and $95 \%$ confidence intervals (Cl) for rectal cancer overall, and without and whith a truncating adenomatous polyposis coli (APC) mulation according to quarthes of intake of (ypes of) dietary lat

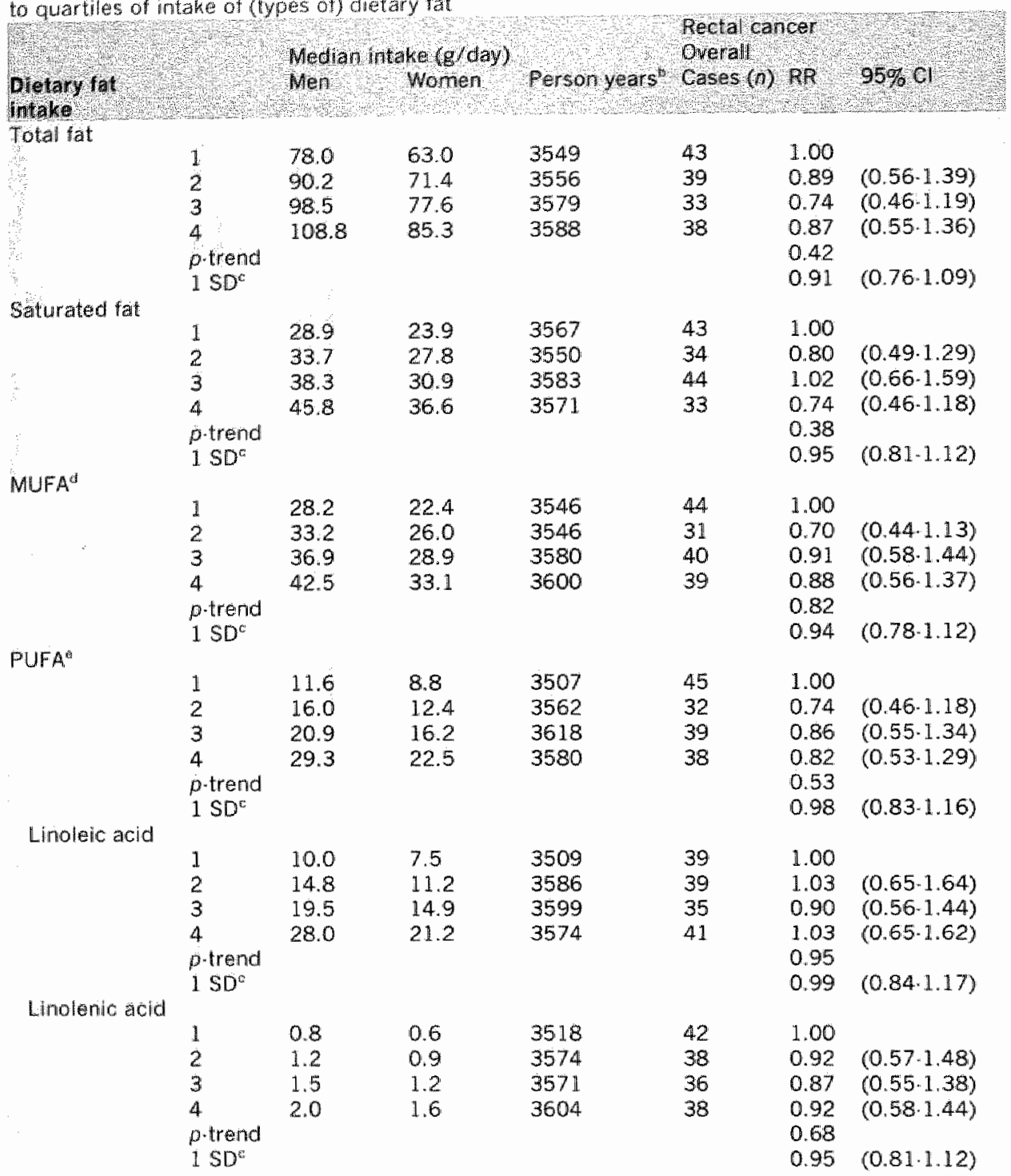

of truncating APC mutations in their tumours, total fat intake and most of the specific types of fat intake variables were also not associated with increased or decreased risk. However, polyunsaturated fat intake, and especially linoleic acid intake, appeared to be associated with an increased risk of colon tumours without hMLHl expression and with colon tumours without truncating APC mutations, but not with colon tumours that harboured a truncating APC 
Table 3. Continued

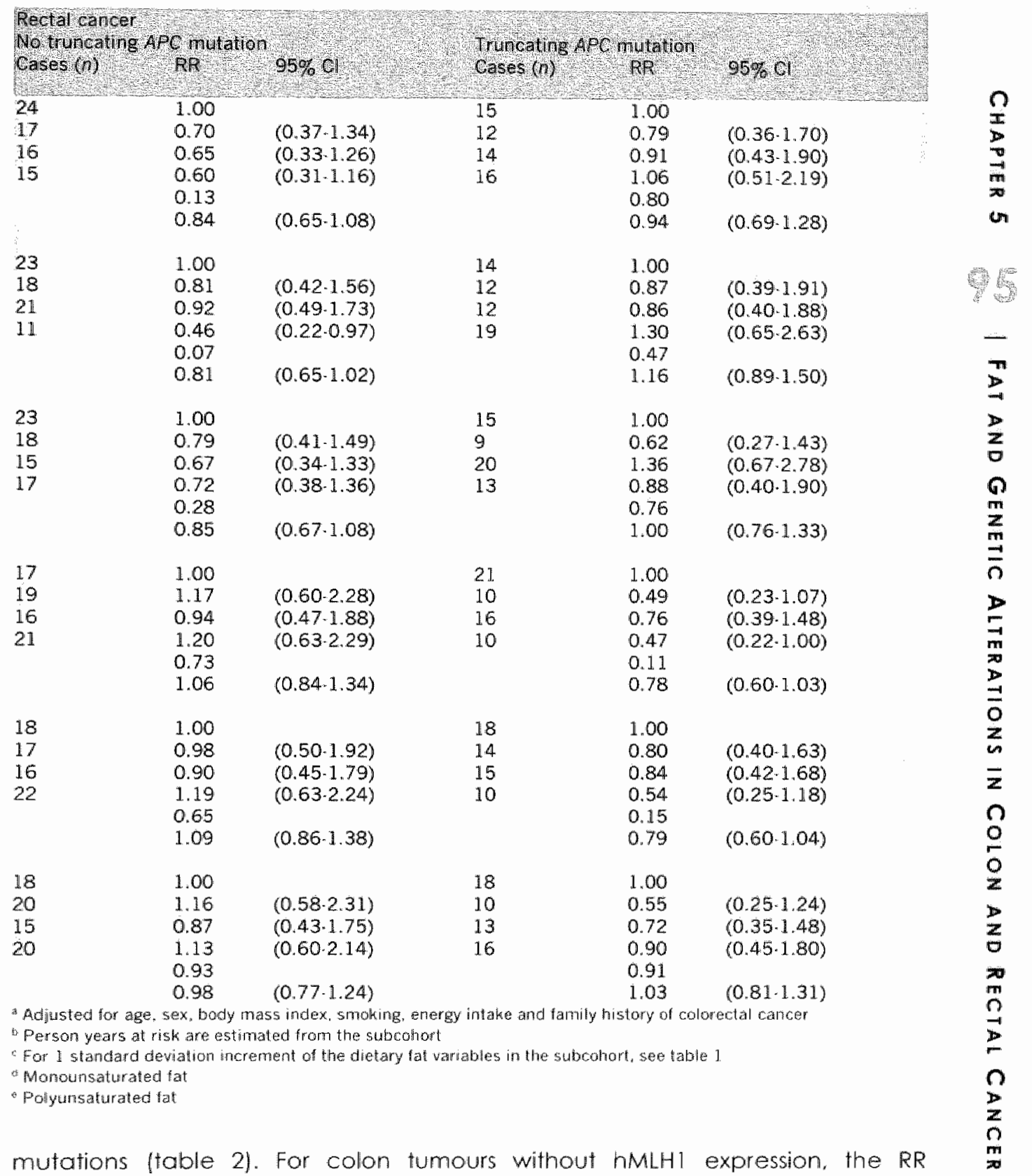
according to the quartiles of linoleic acid intake were increased for all the categories of intake above the reference (lowest quartile of intake); 1.66 . $95 \%$ $\mathrm{Cl} 0.69-3.98), 2.14(95 \% \mathrm{Cl} 0.91-5.00)$ and $2.02(95 \% \mathrm{Cl} 0.86-4.76)$ for the second through the fourth quartiles, respectively. Although none of the RRs reached stiatistical significance, the test for linear trend was borderline significant 
$(p=0,08)$. A similar trend was observed for the risk of colon tumours without truncating APC mutations. The RR over the quartiles of linoleic acid intake were $1.50(95 \% \mathrm{Cl} 1.02-2.21) .1 .68(95 \% \mathrm{Cl} 1.15-2.45)$ and $1.44(95 \% \mathrm{Cl} \quad 0.99-2.11)$ respectively and the $p$-value for trend was 0.05 (table 2). Additional analyses for subgroups of colon fumours with specific truncating point mutations in APC did not show any associations with the intake of fat or different types of fat (data not shown).

For overall rectall cancer, associations with the intake of total fat or different types of fat were not observed (table 3). Moreover, after taking into account truncating $A P C$ mutations in rectal tumours, none of the fat intake variables were significantly associated with risk of rectal cancer. Only the intake of saturated fat appeared to be inversely associated with rectal tumours without $A P C$ truncating mutations. The RR for the highest versus the lowest quartile of intake was 0.46 (95\% Cl $0.22-0.97$ ) and the p-value for trend was 0.07 (table 3). For rectal fumours with specific types of truncating APC mutations no associations were abserved with any of the fat intake variables (data not shown).

Additional analyses were conducted to assess whether the observed associations of polyunsaturated fat intake, and especially linoleic acid intake. with the increased risk af colon tumours lacking hMLHI expression and with colon tumours without truncating APC mutations, were observed because of an underlying association with colon tumours harbouring a K-ras mutation, as previously observed. ${ }^{24}$ Intake of polyunsaturated fat or linoleic acid was not associated with the risk of colon cancer without truncating APC mutations

Table 4 . Adjusted incidence rate ratios (RR) and 95\% confidence intervals (Cl) for colan cancer without any of the gene defects or with only a single gene defect, i.e. either lack of hMLHI expression, a truncating $A P C$ gene mutation or an activating $K$ ras gene mutation, according to quartiles of intake of polyumsaturated fat (PUFA) and linoleic acid intake

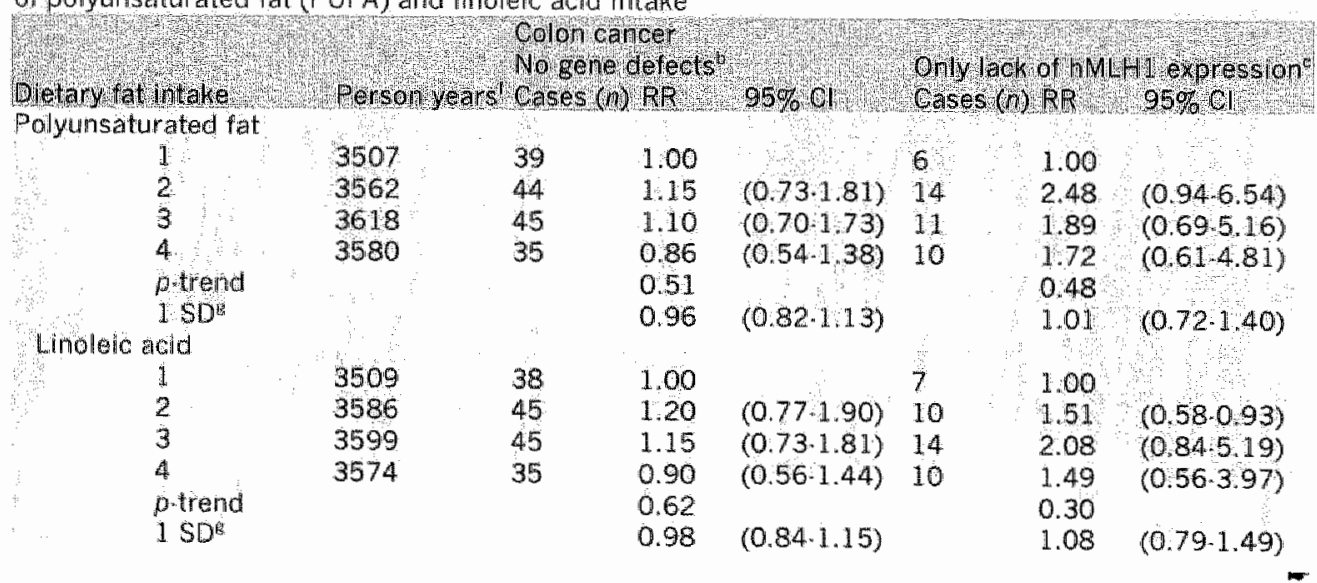


when cases who also had activating K-ras mutations or lack of hMLHI expression in their tumour were excluded from the analyses (data not shown). Also. no associations were observed with risk of colon cancer without any of the gene defects, or with only lack of $\mathrm{hMLH}$ lexpression, or with only truncating $\mathrm{APC}$ mutations (table 4). With increasing intake of polyunsaturated fat and of linoleic acid, a strong increased risk of colon cancer with only activating Kras mutations was observed (table 4) (p-trend<0.001 for both polyunsaturated fat and linoleic acid intake). The RRs for one standard deviation increase in intake were $1.40(95 \% \mathrm{Cl} 1.17-1.68)$ and 1.41 (95\% $\mathrm{Cl} 1.18-1.69)$, respectively.

Likewise, additional analyses were conducted for saturated fat intake in relation to the decreased risk of rectal cancer without truncating APC mutations, also excluding individuals with a K-ras mutation and lack of hMLHI expression. The association did not change substantially. Again, only the highest level of intake showed a significant reduced risk of cancer compared to the reference category (RR 0.40 95\% Cl 0.14-1.15, p-trend=0.09).

\section{DISCUSSION}

In this large prospective study, we observed that the intake of total, saturated and monounsaturated fat was not associated with the risk of colon cancer. rectal cancer, or the different molecular subgroups of cancer based on lack of $\mathrm{hMLH} 1$ expression or truncating mutations in the APC gene. For polyunsaturated fat intake and risk of rectal cancer no assaciation was observed. However, a

Table 4. Continued

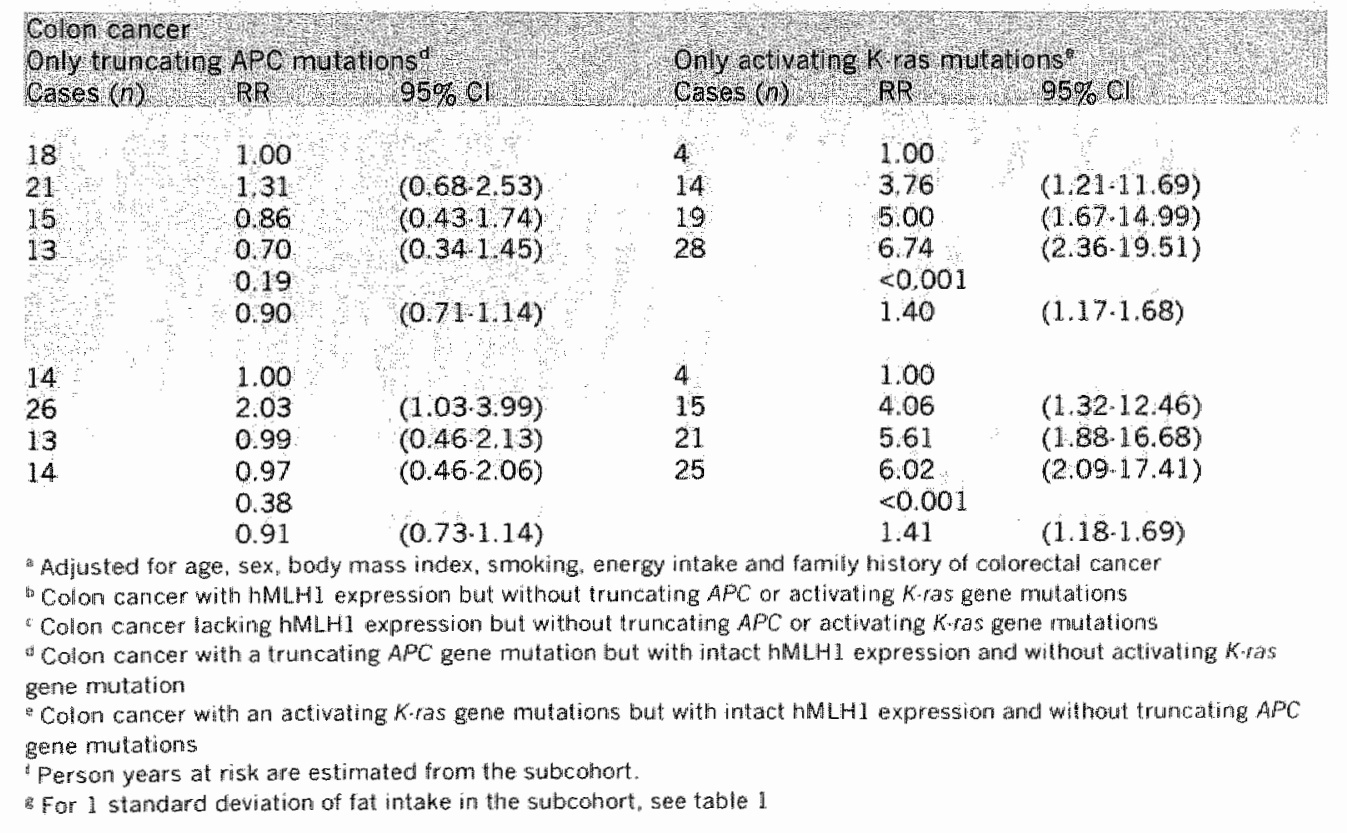


high intake of linoleic acid seemed associated with an increased risk of colon fumours lacking hMLHl expression and an increased risk of colon fumours lacking truncating APC mutations. Since tumours may harbour multiple mutations, we investigated whether these associations reflected an underlying association of linoleic acid intake with K-ras mutations in the fumours. Indeed. the assaciations disappeared when patients with tumours also harbouring $K$-ras mutations, or truncating APC mutations or lacking $\mathrm{hMLH1}$ expression respectively, were excluded from the analyses. Linoleic acid showed a strikingly strong association with increased risk of those colon fumours with only an activating K-ras mutation and no additional truncating APC mutation or lack of hMLHI expression.

As reviewed in the introduction, none of the other epidemialogical studies report on specific fatty acids and the risk of molecular surrogate endpoints for colon or rectal cancer. ${ }^{4723.25}$ Only two other studies report on various types of fat depending on saturation level, but the results are inconsistent across the studies 19.21 .25 including our study. ${ }^{24}$

Diergaarde et al.19 found unsaturated fat intake to be associated with increased colon carcinomas with a truncating APC mutation. No distinction was made between mono- and polyunsaturated fats. In our study, we did not observe any association between various types of fat intake and risk of colon or rectal cancer with or without truncating APC mutations after patients also harbouring a K-ras mutation in their tumour were excluded from the analyses. We observed a possible inverse assaciation between saturated fat intake and risk of rectal tumours without a truncating APC mutation. However, the association was weak, did not increase gradually according to the quartiles of intake and was only a result of the reduced risk in the highest category of intake. Furthermore, in absence of a biological explanation for this finding and considering the large number of associations investigated, the observation may best be attributed to chance.

Slattery et al. ${ }^{25}$ found saturated and monounsaturated fats, but not polyunsaturated fat, to be associated with increased risk of colon tumours with specific $K$-ras mutations, i.e. a $G \rightarrow T$ transversion at codon 12 . No distinction was made between n- 6 and $n-3$ fatty acids. We observed an association befween polyunsaturated fat intake, especially linoleic acid, and increased risk of colon tumours with a K-ras mutation, regardless of the type of mutations. ${ }^{24}$

Finally, Bautista ef al. ${ }^{21}$ observed an inverse association between monounsaturated fats, mostly derived from olive oil in the Spanish diet, and risk of colon cancer without K-ras mutations. Since olive oil was rarely consumed by this elderly Dutch population in the years preceding 1986 (the cohort baseline), this could explain the lack of association for this type of fat in our study.

Several factors hamper comparisons between our findings and those of other epidemiological studies and may in part explain observed inconsistencies in findings across studies. First, as discussed above, other studies did not report specifically on fatty acids and most of these did not include specific types of fat. Second. our study is the first large prospective cohort study incorporating molecular end-points for colon and rectal cancer. One of the other studies was a cross-sectionall case-case comparison study, ${ }^{22}$ and the other studies were 
case-control studies of varying size. with the Spanish and the two Dutch casecontrol studies on carcinomas and adenomas being failly small (with 108, 184, 278 cases, respectively) $17,19-21,23$ and the US case-control study being of large size (with 1,510 or 1,428 cases for analyses with hMLHI and K-ras respectively). ${ }^{18 .}$ 25 Third, apart from the different aberrations studied, various endpoints were considered. Two of the other studies focussed on adenomas instead of carcinomas, ${ }^{20,22}$ and only two studies also incorporated rectal tumours but did not distinguish between the colon and the rectum. $20.2 \mathrm{l}$

We have previously reported the association between linoleic acid intake and increased risk of collon tumours with K-ras mutations. ${ }^{24}$ We now report that the association appears to be confined to those colon tumours with activating K-ras mutations and an otherwise intact APC gene and with hMLHI expression. In addition, the association is strikingly strong, with RRs clearly increasing over the quartiles of linoleic acid intake. The activating K-ras mutations at codons 12 and 13 are predominantly $G \rightarrow T$ and $G \rightarrow A$ mutations ${ }^{33}$ which could be a result of MDA-DNA adduct formation.27. 28 MDA-DNA adduct formation is associated with increased $n-6$ polyunsaturated fat intake $2 \%$, of which linoleic acid is the most abundant source. Therefore, even though chance cannot be ruled out and verification by others is warranted, the observation seems plausible.

Yet, there are still several issues that remain puzzling. First, why is the observed association for linoleic acid confined to colon cancer and not rectum cancer with only a $K$-ras mutation? The multistep model for molecular aberrations underlying colorectal carcinogenesis is likely to apply equally for both tumour subsites. ${ }^{7}$. 8. 15 However, lack of hMLHl expression in our study is rare among rectum cancer patients and there is growing evidence for differences in the aetiology of colon and rectal tumours. ${ }^{39}$

Second, why is the association with linoleic acid observed for $K$-ras and not for truncating APC gene mutations? It is unlikely that adduct formation selectively accurs in one gene but not in the other. However, K-ras is an oncogene requiring only one mutation for the gene to be activated, whereas $A P C$ is a tumour suppressor gene that requires an additional aberration in the second allele for loss of function to occur. This may be reflected in more than half of the patients with an $A . P C$ mutation having multiple mutations in the mutation cluster region of the APC gene, ${ }^{32}$ which complicates the analyses.

This still does not satisfy our third query, i.e., why are the associations specifically confined to this subgroup of colon cancer patients whose tumours are characterized by activating $K$-ras mutations but not truncating APC mutations or lack of hMLHI expression? It is highly speculative but plausible that the mutated $K$-ras gene had an important role in tumour formation or development in this specific group of patients, since in those cases, it apparently was the only important colorectal cancer gene to be mulated. Therefore, associations with mutagens could especially be expected with $K$-ras in this situation. On the other hand, in patients whose tumours also contained mutations in other key genes, the mutation in the K-ras gene may be a result of the mutator phenotype of the tumour rather than exposure to exagenous mutagens, and the mutation in the $K$-ras gene may not have been crucial to tumour formation. Therefore, Breivik and Gaudernack's hypothesis for distinct carcinogens to exert their effectt on 
two proposed types of genetic instability, i.e. microsatelite instability and chromosomal instability, may need to be extended to the potential effect of carcinogens on more specific genetic pathways to colorectall tumourigenesis. as for example the K-ras mutated pathway.

In conclusion, the data from this large prospective cohort study suggest that linoleic acid intake is strongly associated with colon fumours with an aberrant $K$ ras geme, but an intact APC gene and hMLHI expression. Verification in other studies is warranted. Possibly, tumours revealing the involvement of distinct genetic pathways on the basis of specific genefic aberrations, may have a unique aetiology. 


\section{REFERENCES}

1. Woutersen RA, Appel MJ wan Garderenthetmer A, Winands MW. Dietom fot and carcinagemesis. Mutat Res $1999: 443[11 \cdot 2): 111-27$.

2. Potter JD. Nutrition and colorectal concer. Cancer Causes Contro 1996:711):127-46.

3. Willet WC. Diet and cancer. Oncologist 2000;5 (5):393-404.

4. Lin J. Zhang SM, Cook NR, Lee IM, Buning JE. Diefary fat and hatry acials and risk of calorectal cancer in women. Am J Epidemiol 2004: 160110$): 1011-22$.

5. Sanderson P. Johnson IT. Mathers JC. Powers HJ, Downes CS. MaGlynn AF, Dare R. Kampman E. Pool-zobel BL. Bingham SA, Rafter Jl, Emerging diei-related sumagate end points for colorecto cancer: UK Food Standards Agency diet and colonk health workshop report. Br $\mathrm{j}$ Nulr 2004:9)(2):315-23.

6. Wogeistein B. Fearon ER, Hamilton SR, Kern SE. Preisinger AC. Leppert M, Nakamura W White R. Smits AM, Bos JL. Genetic alterations during colorectal-tumor development. N Engl J Med $1988 ; 31919): 525-32$

7. Gryfe R, Swallow C, Bapat B, Redston M. Gallinger S, Coulure J. Mollecular biology of colorectal cancer. Curt Probl Cancer 1997:21/5):233-300

8. Fodde R, smits R. Clevers H. APC, signaltransductian and genetic instabilty in colorectal cancer. Not Rev Cancer 2001:1:11]:55-67.

9. Breiwik J. Gavdernack G. Genamic instability. DNA methylation. and natural selection in colorectal carcinogenesis. Semin Cancer Biol 1999;9(4):245-54.

10. Lengaver $G$. Kinzler $K W$, Vagelstein B. Genetic instability in colorectal cancers. Nature $1997: 386,6625]: 623-7$.

11. Kuismanen SA, Holmberg MT. Salovaara R. de la Chapelle A. Peitomaki P. Genetic anc epigenetic modification of MLH] accounts for a major share of microsateilite-unstable colorectal cancers. Am J Pathol 2000; 156151:1773-9.

12. Breivik J. Gaudemack $G$. Carcinogenesis and naturall selection: a new perspective to the genetics and eploenetics af colorectal cancer. Adv Cancer Res 1999;76:187.212

13. Shth $M$, thou W. Goodiman SN, Lengaver C, Kinzler KW, Vogelsiein B. Evidence that genelic instability occurs at an early stage of colorectal tumorigenesis. Cancer Res 2001:61131:818 22.

14. Smith G. Carey FA. Beattie J, Whikie MJ. Lightfoot IJ Caxhead J. Gamer RC. Steele RJ. Woll CR. Mutations in APC, Kirsten ras, and p53-alternative genetic pathways to colorectal cancer. Proc Natl Acad SCi U S A 2002:991141:9433-8

15. Fearon ER. Vogeistein B. A genetic model for colorectall tumorigenesis. Cell 1990;61: 51:759-67.

16. Wu AH, Shibata D, YU MC. LaI MY, Ross RK. Dietary heterocyclic amines and microsatelite instability in colon adenocarcinomas. Carcinogenesis 200 : 22/101: $681-4$.

17. Diergaarde B. Braam H, wan Mujien GW, Ligtenberg MJ. Kak FJ. Kampman E. Dietary factors and microsatellite instability in sporadic colon carcinomas. Cancer Epidemiol Biomarkers Prev $2003: 12(11 \mathrm{Pt} 1): 1130-6$

18. Slattery ML. Anderson $K$. Cuntin $K$. Ma KN. Schatfer D. Samowitz W. Digtary intake and microsatellite instabilly in colon tumors. Int 1 Cancer 2001:93/4):50i-7.

19. Diergaarde B, wan Geloof WL, van Mulien GN, Kok Fs, Kamoman E. Dielary factlons and the occurrence of truncating APC mutations in spotadic colon carcinomas" a Dutch population based study. Carchogenesis $2003: 24(2): 283-90$.

20. Diergaarde B. Tiemersma EW. Bram H, Van Muijen GN. Wagengast FM, Kok FJ, Kampman E. Dietary factors and trunceling APC mutations in sparadic colorectal adenomas. Int J Cancer 2004.

21i. Batista D. Obrador A, Moreno V. Cabeza E, Canel R. Benito E, Bosch X, Costa J. Ki-ras mutation madities the protective effect of dietary monounsaturated fat and calcum on sporadic colorectal cancer. Cancer Epidemiol Blomarkers Prev $1997: 6(1): 57-61$.

22. Martinez ME, Malzman T, Marshall JR, Einspah J, Reid ME, Sampliner R, Ahnen DJ, Hamillon SR A.berts DS. Risk tactors for Kitras protoancogene mutiation in sporadic colorectal adenomas. Concer Res 1999:591201:51811-5.

23. Kampman E. Voskuil DW, wan kraats AA. Balder HF, van Mijen GW, Goldbohm RA, wan' Weer P. Aninal products and K-ras codon 12 and 13 mulations in colon carcinomas. Carcimogenesis 2000:2 $121: 307-9$.

24. Brink M. Wejenberg MP. De Goeij AF, Schouten L, Koedijk FD Roemen GM. Lentjes MH. De Bruine A. Goldbohm RA, Van Den Brandt PA. Fat and K-ras mutations in sporadic colorectal cancer hn The Netherlands Cohort Study. Corcinogenesis 2004.2519]: $1619-28$. 
25. Sultery ML, Curtin K, Anderson K, Ma KN, Edwards S. Leppert M, Potter S, Schaffer D. Samowitz Wis. Associotions between dielary intake and Ki-ras mutations in calon tumors: a population-based study, Cancer Res 2000;60(24):6935-41.

26. Bardelli $A_{x}$ Cohill DP, Lederer $G$. Speicher MR, Kinzler KW, Vogelstein B, Lengaver $C$. Carcinogenspecific induction of genetic instabilify. Proc Natl Acad Sci U S A 200198|10):5770-5.

27. Marneth LJ. OXy radicals, hipid peroxidation and DNA damage. Toxicology 2002:181-182:219-22.

28. Miedernhofer LJ. Daniels JS, Rovzer CA. Greene RE. Manett LJ. Malondialdehyde, a product of Ipid peroxidation, is mutagenic in human cells. J Biol Chem $2003 ; 278(33) ; 31,426-33$

29. Leuratti $C$. Watson MA, Deag EJ, Welch $A$, Singh $R$, Gottschalg $E$, Mamett LJ. Atkin W, Dar NE, Shuker DE. Binghom SA. Detection of malondialdehyde DNA adducts in human colorectal mucosa: relationship with diet and the presence of adenomas. Cancer Epidemiol Biomarkers Prev 2002;1 113):267-73.

30. wan den Brandi PA, Goldbohm RA, van "f Veer P. Volovics A, Hermus RJ, Sturmans F. A large-scale prospective cohort study on diet and cancer in The Netherlands. 1 Clin Epidemial 1990:43(3):285. 95.

31. Wan den Brandf PA, Schouten L., Goldbohm RA, Doront E. Hunen PM. Development of a record linkage protocol for use in the Dutch Cancer Registry for Epidemiological Research. Int J Epidemiol 1990:19(3):553-8.

32. Luchtenborg M. Weijenberg MP, Roemen GM, de Bruine AP, van den Brandt PA, Lentjes MH, Brink $M$. van Engeland M, Goldbohm RA, de Goeil AF. APC mutations in sporadic colorectal carcinomas from the Netherlands Cohort Study. Corcinogenesis 2004:2517):1219-26.

33. Brink M, de Goeil AF, Weijenberg MP, Roemen GM, Lentjes MH, Pachen MM, Smits KM, de Bruine AP, Goldbohm RA, wan den Brandt PA. K-ras oncogene mutations in sporadic colorectal cancer in The Netherlands Cohort Study. Carcinogenesis 2003:24[4]:703-10.

34. Newo table. Dutch food composition table 1986-1987. 1986.

35. Goldbohrm RA, van den Brandi PA, Brants HA, van't veer $P$, Al M, sturmans $F$. Hermus RJ. Validation of a dietary questionnaire used in a large-scale prospective cohort study on diet and cancer. Eur J Clin Nutir $1994: 48(4): 253-65$.

36. vam Poppel G. Intake of trans fatty acids in western Europe: the TRANSFAIR study. Lancet 1998:35119109):1099.

37. Willett W. Nutitional Epidemiology, vol. 30. New York: Oxford University Press, 1998.

38. Lin DY. Weil W. The robust inference for the Cox Proportional Hazards Model. JASA $1989: 84(408): 1074-78$.

39. Wei EK, Giowannuci E. WU K, Rosner B. Fuchs CS. Willett WC. Colditz GA. Comparison of risk factors for colon and rectal cancer. Int J Cancer 2004;108(3):433-42.

40. Schoenfeld D. Partial residuals for the proportional hazards regression models. Biometrika $1982: 69(1): 239-41$. 


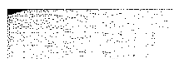

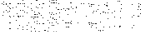

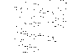


$\begin{array}{lllllll}C & H & A & P & T & E & R\end{array}$ 6 


\section{CIGARETTE SMOKING AND COLORECTAL CANCER: APC MUTATIONS, HMLH 1 EXPRESSION AND GSTM 1 AND GSTT 1 POLYMORPHISMS}

MARGREET LÜCHTENBORG MATTY P WEIJENBERG ELLEN KAMPMAN GOOS N VAN MUIJEN GUIDO MJM ROEMEN MAURICE PA ZEEGERS R ALEXANIDRA GOLDBOHM 


\section{A B STRACT}

The contribution of cigarefte smoking to sporadic colorectal cancer may differ according to molecular aspect of the fumour or according to glutathione Stransferase M1 (GSTM 1) or glutathione S-transferase TI (GSTI) genotype.

In the prospective Netherlands Cohort Study on dief and cancer, adjusted incidence rate ratios for 1986-1993 were computed for overall colorectal cancer, tumours with and without adenomatous polyposis coli (APC) mutations, and fumours with and without human mut-L homologue 1 (hMLHI) expression. according to cigarette smaking characteristics $(66)$ cases, 2,948 subcohort members). Case-only analyses were performed to estimate odds ratios for interaction between cigarette smoking and GSTMI and GSTII genotypes.

In comparison with never smokers, a high smoking frequency increased the risk of colorectal cancer (for a five cigarefte/day increment, incidence rate ratio (RR) 1.07, 95\% confidence interval (Cl) 1.03-1.12), and this association was stronger in 371 tumours without a truncating APC mutation (RR 1.11.95\% Cl 1.051.17). Long-term smoking was associated with lack of hMLHI expression in 56 tumours (for a 10 year increment, RR $1.17 .95 \% \mathrm{Cl} 1.00-1.37$ ). No statistically significant interactions between smoking and GSTMI or GSTI genotype were observed.

These results indicate that cigarette smoking is associated with risk of colorectal cancer, and this association may depend on molecular characteristics of the tumour as defined by APC mutation and hMLHI expression status. 


\section{INTRODUCTION}

Long-term smoking is a potential risk factor for developing colorectal cancer.' 2 Long-term, heavy smoking has consistently been found to be associated with colorectal adenomas, 3 whereas associations with colorectal carcinomas have been inconsistent. ${ }^{3}$ The observed association between cigarette smoking and both small and large adenomas led to the current assumption that tobacco smoking is involved in early tumourigenesis.

If cigarette smoking is an early event in tumourigenesis, long-term follow-up would show a positive association between smoking and colorectal cancer when the extensive lag time (over 30 years) for the whole carcinogenic process to take place, is taken into account. ${ }^{3}$ Indeed, Giovannucci et al. 4.5 found a two-fold increase in risk of colorectal cancer after 35 years of smoking. This was supported by a report from another long-term US cohort, ${ }^{\circ}$ but not by other reports. 7.9

Most sporadic colorectal cancers are thought to arise through underlying genetic pathways, which involve aberrations in a number of genes, as described by Fearon and Vogelstein.10 Inactivation of the adenomatous polyposis coli (APC) tumour suppressor gene is thought to be a key event early in colorectal tumourigenesis. This is underscored by the finding of somatic mutations in the mutation cluster region of APC leading to a truncated and therefore inactive APC protein in the majority of sporadic colorectal adenomas and carcinomas."13 We previously reported on the occurrence of a large number of mutations in the mutation cluster region of the APC gene, however, in just $37 \%$ of patients these would lead to a truncated APC protein. ${ }^{14}$ since smoking is thought to be involved in the early stages of colorectal tumourigenesis, smoking may be associated with mutations in the APC gene. This is supported by results from rodent studies in which benzo(a)pyrene was found to induce $G \rightarrow T$ transversions and $N$-nitrosamines to induce $G: C \rightarrow A: T$ transitions in ras oncogenes, ${ }^{15}$ both of which are important constituents of cigarette smoke.

Colorectal cancer can be divided broadly into two subgroups based on genomic instability. Whereas the majority of sporadic colorectal tumours is chromosomally instable, a smaller subset ( -10 to $15 \%$ of tumours) exhibits loss of mismatch repair manifested by microsatellite instability. In approximately $90 \%$ of microsatelite instable tumours, absence of human mut- $L$ homologue 1 (hMLH1) expression was observed. ${ }^{16}$ Studies have shown that microsatellite instability and mutations in APC, TP53 and K-ras genes occur almost mutually exclusively, ${ }^{17-19}$ which suggests that these aberrations represent separate pathways. The risk of smoking may be associated with the specific subset of colorecial tumours displaying microsatellite instability. Cigarette smoking was found to be associated with microsatelilite instable colorectal tumours in three case-control studies, ${ }^{20-22}$ whereas another case-control study could not confirm this.23

Persons with a homozygous deletion of the glutathione S-transferase GSTMI or GSTI genes, have no enzyme expression and may therefore be at an increased risk of developing colorectal cancer when exposed to carcinagens from cigarette smoke. However, previous reports on the interaction between 
tobacco smoking and GSTMI and/or GSTI have not shown a relation between smoking and genotype. ${ }^{24-28}$ in the absence of data on GSTMI and GSTI genotypes in controls, a case-only design provides an efficient means of estimating possible interactions with a greater precision than can be obtained from case-control studies. ${ }^{29}$

Our aim of this analysis was to investigate associations between cigarette smoking and overall colorectal cancer in a prospective cohort study. In addition, we studied associations between smoking and (specific) mutations in the APC gene and absence of hMLHI expression, which are thought to represent distinct mechanisms involved in colorectal carcinogenesis. We evaluated possible interactions between cigarette smoking and the GSTMI and GSTl genotypes in a nested case-only design.

\section{MATERIALS AND METHODS}

\section{STUDY POPULATION}

The prospective Netherlands Cohort Study on diet and cancer (NLCS) was initiated in September 1986. The study design has been described in detail elsewhere. ${ }^{30}$ At baseline, a total of 58,279 men and 62.573 women between the ages of 55 and 69 years completed a self-administered food frequency and lifestyle questionnaire. The study population was derived from 204 municipal population registries throughout the Netherlands.

Incident cancer cases are identified by monitoring of the entire cohort for cancer accurrence through annual record linkage to the Netherlands Cancer Registry (nine regional cancer registries throughout the Netherlands) and to Pathologisch Anatomisch Landelijk Geautomatiseerd Archief IPALGA, a nationwide network and registry of histo- and cytopathology!. ${ }^{31}$ Together the NCR and PALGA provide nearly $100 \%$ coverage of the municipalities included in the NLCS.

Accumulation of person-time in the cohort was estimated through biennial vital status follow-up of a subcohort of 3,500 men and women who were randomlly selected after baseline exposure measurement. ${ }^{31}$ Cases with prevalent cancer other than non-melanoma skin cancer were excluded from the subcohort. resulting in a subcohort of 3,346 men and women. No subcohort members were lost to follow-up.

The first 2.3 years of follow up were excluded because of incomplete nationwide coverage of PALGA in some of the municipalities included in the NLCS in that period. Within this period, 83 subcohort members deceased or were diagnosed with cancer other than non-melanoma skin cancer, leaving 3.263 subcohort members for analysis. From 1989 untill 1994, 929 incident cases with histologically confirmed colorectal cancer were identified within the cohort, of which 819 could also be linked to a PALGA report of the lesion ffigure 1). The PALGA reports were used to identify and locate tumour tissue from eligible calorectal cancer patients in Dutch pathology laboratories. 


\section{TISSUE SAMPLES AND DNA ISOLATION}

Tumour material from colorectal cancer patients was collected after approval by the Ethical Review Board of Universiteit Maastricht, PALGA, and the NCR. Tissue samples from 819 colorectal cancer patients were localised in 54 pathology laboratories throughout The Netherlands. Forty-four [5\%] tumour tissue samples could not be retrieved. Of 775 available tissue samples. 737 (95\%) contained sufficient tumour material for molecular analyses (figure 1). DNA isolation was described in detail elsewhere. ${ }^{32}$ Genomic DNA was extracted from macrodissected tumour tissue using proteinase $K$. DNA concentration and purity were measured in a spectrophotometer at $260 \mathrm{~nm}$ and $280 \mathrm{~nm}$.

\section{APC MUTATION ANALYSIS}

The majority of somatic mutations in APC occur in the mutation cluster region [codons 1,286-1,520). Analysis of specific mutations in the mutation cluster region was performed on archival adenocarcinoma DNA by amplification of the mutation cluster region in four overlapping DNA fragments in a nested polymerase chain reaction (PCR) followed by direct sequencing of purified fragments as previously described. ${ }^{14}$ The detection limit was $5 \%$ mutalted DNA and duplicate experiments revealed good reproducibility (85\%).14 From 72 of the 737 patients with a sufficient DNA yield, one or more fragments of the mutation cluster region could not be amplified and these patients were excluded from this study, leaving 665 patients (90\%) available for subsequent analyses (figure 1).

\section{HMLHI IMMUNOHISTOCHEMISTRY}

Formalin-fixed, paraffin-embedded tissues were sectioned at $4 \mu \mathrm{m}$ and included tumour tissue with normal adjacent mucosa. Endogeneous peraxidase activity was blocked with $3 \%$ hydrogen peroxide. Slides were submitted to microwave antigen retrieval in IMM EDTA buffer $(\mathrm{pH} 8.0)$ and incubated with $10 \%$ normal horse serum for ten min at room temperature. Sections were then incubated overnight at $4^{\circ} \mathrm{C}$ with mouse monoclonal antibodies against $\mathrm{hMLH} 1$ protein (clone G168-15. PharMingen, San Diego, CA) at a 1:100 dilution. Antibody binding was detected by incubating the sections at room temperature with the peroxidase-labelled DAKO Enwision System IDAKO. Carpinteris, CA and using diaminobenzidine as a chromogen. Sections were counterstained with haematoxylin.

Lesions were considered to lack $\mathrm{hMLH} 1$ protein expression when unequivacal absence of nuclear staining of the tumour epithelial cells was observed. Nuclear staining of normal epithelial and stromal cells or lymphocytes served as internal positive control. Staining profiles were scored independently by at least two observers and. in case of discordant results discussed with a pathologist until consensus was reached. hMLHI expression could be determined in 724 of 737 patients, for whom tumour DNA was available.

\section{GSTM 1 AND GSTT1 POLYMORPHISMS ANALYSES}

A semi-nested multiplex PCR was performed for simultaneous assessment of the presence or absence of GSTMI and GSTTI alleles. Flank PCR was performed to generate PCR products for GSTMI and GSTI alleles and $\beta$-globin Using DNA derived from formalin-fixed paraffin-embedded tumour tissue. In a 1:100 dilution, the flank PCR product served as a template for a second round of PCR. 
In each PCR one round of 35 cycles was performed. In each PCR series positive (B-globin amplification) and negative (no DNA) controls were included. The absence or presence and length of PCR products of GSTMI and GSTI alleles were checked by electrophoresis on $2 \%$ agarose gels and visualised with ethidium bromide. Reproducibility was shown to be $91 \%(42 / 46)$. Genotypes of GSTM1 or GST71 could not be determined in 79 patients from whom tumour DNA was available and these patients were excluded from this study.

\section{EXPOSURE ASSESSMENT}

In the questionnaire, tobacco smoking was addressed through questions on age at first and last exposure to smoking, smoking frequency, smoking duration and inhalation for cigarette, cigar and pipe smokers. The dietary section of the 150-item semi-quantitative food frequency questionnaire, concentrated on habitual intake of food and beverages as well as lifestyle factors during the year preceding the start of the study.

Questionnaire dato were key-entered twice and processed for all incident cases in the cohort and for all subcohort members in a manner blinded with respect to case/subcohort slatus. Subjects, whose dietary data were incomplete or inconsistent ( 49 cases, two of whom were also subcohort members and 216 subcohort members), were excluded from the analyses. Criteria used for this selection were 60 or more questionnaire items left blank or 35 items that were eaten less than once per month and/or one or more item blacks (groups of items, e.g. beverages) left blank. Eventually, 685 colorectal cancer patients (348 men, 268 women) of whom 12 were also subcohort members, and 3,048 subcohort members (1,525 men, 1.598 women) were included in the analyses (figure 1).

\section{STATISTICAL ANALYSIS}

The data analyses were conducted separately for overall colorectal cancer, colorectal cancer with and without a truncating APC mutation, fumours with a specific $C: G \rightarrow T: A$ or $G: C \rightarrow T: A$ point mutation resulting in a stop codon, and colorectal cancer with and without hMLHI expression.

Using the Mann-Whitney $U$ test or Student's t test, we analysed differences in mean values of age at baseline (years). intake of alcohol (g/day), and body mass index (BMI; $\mathrm{kg} / \mathrm{m} 2$ ] between all colorectal cancer patients and subcohort members, between patients with and without a truncating mutation in the mutation cluster region of the APC gene, and between patients with absent and present hMLHI expression. The distributions of sex, family history of colorectal cancer (yes/no), and leisure time physical activity (<30, 30-60, 60-90, $>90 \mathrm{~min} / \mathrm{day}$ ) between all colorectal cancer patients, patients with a truncating APC mutation, or patients with absent hMLHI expression and subcohort members were tested using the $\chi^{2}$ test.

Incident rate ratios $(R R)$ and corresponding $95 \%$ confidence interval (Cl) for overall colorectal cancer according to smoking frequency (cigarettes/day). smoking duration (years), age when starting smoking (vears), time since smoking cessation (years), and corresponding continuous variables compared to lifelong non-smokers were estimated using Cox proportional hazards regression models. In addition, associations were estimated for specific fumour molecular endpoints. 


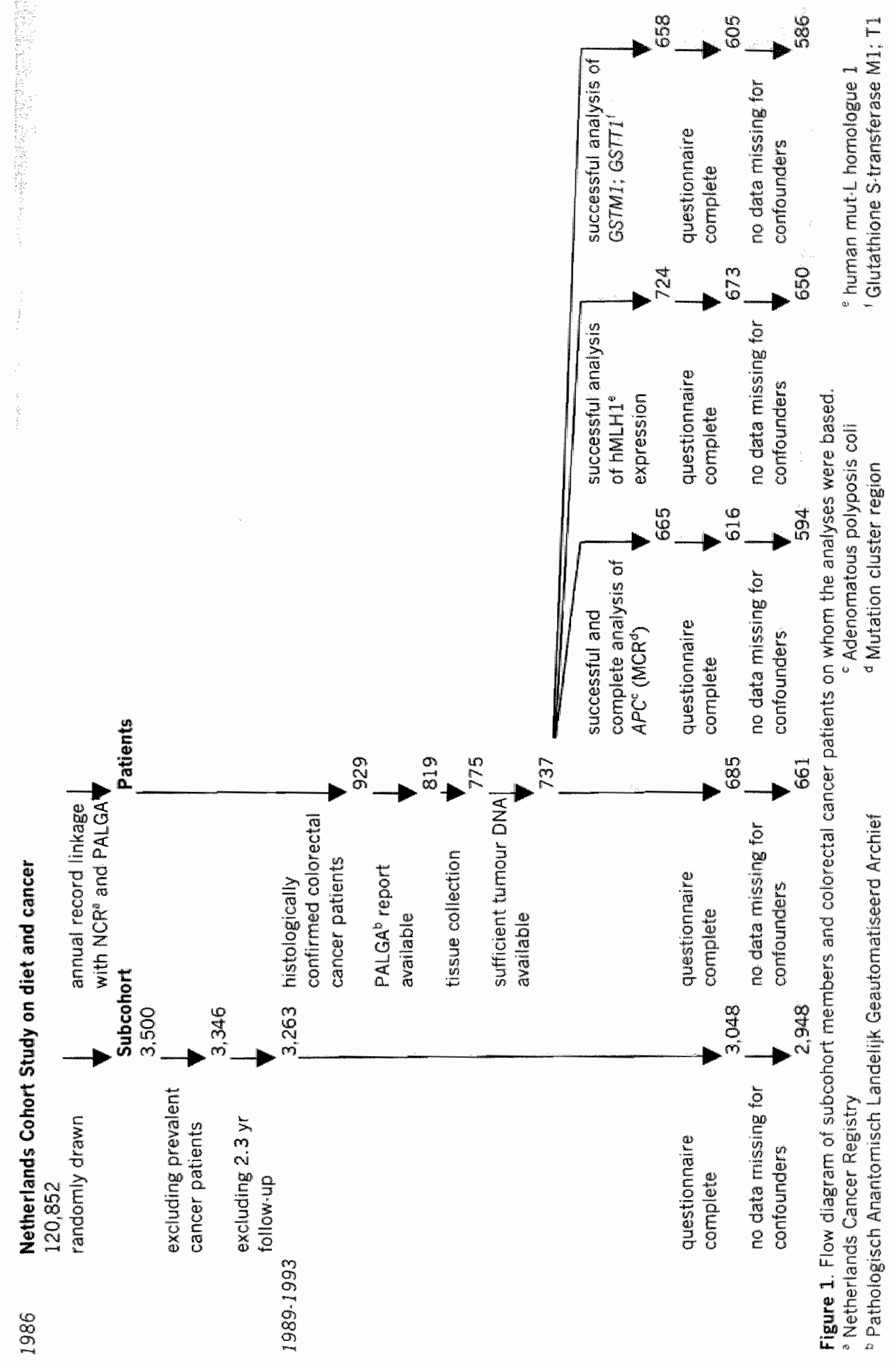


Standard errors were estimated using the robust Huber-White sandwich estimator to account for additional variance introduced by sampling from the cohort. ${ }^{33}$ The proportional hazards assumption was tested using the scaled Schoenfeld residuals.34 Tests for dose-response trends over the different categories of smoking variables were estimated by fitting the ordinal exposure variables as continuous terms and evaluated using the Wald test. For estimation of the $p$-value for trend over the categaries of age when starting smoking and years since smoking cessation life-long and the corresponding continuous analyses non-smokers were excluded.

Age at baseline (years), sex, family history of colorectal cancer (yes/no), intake of vegetables (g/day), fruit (g/day), alcohol (g/day), coffee (cups/day), meat $(\mathrm{g} / \mathrm{day})$, fat $(\mathrm{g} / \mathrm{day})$, dietary fibre $(\mathrm{g} / \mathrm{day})$, calcium $(\mathrm{mg} / \mathrm{day})$, energy $(\mathrm{kJ} / \mathrm{day})$. and $B M \mid(\mathrm{kg} / \mathrm{m} 2)$, and physical activity in leisure time $(<30,30-60,60-90,>90$ min/day) were considered as potential confounders. Those variables that were found to statistically significantly $(p<0.05)$ contribute to the multivariate model of overall colorectal cancer (age at baseline, sex, BMI, family history of colorectal cancer), by means of the Wald test, or showed a 10 percent or more influence on the RR for colorectal cancer were included as covariates in the multivariate analyses. Adjustment for BM gave rise to missing values in 100 subcohort members, 13 colon cancer cases and six rectal cancer cases (figure 1).

In order to estimate interaction of the GSTMI and GSTII genotypes, a case-only design was applied. Odds ratios (OR) for interaction between genotype at risk |GSTMI or GSTTI null genotypel and smoking variables were obtained using logistic regression modelling. Adjustment for family history of colorectal cancer did not alter assessed ORs.

All $p$-values reported are for a two-sided test; $p$-values of less than 0.05 were considered to be statistically significant.

\section{RESULTS}

The presented multivariate adjusted RRs for colorectal cancer according to smoking are based on 661 colorectal cancer patients and 2,948 subcohort members (figure 11. Smoking habits and general characteristics of the population under study are shown in table 1. Colorectal cancer patients were slightly older than subcohort members $(62.8$ vs. 61.3 year, $p<0.001)$ and more often men $(56 \%$ vs. $48 \%, p<0.0011$. When considering specific malecular features of the calorectal tumours of these patients, relatively more men were found to harbour a tumour with hMLHI expression than without ( $57 \%$ vs. $43 \%, p=0.04)$.

Multivariate adjusted RR for averall colorectal cancer, fumours with and without a truncating APC mutation and tumours with and without hMLHI expression according to the smaking variables are shown in table 2. Additional adjustment for family history of colorectal cancer and BMI resulted in similar risk estimates as compared to the age and sex adjusted RRs. Since smoking of cigars and pipe was rare [table 1), only data on cigarette smoking are presented. 
Table 1. Distribution of subcohort members, colorectal cancer patients with and without a truncating mutation in the adenomatous polyposis coli gene (APC stop), and patients with absent and present human Mut- homologue 1 (hMLHI) expression according to age, sex. fanily history of colorectal cancer, body mass index, alcohol intake, physical activity, and tobacco product ever smoked"s

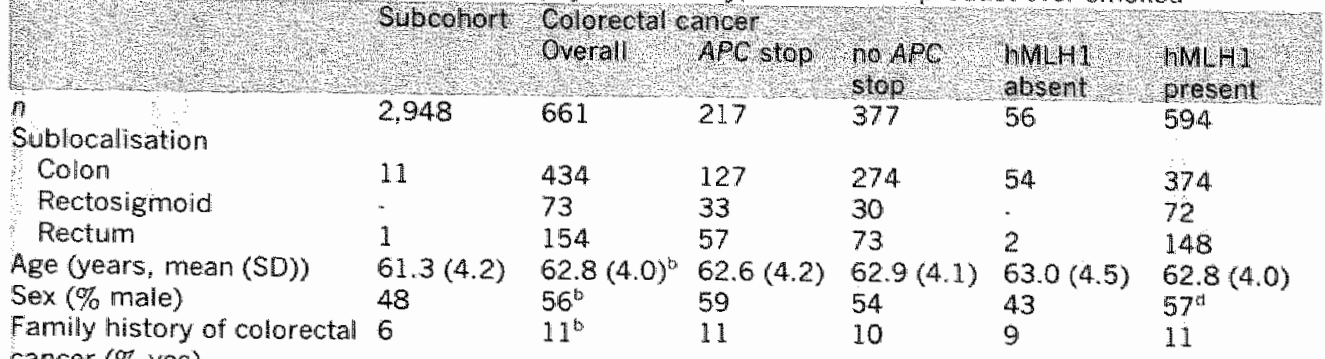

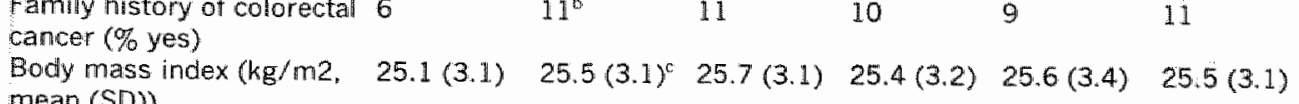

" $p<0.001, " p<0.005$; for comparisons between the colorectai cancar overall group and subcohort, patients that were also subcohort members were exluded from the subcohort group. " $p=0.04$; for comparison between patients without and with HMLHI expression.

Ex-smokers were found to be at increased risk of overall colorectall cancer in comparison with never, smokers (RR 1.30, 95\% Cl 1.03. 1.65), whereas current smokers were not $\{R R \quad 0.91,95 \% \mathrm{Cl} 0.71,18\}$. A high frequency of cigarette smoking was associated with a moderately increased risk of colorectal cancer (RR 1.07, $95 \% \mathrm{Cl} 1.03,1.12$ per five cigareftes/day increment). The Pearson correlation coefficient between smoking frequency and smoking duration was weak $(r=0.22)$. Additional adjustment for smoking duration slightly increased the estimated $R R$ (RR 1.08, $95 \% \mathrm{Cl} 1.03,1.14$ per five cigarettes/day increment). long-term smoking was not associated with overall colorectal cancer risk (RR 1.02. $95 \% \mathrm{Cl} 0.96 .1 .07$ for 10 years increment of smoking durationl. These results are based on patients from whom tumour DNA was available. Analysis of the patients initially recognised within the cohort yielded similar results to those presented here (data not shown).

Tests for interactions between sex and any of the smoking characteristics used in this study were not statistically significant $(p=0.16$ and $p=0.47$ for smoking frequency and duration, respectively). Therefore, results are presented for men 
Table 2. Adjusted incidence rate ratios (RP) and corresponding $95 \%$ confidence interwals (C) for colorectal cancer, colorectal cancer with and without a truncating adenomatous polyposis coli (APC) gene mutation and colorectal cancer with absent and present human Mut-L homologue 1 (hMLHI) expression according to cigarette smokng features in categorical and continuous analyses

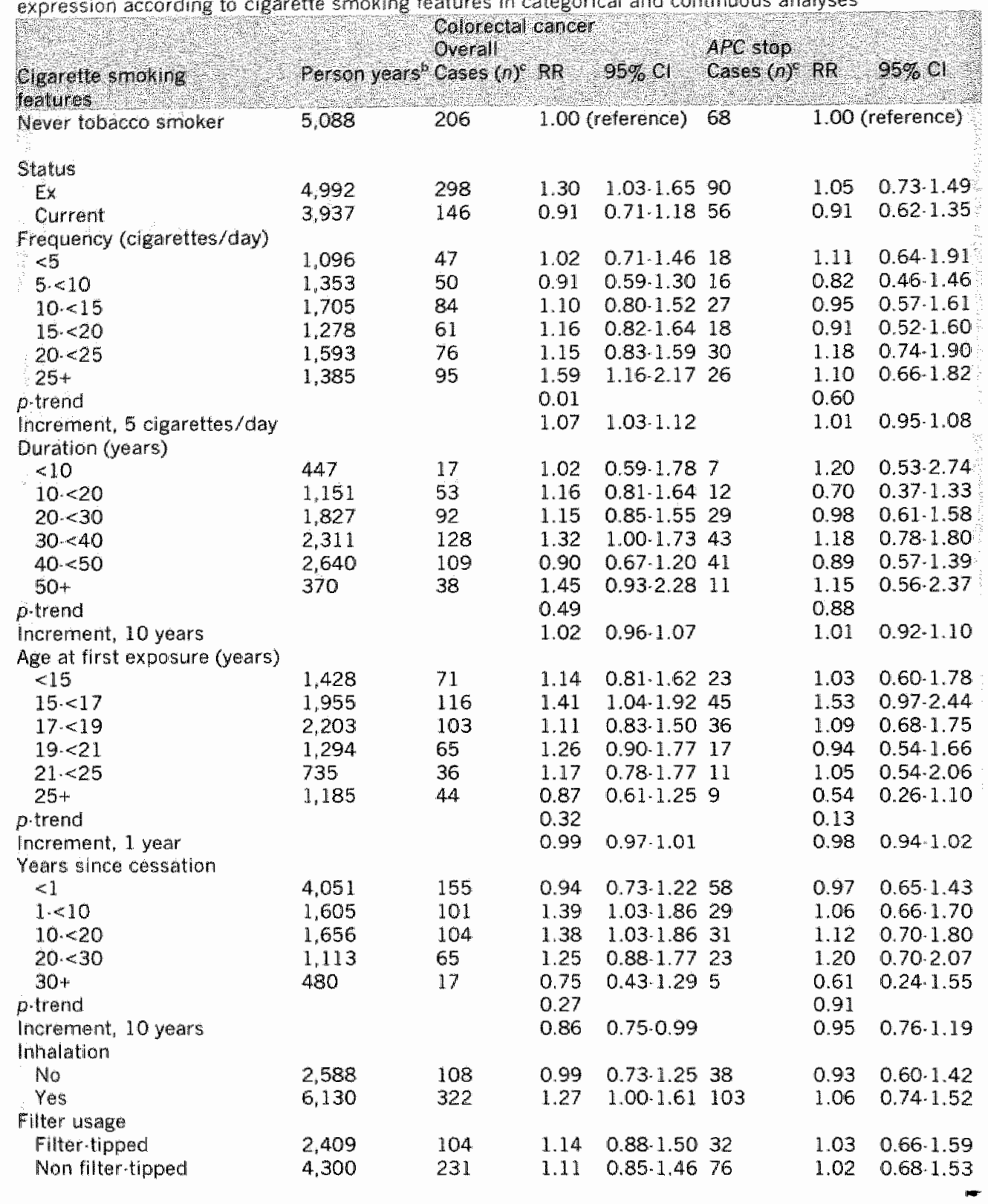


Table 2. Continued

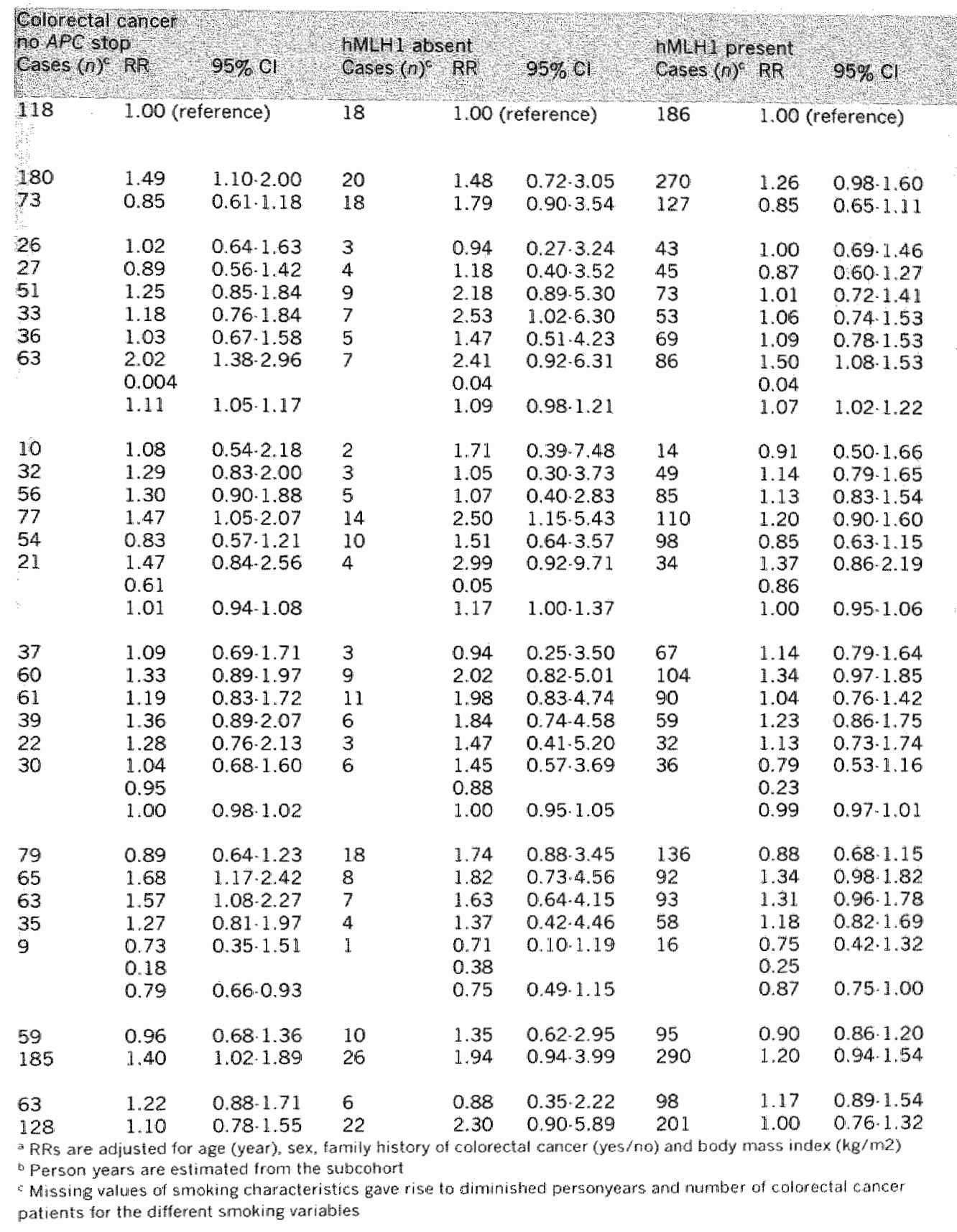


and women combined. When the association between smoking frequency and colorectal cancer was examined for men and women separately, no association was observed in women, but RRs for men were similar to the observed overall RRs.

When we considered APC mutation status, introduction of a stop codon does not appear to be associated with any of the smoking variables (table 2). Moreover, specific point mutations in APC that would lead to introduction of a stop codon and that can be expected to be associated with cigarefte smoking, i.e. $G: C \rightarrow A: T$ transitions (65 patients) and $G: C \rightarrow T: A$ transversions (34 patients) were also not associated with any of the smoking variables, with two exceptions: The categorical variable for age at starting smoking was inversely associated with $G: C \rightarrow A: T$ mutations ( $p$-trend $=0.03$ ), but no statistically significant association was observed for the continuous variable (data not shown). smoking cessation was associated with a reduced risk of colorectal tumours harbouring a $G: C \rightarrow T: A$ mutation $(R R 0.53,95 \% \mathrm{Cl} 0.28 .0 .99$ per 10 years of smoking cessation). In contrast, fumours not harbouring a truncating APC mutation appeared to be associated with former smoking but not with current smoking status (RR 1.49,95\% $\mathrm{Cl} 1.10,2.00$ and $\mathrm{RR} 0.85,95 \% \mathrm{Cl} 0.61,1.18$ for exsmokers and current smokers vs. never-smokers, respectively) and smoking frequency [RR 1.11,95\% Cl 1.05, 1.17 per five cigareties/day increment].

Absent hMLHI expression appears to occur almost exclusively in patients without a truncating APC mutation. Of 56 patients with absent hMLHI expression, only five also harboured a truncating APC mutation. When estimating associations for smaking variables in the limited group of patients with a fumour lacking hMLHI expression, positive associations, though not statistically significant, were found for smoking status (RR 1.48,95\% $\mathrm{Cl} 0.72,3.05$ and RR $1.79,95 \% \mathrm{Cl} 0.90,3.54$ for ex-smokers and current smokers vs. neversmokers, respectively), smoking frequency (RR $1.09,95 \% \mathrm{Cl} 0.98,1.21$ per five cigarettes/day increment), smoking duration (RR $1.17,95 \% \mathrm{Cl} 1.00,1.37$ per 10 years increment), inhalation (inhalation vs. never smokers $\mathrm{RR} 2.18,95 \% \mathrm{Cl} 1.03$, 4.62) (table 3). When smoking frequency and smoking duration were simultaneously included in the analysis, risk ratios were smaller, and smoking duration was found to be more influential than smoking frequency (RR 1.03, 95\% Cl $0.91,1.16$ per five cigarettes/day increment and $1.15 .95 \% \mathrm{Cl} 0.97,1.38$ per 10 years increment of smoking).

Among patients with fumours that expressed hMLHI, a similar, statistically significant positive association with smoking frequency was observed (RR 1.07 , $95 \% \mathrm{Cl} 1.02 .1 .22$ per five cigarettes/day increment), but no association with smoking duration was observed $(R R \quad 1.00,95 \% \mathrm{Cl} 0.95,1.06$ per 10 years increment).

Table 3 presents the ORs for interaction between the GSTMI and GSTI null genotypes and all smoking variables for overall colorectal cancer, as determined in the case-only design. A borderline-significant $(p=0.06)$ interaction was observed between the GSTMI null genotype and smoking frequency $1 O R$ for interaction 1.07, 95\% Cl 1.00, 1.1.14 for GSTM1 null and an increment of five cigarettes/day) but not with GSTI null genotype and any of the smoking characteristics. 
Table 3.Odds ratios for interaction (ORi) and corresponding $95 \%$ confidence intervals (C) for smoking accotding to ghutathione Stransferase GSTMI and GSTI1 genotypes*

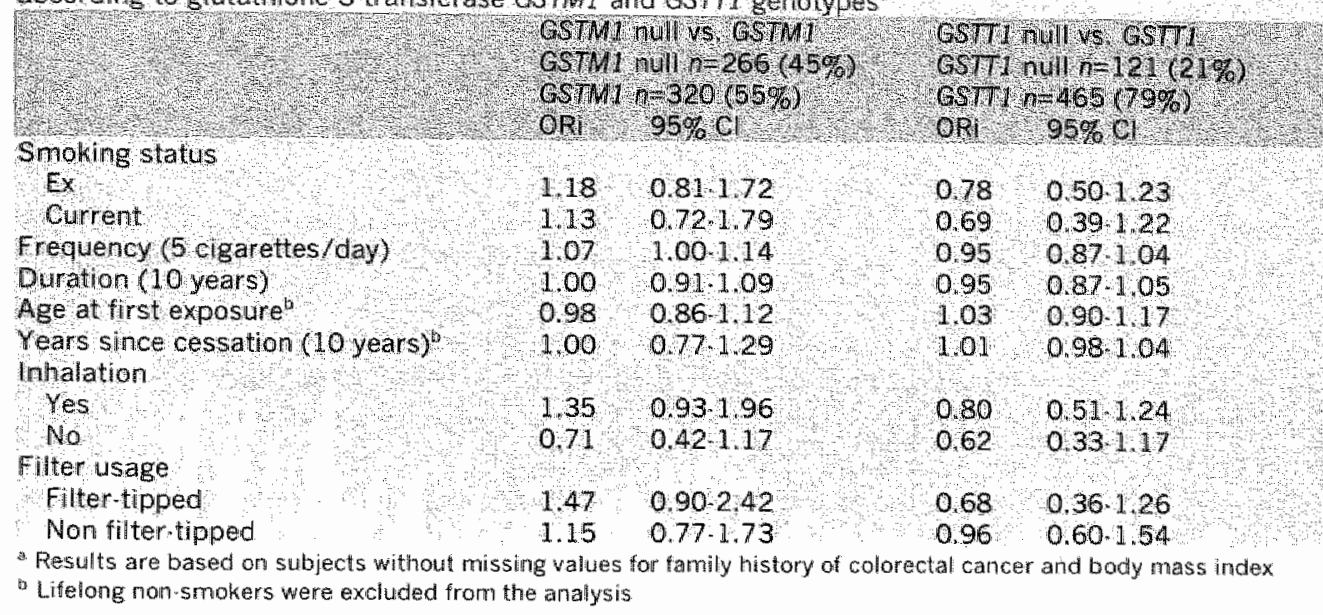

\section{DISCUSSION}

Among colorectal cancer patients from a large prospective cohort in the Netherlands, we investigated the associations between cigarette smoking characteristics and overall colorectal cancer, tumours without and with (specific) APC mutations and tumours with and without hMiLHI expression. Moreover, we examined interactions between smoking and GSTMI and GSTTI genotypes. Of the smoking characteristics examined in this study, smoking cigarettes, and mainly the number of cigarettes smoked per day (frequency), was found to be associated with an increased risk of colorectal cancer. This association was mast pronounced in tumours without a truncating APC mutation. If was also observed in fumours lacking hMLHI expression, but the latter were mainly associated with long-term smoking. No statistically significant interactions between the GSTMI or GSTI null genotype and smoking frequency were observed.

In the questionnaire used in this sludy, questions retrospectively covered a period long enough to delect possible associations, as the suggested 30 to 45 years induction time 3 was met in most cases. The relative importance of dose and duration of cigarefte smoking remains somewhat in question, because these parameters are correlated. In this study, the correlation between the two characteristics was found to be rather low $(r=0.22)$ and correcting smoking frequency for duration did not alter risk estimates much. For the association between cigarette smoking and overall colorectal cancer, frequency appeared to be more influential than smoking duration. This is accordance with previous studies that have also found that dose, or amount usually smoked per day, is an important predictor of risk. 35 it seems plausible that the obsolute daily quantity of carcinogens from cigareftes delivered to the colorectal epithelium is important in producing mutations at a sufficiently high rate. 
In accordance with a case-control study, where no association between cigarette smoking and truncating APC mutations was observed, ${ }^{23}$ we did not abserve an association between cigarette smoking and truncating mutations in the APC gene. The associations observed for specific point mutations leading to truncation may be chance findings and would need to be confirmed in another study.

Cigarette smoking appeared to be associated with tumours without a truncating $A P C$ mutation. A proportion of tumours not harbouring truncating $A P C$ mutations lack hMLHI expression. We observed positive associations of smoking frequency and especially smoking duration in colorectal cancer without $\mathrm{hMLHI}$ expression. This is in agreement with other previous case-contro! studies that have found cigarette smoking to be associated with microsatelite instability in colon ${ }^{20}$ and colorectal21.22 tumours, but not with another report.23 Cigarette smoking may directly affect the methylation of the $\mathrm{hMLHI}$ promotor region, resulting in absent $\mathrm{hMLH1}$ expression and hence deficient DNA repair ${ }^{21}$. On the other hand, cigarette smoke contains numerous carcinogenic compounds that may cause mutations. When DNA repair mechanisms fail le.g. by lack of hMLHI expression) tumours may become more susceptible to mutations that eventually could lead to a carcinoma.

Polymorphisms in the genotype of the carcinogen metabolising glutathione Stransferases may alter colorectal cancer risk. One study found a borderlinesignificant twolold elevated risk associated with the GSTM1 null genotype and smoking cigarettes in comparison with never smokers and presence of the GSTMI allele for rectal cancer in men, 28 but not for colon cancer. ${ }^{26}$ No interaction was found for GSTMI in colon adenomas ${ }^{24}$ or for GSTMI and GSTI in colorectal cancer. 25,27

A valid interpretation of the interaction parameter as estimated from a caseonly study requires the assumption of independence between the gene polymorphism and exposure in the population. ${ }^{36,37}$ in a large group of controls from the database of the International Collaborative study on Genetic Susceptibility to Environmental Carcinogens, it was shown there is no association between smoking and the GSTMI or GSTI genotypes. We did not observe statistically significant interactions between GSTMI or GSTI and any of the smoking variables. A borderline-significant interaction between smoking frequency and GSTMI genotype was observed. Although the OR for interaction between the GSTMI genotype and smoking frequency is difficult to interpret in the absence of information on the colorectal cancer risk conferred by the GSTMl null genotype per se, the effect of GSTMl genotype on cigarette smoking seems negligible. Because of the limited number of tumours displaying hMLHI deficiency, no interaction of the GSTMI and GSTI genotypes in this potentially interesting group could be estimated.

Although associations studied here were hypothesis-based, studying the different subsets of tumours resulted in multiple testing. which may have given rise to chance findings. The statistically significant results observed for overal colorectal cancer in this study are in accordance with results from other studies. ${ }^{3}$ Absence of $\mathrm{hMLH}$ is a rare occurrence in sporadic colorectal cancer. therefore just 53 patients were available in our reasonably large cohort of 
patients to study associations between cigarette smoking and risk of colorectal tumours without hMLHI expression. This limited number of patients may give rise to spurious findings, but the observed associations for $\mathrm{hMLHI}$ deficient tumours are also in keeping with previous reports on colon cancer. $20-22$

This study indicates that smoking cigarettes may contribute to colorectal cancer. The association between frequency of cigarette smoking and colorectal cancer is most apparent in cancers that do not harbour a truncating mutation in the APC gene. Duration of smoking was associated with hMLHI deficient tumours, though estimated risk ratios were moderate, and their corresponding confidence intervals wide. Finally, modification of the effect of cigarette smoking by the GSTMI and GSTTI null genotypes seems negligible. 


\section{REFERENCES}

1. Potier Jo. Colorectal camcer: molecules and populations. 3 Nati Cancer Ins: 1999:911111:916-32.

2. World Cancer Researifh Fund. American instivte for Cancer Research. Food numition and the prevention of concer: A global perspective, ed. 1sl. Washington, DC: WCRF/ARC, 1997.

3. Giovannucil E. An updoted rewiew of the epidemiological evidence that cigarette smokng increases ifst of colorectal cancer. Cancer Epidemol Biomarkers Prew 2001:1017):725-31.

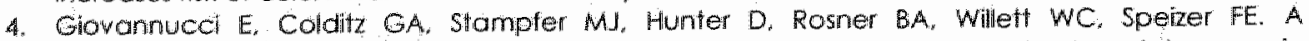
prospective study of cigarette smoking and risk of colorectal adenoma and colorecta cancer in U. s. women. J Hath Gancer Inst 199.4:86131:192-9.

5. Glovannuci E Rimm EB, Stompfer M. Colditz GA. Ascherio A. Keomey J. Willeft WC. A prospective study of cigarette smaking and risk of colorectal adenoma and colorectal cancer in U.S. men. J Natl Cancer inst $192406(3): 183-91$

6. Meineman EF, Zahm $\mathrm{HH}$, Mcloughlin JK, Vaught JB. increased risk of colorectal cancer among smokers: results of a 26-year follow-up of Us weterans and a rewew. Int J Cancer 1994:59(6):728-38.

7. Nyren O. Aergstrom R. Nysirom L. Engholm G. Ekbom A. Adami HO. Knutsson A. 5 ijemberg N. Smoking and colorectol cancer: a 20 -year follow-up study of Swedish construction workers. I Natl Cancerins 1996:881181:1302-7.

8. Engelaind A, Andersen A, Haldorsen T, Tretli S. Smoking habits and risk of cancers other thon lung cancer: 28 years follow-up of 26,000 Norwegian men and women. Cancer Causes Control $1996: 7[5): 497-506$

9. Nordund LA, Carstensen JM, Pershagen $G$. Cancer incidence in female smokers: a 26 -year lollow-up. Int J Cancer 1997:73151:625\%8.

10. Fearon ER, Vogelstein B. A genetic model for colorectal fumorigenesis. Cell 1990;61 (5):759-67.

11. Powell SM, Ziz N, Beazer-Barclay Y, Bryan TM, Hamilton SR, Thibodeau SN, Vogelstein B, Kinzler KW. APC mutations occur early during colorecial tumorigenesis, Nature 1992,359:63921:235-7.

12. Miyoshi Y. Nagase H, Ando H, Horil A, Ichil S, Nakatsuru S, Aoki T, Miki Y, Mori T, Nakamura Y. Somatic mutations of the APC gene in colorectal tumors: mutation cluster region in the APC gene. Hum Mal Genet 1992; 1: 4:1:229-33.

13. Konishi M, Kikuchi-Yanoshita R, Tanaka K. Muraaka M, Onda A, Okumuna Y. Kishi N. Wwama T, Mori $T$, Kaike M. Ushio K. Chiba M. Nomizu S, Konishi F, Utsunomiya J, Miyaki M. Malecular nature of colon tumors in hereditary nonpolyposis colon cancer, familial polyposis, and sporadic colon cancer. Gastroenterology 199:111121:307-17.

14. Luchlenborg M. Weijenberg MP, Roemen GM, de Bruine AP, van den Brandt PA, Lentjes MH. Brink $M$, van Engeland $M$, Galdbohm RA, de Goeil AF. APC mutations in sporadic colorectat carcinomas from The Netherlands Cohort Study. Carcinogenesis 2004:25(7):1219-26.

15. marris CC. Chemical and physical carcinogenesis: advances and perspectives for the 1990s. Cancer Res 1991:51118 5uppl):50235 44s.

16. Thibadedu SN. French AJ, Cunningham JM. Tester D. Buigart LJ. Roche PC, McDonnel SK, Schaid DJ. Vockley CW. Michels VV. Far GH. Jr., OConnell M. Mirrosalellite instability in Colorectal concer: different mutator phenotypes and the principal involvement of hMLHI. Cancer Res $1998 ; 58,8): 17138$

17. Olschwang S. Wamelin R. Laurent-Puig P. Thulle B, De Rycke Y, Li YJ, Muzeau F Grodet J, Salmon RJ, Thomas $G$. Altematiwe genetic pathways in colorectal carcinogenesis. Proc Nati Acad Scil U S A $1997: 94(22): 121227$.

18. Salatushor S, Kressner U. Pahman L. Glimelus B. Lindmark G. Lindiblom A. Collorectal cancer with and without microsatellite instability involves different genes. Genes Chiomosomes Cancer $1998: 26(3): 247,52$

19. Samowitz WS, Holden WA. Curtin K, Eowards SL, Walker AR, Lim HA, Robertson MA, Nichols MF, Gruenthal KM, Lynch BJ, Lepper MF. Slattery ML. Inverse Relationship between Microsatellite Instabilty and Kuras and 53 Gene Alterations in Colon Cancer. Am J Pathol 2001:158:41:1517-24.

20. Slattery ML, Gurtin K. Anderson K. Ma KN, Ballard L. Edwards S, Schaffer D. Potter J, Lepper: M. Samowitz WS. Associations between clgarette smoking. lifestyle factors, and microsatellite instability in colon turnors. J Nall Cancer inst 2000:92(22):1831-6.

21. Yang P. Cunningham IM, Halling KC. Lesnick TG. Burgart LJ. Wegert EM. Christensen ER. Lindor NM. Kahmonn JA. Thibodeau SN. Higher risk of mismatch repair-deficient colorectal cancer in alpha(1)-antitrypsin deficiency comers and cigarette smokers. Mol Genet Metab 2000:71 [4/:63945. 
22. Wu AH. Shibata D. Yu MC. Lai MY Ross RK. Dietary heteracyclic amines and micrasatelite instability in colon adenocarcinomas. Carcinogenesis $2001: 221101: 1681-4$.

23. Diergaarde B, Vrieling A, van Kraats AA, van MUijen GN, Kok FJ, Kampman E. Cigarette smaking and genetic alterations in sporadic colon carcinomas. Carcinogenesis 2003:24/3:565-71.

24. Lin HJ. Probst-Hensch NM, Ingles SA, Han CY, Lin BK Lee DB, FrankI HD. Lee ER Longnecker MP. Halle RW. Glutathiome transferase (GSTMI) null genotype, smoking, and prevalence of colorectal adenomas. Cancer Res 1995:5.5(6):1224-6.

25. Gertig DM. Stampfer M. Haiman C. Henmekens $\mathrm{CH}$, Kelsey K. Hunter DJ. Glutathione S-transferase GSTMI and GSTI polymorphisms and colorectal cancer risk: a prospective study. Cancer Epidemiol Biomarkers Prev 1998:7|111:1001-5.

26. Slattery ML, Potter JD. Samowitz W, Bigler J, Caan B, Leppert M. NAT2, GSTM-1, cigarette smoking. and risk of colon cancer. Cancer Epidemiol Biomarkers Prev 1998:7(12):1079-84.

27. wan der Hel $O L$. Bueno de Mesquita HB, Roest M. Slothouber B, van Gils C, van Noord PA Grobbee DE, Peeters PH. No modifying effect of NATI. GSTMI, and GSTT on the relation between smoking and colorectai cancer risk. Cancer Epidemiol Biomarkers Prev 2003:12171:681-2.

28. Slattery ML, Edwards S. Curtin K, Schaffer D. Neuhausen S. Associations between smoking, passive smoking. GSTM-1, NAT2, and rectal cancer. Cancer Epidemiol Biomarkers Prev 2003; 12|9]:882-9.

29. Piegorsch WW, Weinberg CR. Taylor JA. Non-hierarchical logistic models and case only designs for assessing susceptibility in population-based case-contral studies. Stat Med 199 4:13(2):153-62.

30. van den Brandi PA, Goldbohm RA, van 't Veer P. Volovics A. Hermus RJ. Stumans F. A large-scale prospective cohort study on diet and cancer in The Netherlands. J Clin Epidemial 1990; 43(3):285 95.

31. wan den Brandt PA, Schouten L.j, Goldbohm RA, Dorant E, Hunen PM. Development of a record linkage protocol for use in the Dutch Cancer Registry for Epidemiological Research. Int J Epidemiol 1990:19(3):553-8.

32. Brink M. De Goeil AF, Weijenberg MP, Roemen GM, Lentjes MH, Pachen MM, Smils KM, De Bruine AP, Goldbohm RA, Van den Brandt PA. K-ras oncogene mutations in sporadic colorectal cancer in The Netherlands Cohort 5tudy. Carcinogenesis 2003:24:4]:703-10.

33. Lin DY. Wel LJ. The robust inference for the Cox Proportional Hazards Model. JASA 1989:84(408):107.4-78.

3.4. Schoenfeld D. Partial residuals for the proportional hazards regressian models. Biometrika 1982:69|11:239-41.

35. Slattery ML Potter JD. Friedman GD. Ma KN, Edwards S. Tobacco use and colon cancer. Int J Cancer 1997:70|3|:259-64.

36. Yang $Q$. Khoury MJ. Evalving methods in genetic epidemioliogy. Ill. Gene-environmentt interaction in epidemiologic research. Epidemiol Rev 1997:19:11:33-43.

37. Albert PS, Ratnasinghe D, Tangrea J, Wachalder S. Limitations of the case-only design for identifying gene-environment interactions. Am J Epidemiol 2001:154|8/:687-93.

38. Smits KM. Gaspori L. Weijenberg MP. Dolzan V. Golka K, Roemer HC. Nedelcheva Kristensen V Lechner MC. Mehling Gl. Seidegard J. Strange RC. Taioli E. Interaction between smaking. GSTMI detetion and colorectal cancer: results from the GSEC study. Biomarkers 2003:8/3-4):299-310. 
$\begin{array}{lllllll}C & H & A & P & T & E & R\end{array}$ 


\section{GENERAL DISCUSSION}




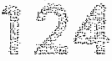


Diet is thought to be an important contributing factor to colorectal cancer risk. However, existing associations may be obscured by the heterogeneity of the cancer endpoint and the genetic make-up of the individual. In the studies described in this thesis, we investigated the occurrence of mutations in genes relevant to the early stages of colorectal carcinogenesis, i.e., the adenomatous polyposis coli (APC). CTNNBI and Kirsten ras (K-ras) genes, as well as expression of the human Mut-L homologue 1 (hMLHI) protein. Next, we investigated whether we could elucidate associations of meat, dietary fat, and smoking with colorectal cancer while accounting for these molecular aberrations in colorectal fumours or for genetic susceptibility determined by polymorphisms in the glutathione S-transferase MI and TI (GSTMI. GSTTI) genes. These studies were performed in a large group of colorectal cancer patients from the Netherlands Cohort Study on diet and cancer (NLCS). In this chapter, the main findings are summarised, methodological issues are discussed, and implications of the results and the perspectives for future research are presented.

\section{MAIN FINDINGS}

Mutations in the APC gene are considered a hallmark of colorectal cancer. Although our observation of $37 \%$ of tumours harbouring a truncating APC mutation seems low compared to the general assumption that up to $80 \%$ of colorectal tumours arise through a pathway involving loss of APC function.' it is in keeping with mutation frequencies of 30 to $70 \%$ observed in other studies. 1.9 Intriguingly, APC mutations, regardless of their putative effect, were a frequent finding in patients from our study. A large proportion of mutations would result in a single altered amino acid (52\%) or no putative alteration (20\%) of the APC protein, rather than to introduction of a stop codon $(28 \%)$. Patients with rectosigmoid and rectal tumours had a higher frequency of truncating APC mutations as compared to patients with a proximal or distal colon tumour (53 and $45 \%$ versus 31 and $32 \%$, respectively) (chapter 2 ).

in general, colorectal cancer is characterised by genetic instability. Whereas the majority of colorectal tumours display chromosomal instability, a small proportion (approximately 10 to $15 \%$ ) is marked by microsatellite instability. In the widely accepted model for colorectal carcinogenesis, a carcinoma arises through the accumulation of mutations in a number of key genes (e.g. APC. Kras, TP53).10 Results from our study, where we investigated the occurrence of $A P C$. CTNNBI and $K$-ras gene mutations as well as hMLHI protein expression. indicated that colorectal cancer is more heterogeneous than predicted by the model, which is in accordance with a repart from another cohort study. Although APC and K-ras mutations were found to occur simultaneously more often than expected by chance alone, most tumours do not harbour mutations in both genes. Patients with hMLHI deficient tumours were older and more often women. Tumours lacking hMLHI expression were found almost exclusively in the proximal colon and showed less differentiation. In contrast to the report that approximately half of colorectal tumours lacking truncating APC mutations narbour a mutation in the CTNNBI gene, 12 the contribution of CTNNBI mutations to colorectal carcinomas seems negligible in our study (chapter 3 ). 
In the study of associations between meat. meat products and fish consumption and the occurrence of different types of APC mutations as well as expression of $\mathrm{hMLH}$ I. the observed associations were weak. However, our data suggested that several types of fresh meat and meat products contribute differently to the defiology of colon and rectal cancer, depending on APC mutation status of the fumour, but was not associated with absence of hMLHI expression (chapter 4).

In the study on dietary fat intake and hMLHI expression. APC and K-ras mutations, intake of total, saturated and mono-unsaturated fat was not associated with the risk of colon and rectal cancer or the different molecular subgroups. However, a striking positive association was observed for linoleic acid with colon tumours harbouring an activating K-ras multation, but without an additional APC mutation or lacking hMLH1 expression (chapter 5).

Although estimated risk ratios were moderate, the association between cigarette smoking and colorectal cancer suggests that smoking of cigarettes contributes to colorectal cancer. The association with smoking frequency was most apparent in carcinomas that did not harbour a truncating mutation in the APC gene. Prolonged duration of smoking was associated with fumours lacking $\mathrm{hMLHI}$ expression. Finally, modification of the effect of cigarette smoking by the GSTMI and GSTII null genotypes seemed negligible (chapter 6).

\section{METHODOLOGICAL CONSIDERATIONS}

Before discussing the implications of the findings from the studies described in this thesis, it is important to highlight several methodologicall issues. In chapters 2 through 6 strength and limitations of the studies have been described. In the following section these issues will be addressed in more detail.

\section{SELECTION BIAS \\ Follow-up}

Since the Netherlands Cancer Registry (NCR) and the Pathologisch Anatomisch Landelijk Geautomatiseerd Archief (PALGA) did not yet operate at a nationwide level at the start of the study in 1986, the choice of the municipalities included in the NLCS partially depended on the quality of coverage of the cohort by these databases, thus minimising loss to follow-up. ${ }^{13}$ Based on hospital discharge data, from 1988 onwards the estimated coverage of Dutch municipalities by the NCR and PALGA together was nearly 100\% for the municipalities included in the cohort. The pathology laboratories in the municipalities not yet covered by PALGA in 1989 did not differ from the ones in municipalities that were completely covered by PALGA with respect to being located in an academic hospital or a cancer treatment centre. Therefore, it is not expected that differential selection bias took place with respect to dietary intake or patient and tumour characteristics including the GSTMI and GSTII polymorphisms and APC. CTNNBI and K-ras mutation status or mismatch repair deficiency. 
Additional analyses showed that there were no statistically significant differences in dietary intake levels nor in clinicopathological characteristics of the fumour (Dukes" stage and differentiation grade) or patient characteristics lage, family history of colorectal cancer) of patients lost to follow-up due to unavailable tumour tissue compared to the calorectal cancer patients whose tumour tissue blocks were used for subsequent analyses (chapters 4 through 6). Therefore, selection bias due to loss to follow-up of fumour tissue is unlikely.

\section{Molecular analyses}

A second source of selection bias may be related to the success rate of the analyses of the various endpoints, i.e. APC, CTNNBI, K-ras mutation analyses, hMLHI immunohistochemistry, and GSTMI and GSTI polymorphism detection. Tumour DNA was isolated from archival formalin-fixed, paraffin-ennbedded tumour tissue blocks that were macro-dissected using a haematoxylin and eosin stained section as a reference. Depending on the conditions of fixation and storage, the extracted archival DNA is more or less fragmented, which means that only DNA fragments from approximately 100 to 400 bp can be amplified. Mutations in the APC, K-ras, and CTNNBI genes were detected by using a nested PCR protocol to amplify relevant parts of these genes, followed by direct sequencing.

In order to study the large mutation cluster region of the APC gene. amplification of overlapping segments with sizes ranging from $356 \mathrm{bp}$ to $511 \mathrm{bp}$ was performed. However, in 10\% of patients for whom fumour DNA was available, the analysis could not be completed for all four APC fragments. In order to avoid a potential overrepresentation of false negative results, we have excluded those patients for whom one or more fragments could not be amplified, regardless of the data available on those fragments that were analysed.

With regard to K-ras mutation analysis, this constituted less of a problem, as the relevant codons 12 and 13 could be amplified and analysed for mutations in one single fragment of $114 \mathrm{bp}$, and in only $5 \%$ of cases this gene fragment could not be amplified.

Analysis of the CTNNBI gene was restricted to tumours that did not harbour a fruncating $A P C$ mutation and fumours that were hMLHI deficient. CTNNBI mutations were observed in too few patients to include this endpoint in the molecular epidemiological analyses.

Polymorphisms in the GSTM1 and GSTII genes were established by nested PCR followed by gel electrophoresis to assess presence or absence of the GST alleles. Analysis of the GSTMI and GSTI polymorphisms could be completed in $85 \%$ of cases. This relatively low success rate is due to the fact that we only included patients for whom the analyses for both genes were complete and fumour DNA from some patients was unavailable as this was used earlier for $A P C$ and $K$-ras mutation analyses.

The success rate of the molecular analyses is partially dependent on the quality of the tumour DNA available, which relies on the methods of tissue fixation and storage of the pathology laboratories of the various hospitals that provided the tumour tissue blocks. These methods differ between laboratories and vary over 
time. To what extent the success rate may be attributed to the fumour itself and its defiology remains unclear, but it seems likely that any misclassification of the endpoints is random and not related to exposure.

\section{VALIDITY AND REPRODUCIBILITY OF MOLECULAR ANALYSES}

For the studies included in this thesis, a number of laboratory procedures have been carried out. Important to our data analyses was the validity and reproducibility of these assays.

Although the tumour areas of the tissue blocks were identified and isolated by macro-dissection, we may have included DNA from adjacent normal tissue that would potentially mask the detection of APC, K-ras and CTNNBI mutations in the tumour DNA. The sensitivity of our assays was estimated to be approximately 5\% multated DNA in a background of wild type DNA, which means that inclusion of a relatively small amount of normal DNA would not have hampered detection of mutations relevant to the tumour. However, this high sensitivity may have led to the detection of mutations that are present only in sub-clones of the fumour and thus represent tumour heterogeneity, rather than revealing a mutation that has been relevant for cancer development.

Expression of hMLHI was determined by immunohistochemistry, and validated by comparison with BAT-26 analysis for a limited series of specimens, which revealed $99 \%$ correspondence between hMLH1 deficiency and microsalellite instability as determined by BAT-26 analysis. BAT-26 has previously been shown to identify microsatellite instability in sporadic colorectal cancer. ${ }^{14}$

In our study of genetic predisposition due to polymorphisms in the GSTMI and GSTI genes, we could determine a homozygous deletion or the presence of at least one of the GSTMI and GSTII alleles. No distinction could be made between heterozygous or homozygous presence of the GSTMI and GSTI alleles. For both GSTMI and GSTI1, the hypothesized consequence of the null genotype is reduced or absent conjugation activity. Evidence is lacking whether heterozygosity in either GSTMI or GSTII affects enzyme function. ${ }^{15}$

Reproducibility is important for interpretation of the results and was assessed by duplicate analyses of a number of gene fragments that were amplified from the isolated tumour DNA. The reproducibility for APC $(85 \%), K$-ras $[88 \%)$, and GSTMI/T1 (91\%) gene analysis was good, taking into account the standardisation and validation procedures used for these molecular analyses. Since duplicate experiments performed on DNA obtained from colon cancer cell lines consistently yielded identical results, the lower level of reproducibility observed in the tissue samples may reflect heterogeneity of the tumour tissue.

Finally, all mutation and expression profiles were assessed by at least two observers to minimise errors arising from inter-observer variation. Considering the high sensitivity and good reproducibility of the assays, the quality of the molecular data used in the studies described in this thesis can be deemed satisfactory. 


\section{CHOICE OF STUDIED ENDPOINTS}

When studying the associations between environmental exposures and mutations in genes involved in colorectal cancer, it is important to differentiate between mutations that have known oncogenic consequences versus those which tumourigenic effects are uncertain.

With regard to the $K$-ras mutations, we have focussed on the activating mutations in codons 12 and 13 and did not consider mutations of which effect on the activity of the K-ras protein is unknown. The latter were observed in 18 patients. Mutations in codon 61, located in exon 2, are also reported to affect K-ras activity, but these mutations were not determined since these represent approximately $5 \%$ of the activating alferations only. 16 Therefore, and for efficiency reasons, mutation analysis of the $K$-ras oncogene was restricted to exon 1.

We have limited the mutation analysis of the APC gene to the mutation cluster region, in which 68 to $77 \%$ of somatic mutations are found. Therefore, we may have missed up to one third of all mutations that may occur in this large gene. However, most colorectal cancers that have APC mutations, exhibit at least one truncating mutation in the mutation cluster region ${ }^{17}$ and all truncating mutations in this region result in loss of the C-terminal part of the APC protein, which harbours functional domains that are critical to APC's tumour suppressor function. ${ }^{18}$

An inherent problem of studying alterations in the APC gene is its character as a tumour suppressor gene, since it would require two hits to inactivate both alleles. However, there is evidence that in a fumour harbouring a mutation in the mutation cluster region of the APC gene the other allele is often deleted. ${ }^{17}$

Similar considerations as those with respect to the choice of K-ras mutations studied apply to the analyses with regard to mutations in the APC gene. We have focussed on patients harbouring a tumour with a point or frameshift mutation in the mutation cluster region that would lead to introduction of a stop codon and consequently to truncation of the APC protein and loss of function. as these are generally accepted to contribute to tumour formation. Following this line of reasoning with respect to specific point mutations hypothesized to be associated with environmental exposures, these analyses were also based on specific point mutations giving rise to introduction of a stop codon.

Since a large proportion of fumours harboured a missense mutation in the APC gene, this group was analysed separately with regard to the exposures under study. As the functional implication of these mutations is unknown, results are difficult to interpret. It is plausibie that the occurrence of missense mutations partially represents increased mutation rates in the tumour rather than defective APC function.

Another impairment of A.PC function could be caused by gene silencing through promotor hypermethylation.19.20 However, since this is a rare occurrence and probably reflects other mechanisms than the mechanisms hypothesized to induce specific APC mutations that were studied, this is likely not to have led to significant misclassification in our study. 
Although CTNNBI mutations were suggested to occur in approximately $50 \%$ of tumours lacking a truncating mutation in the APC gene, ${ }^{12}$ in our study only five of 464 patients without a fruncating APC mutation and/or WMLHI deficient fumour, harboured a mutation in the codons that encode phosphorylation sites. This very limited number of tumours harbouring a mutation in the CTNNBI gene did not allow for molecular epidemiological analyses to estimate associations between meat, fat and cigarette smoking and these genetic aberrations. In contrast to suggestions from literature, 12.21.22 a major role for CTNNBI mutations in colorectal cancer seems unlikely.

Differences between microsatellite instable tumours and chromosomally instable tumours have been proposed to reflect environmental exposure ${ }^{23}$ and therefore are an interesting group of tumours to study. Of the microsatellite instable tumours, approximately $90 \%$ show absence of $\mathrm{hMLH}$ l expression. ${ }^{24}$ In sporadic colorectall cancer, the absence of hMLHI expression is generally due to hypermethylation of the promotor region $25-27$ and not to mutations in this gene as is the case in hereditary non-polyposis colorectal cancer.

\section{VALIDITY AND REPRODUCIBILITY OF EXPOSURE ASSESSMENT}

A crucial factor with regard to the studies described here, is the validity of the exposure data used. With regard to possible information bias, exclusion of the first 2.3 years of follow up is likely to have eliminated possible pre-clinical disease that may have affected exposure status in the case group. Under- or overreporting of dietary and smoking factors at the start of a cohort study will most likely be non-differential, especially with regard to APC. K-ras mutation status, hMLH1 1 expression status or polymorphisms in GSTM1 and GSTT1.

Data on consumption of various dietary factors were validated against a nineday record method. ${ }^{28}$ The observed Pearson correlation coefficients for meat (0.46), meat products (0.54) and fish (0.53) were modest. ${ }^{28}$ The sex and energyadjusted correlation coefficients for total fat (0.52), saturated fat 10.58$)$ and polyunsaturated fat $(0.75)$ were slightly better. ${ }^{28}$ Although estimates of intake may not be as accurate as desirable, if misclassification occurs, it is more than likely to be non-differential. Therefore, it is possible that true associations are stronger but would still remain weak or undiscovered in this study.

Our data with regard to dietary factors were derived from the 150-item food frequency questionnaires that the study participants filled in at the start of the study. Diet was assessed only once, but the small decline in test-retest correlation coefficients over lime 10.07 over five years) in the reproducibility study of the food frequency questionnaire suggests that the exposure is relatively stable over time..$^{29}$

One of our hypotheses with regard to the carcinogenic properties of meat consumption was based on the content of carcinogens, which are formed during meat preparation such as heterocyclic aromatic amines (HCA) and polycyclic aromatic hydrocarbons (PAH). Since we did not have data on habitual preparation of meat of all cases and subcohort members at baseline, the consumption of several types of meat was used as a proxy for intake of heat-induced carcinogens present in meat. Large variations in the intake of 
HCA and PAH from meat can be expected as these are the result of varying preparation methods. 30 Data from meat preparation in subcohort members at a follow-up investigation, however, showed little variation in surface browning of meat, suggesting that the range in the content of heat-induced carcinogens would be limited. 31 PAH levels in meat as prepared by the Dutch population under study are expected to be low, as PAH are induced by grilling or barbecuing of meat, which is not a common means of meat preparation in the Netherlands. The main source of PAH would be from tobacco smoke, and smoking status was included as a confounder in the used models and investigated separately in chapter 6. N-nitrosamines and their precursors are compounds that can be formed endogenously ${ }^{32}$ but are also found in red and processed meat. ${ }^{33}$ Variations in intake of these meats could therefore reflect variations in exposure to $\mathrm{N}$-nitrosamines.

\section{CONFOUNDING}

In chapters 4 through 6 , we have examined the relationship between meat and fish consumption, dietary fat intake and smoking on the presence or absence of (specific) APC mutations and lack of hMLHI expression. Key factors influencing risk of colon and rectal cancer were age, sex and family history of colorectal cancer. These factors were included in all analyses performed. Other possible confounding factors were chosen based on literature and their influence tested by introducing all of these factors as covariates to the multivariate models for overall colon and rectal cancer. The covariates that influenced the estimated risk ratios by $10 \%$ or more and/or contributed statistically significantly $[p<0.05]$ to the multivariate model in either the model for colon or rectal cancer or both were included in the model.

We did not investigate confounding factors specifically for the separate endpoints studied, because, as yet, there is insufficient information available on potential confounders for the exposures and these particular endpoints to take these into account. Possibly, factors that confound the relationship between the exposures of interest and colon and rectal cancer do not play an important role with regard to the molecular endpoints. Conversely, other factors may confound associations when considering these particular endpoints. However, exarnining large numbers of potential confounders in separate models for all the endpoints studied, would severely increase the chance of type I errors with regard to identifying confounders.

\section{MULTIPLE COMPARISONS}

Based on hypotheses priar to analysing our data. we have conducted several survival analyses with various endpoints (presence and absence of (specific) truncating and missense mutations in the APC gene and (specific) missense mutations in the K-ras gene, presence and absence of hMLHI expressionl. Even though our analyses were hypothesis-based, the multiple comparisons for the exposures investigated in this thesis prompt us to consider the possibility of chance findings when interpreting the results from our studies. 


\section{INTERPRETATION OF FINDINGS}

\section{CURRENT MOLECULAR EPIDEMIOLOGICAL EVIDENCE}

To the best of our knowledge only one other study has investigated dietary factors and the occurrence of truncating APC mutations in colorectal cancer ${ }^{9}$ In this case-control study of dietary intake and risk of colon cancer with or without truncating $A P C$ mutations, moderate positive associations for colon tumours that harbour a truncating APC mutation were found with red meat and fish consumption, which is in contrast with results from our study (chapter 4). This may be due to the relatively small numbers of patients and controls 1184 cases and 259 controls!, but also to differences in definitions used with regard to types of meat as well as differences in exposure assessment between that study and our own study.

Just one other study included associations between dief and hMLHI expression next to diet and microsatellite instability and found these associations to correspond. ${ }^{34}$ Absence of hMLHI expression appears to be good marker for microsatellite instability (chapter 3 and references ${ }^{34}$. 35 ). Therefore, the results obtained from the analyses based on absence of hMLHI expression may be representative of microsatelite instable tumours and results from our study allow for comparison with results from studies that have estimated microsatellite instability.

Few other epidemiological studies have examined associations befween diet and microsatellite instability. ${ }^{34}, 36-38$ Again, in contrast with our study in which no association between meat consumption and hMLHI expression was observed. in a case-control study that addressed associations between dietary factors and microsatellite instability that was based on 40 microsatellite instable tumours, an inverse association of red meat with microsatellite instable tumours was observed.34 Cigarette smoking was found to be associated with microsatellite instable colorectal tumours in three case-control studies, ${ }^{37}$. 39. 10 whereas another case-control study could not confirm this. 11 Results from our study (chapter 6) indicated that smoking was associated with fumours that did not harbour an APC mutation, and this may partially be ascribed to tumours that lack hMLHI expression.

\section{TUMOUR INITIATION VERSUS PROGRESSION}

Dietary and lifestyle habits were measured once at the start of our study, which may imply that dietary factors that have contributed to tumour progression rather than initiation are most likely to be observed. However, the group under study has been shown to have a relatively stable dietary pattern with a 0.07 decline in test-retest correlation coefficients over five years and can therefore probably also be extrapolated retrospectively over a period of at least five years. ${ }^{29}$ However, whether this covers a period long enough to extend back to fumour initiation remains in question, as the period between fumour initiation and the clinical appearance of a colorectal tumour may be as long as 40 years. 
We have investigated the associations between meat and fat intake as well as smoking and molecular endpoints of colorectal cancer, defined by (truncating) mutations in the fumour suppressor gene APC, activating mutations in the protooncogene $K$-ras and expression of the mismatch repair protein hMLHI. APC mutations are generally considered a gate-keeping event in colorectal carcinogenesis. K-ras mutations are also involved in the early stages of tumour development. The time window of mismatch repair deficiency, as represented by a.O. hMLHI expression is still under debate, but probably also represents an early event. Studying these genetic alterations was based on the hypotheses that carcinogenic compounds derived from meat, fatty acid metabolism and cigarette smoke could induce mutations, and that mutations in genes affected during the early stages of colorectal cancer, that are relevant to its progression to a carcinoma, will still be present in carcinomas.

It has been suggested that different molecular pathways to colorectal cancer may reflect different environmental exposures.23 in particular. Breivik and Gaudernack ${ }^{42}$ proposed that the type of instability in cancers may reflect the selection pressures exerted by specific carcinogens. They predicted that cells exposed to bulky-adduct forming agents will develop chromosomal instability. whereas cells exposed to methylating agents will develop mismatch repair defects and consequently microsatellite instability. Evidence to support this theory has been provided by a study in a colorectal cancer cell line. in which cells resistant to bulky-adduct forming agent 2-amino-1-methyl-6phenylimidazo[4,5-b]pyridine (PhIP) exhibited chromosomal instability, whereas cells resistant to the methylating agent $N$-methyl- $N^{\prime}$-nitro- $N$-nitrosoguanidine (MNNG) exhibited microsatellite instability and conversely, cells made chromosomally instable are resistant to PhiP, whereas microsatellite instable tumour cells are resistant to MNNG. ${ }^{43}$

In our study of genetic alterations (chapter 3 ) the most pronounced differences with regard to age at diagnosis, sex, sub-tocalisation, and tumour differentiation were also found between tumours that did or did not express hMLH1. In addition, we abserved differences between tumours with alterations in the APC and K-ras genes as well as expression of hMLHI with regard to the studied exposures. However, they cannot all be related to the mechanism described by Breivik and Gaudernack.2 In our study of associations between meat and APC mutations (chapter 4), we found evidence for a positive association between beef (in colon) and other meat consumption (in colon and rectum) and truncating APC mutations, which may reflect the bulky-adduct pathway. No clear association between fat intake and truncating mutations in the APC gene was observed, but linoleic acid was strongly associated with tumours harbouring an activating $\mathrm{K}$-ras mutation (chapter 5), again possibly reflecting a bulkyadduct pathway. On the other hand, cigarette smaking was associated with increased risk of colorectal cancer, and this association was most pronounced in tumours lacking a truncating APC mutation, and could partially be ascribed to hMLHI deficiency (chapter 6). According to the proposed mechanism, this would reflect a methylating agents pathway, whereas cigarette smoke mainly contains bulky-adduct forming agents. ${ }^{44}$ Additional studies may provide further insight on the rale of possible carcinogens in different molecular pathways leading to colorectal cancer. 


\begin{abstract}
Although environmental factors may be involved in fumour initiation, they could also play a role in tumour progression. A mutation in the APC ar $K$-ras gene or a mismatch repair defect may render the fumour more susceptible to environmental factors and thus the association studied would reveal more about the progression of the tumour rather than its initiation. From observational studies, like those described in this thesis, it is nof possible to deduct clear clues as to whether dief and cigarette smoking play a part in tumour initiation or its progression. Studies of dietary factors and the occurrence of mutations in APC and $K$-ras and mismatch repair deficiency in adenomas may provide further insight in the actual initiation. In a case-contral study on diet and sporadic colorectal polyps, red meat and high intake of fat were found to be positively associated with polyps lacking a truncating APC mutation. ${ }^{45}$ As it is unknown what proportion of colorectal adenomas would develop into a carcinoma and which genetic alterations drive this progression, results from studies in adenomas cannot provide sufficient information on the relationship between dietary and lifestyle factors and colorectal cancer. However, these data could provide insight as to whether dietary factors play a role in the initiation or the progression of tumours.
\end{abstract}

Our findings support the idea that the exposures studied are involved in initiation of tumours through specific alterations although we cannot rule out that they may be associated with the progression of colorectal cancer.

\title{
TUMOUR LOCALISATION AND SEX
}

In the course of tumour development factors other than the ones under study in the framework of this thesis play a role. As reviewed by lacopetta, 46 severall differences exist between the right and left colon that could predispose the tumours originating at these sites to develop along different pathways, thus prompting consideration of separate analyses for various sites in the colon and rectum. Differences in genetic alterations or differences to various environmental exposures may reflect this. For example, the faecal bulk changes in composition during passage through the colorectal tract. Because these factors are intertwined, it is difficult to establish which factor determines the true underlying difference. By studying genetic alferations observed as several endpoints we may have differentiated enough. We have taken into account the potential differences between sub-localisations in the colorectal tract in the studies of associations between meat, fish and dietary fat consumption by stratifying the analysis for colon and rectal cancer. With regard to the associations studied between cigarette smoking and colorectal cancer, where exposure may be considered more systemic than through direct contact with the colorectal epithelium alone, we did not stratify on sub-localisation. No differences in risk estimates were observed, when analyses were performed for colon and rectal cancer and sub-groups with different molecular alterations separately.

We have not reported associations for men and women separately. When statistically assessing interaction by sex, it was found to be absent. Moreover. although the positive association between smoking and colorectal cancer was observed in men, but not women (chapter 6), the risk estimates for the various 
exposures and endpoints did not differ much between men and women. However, it remains possible that sex influences risk for certain exposures or the formation of a colorectal cancer, but studying different groups, i.e. also stratifying for sex would inevitably lead to large reduction in power and enhance the chance of spurious findings.

\section{GENERAL CONCLUSION}

The studies described in this thesis, have contributed to the existing knowledge in several ways. In the first two studies described in this thesis, a distinct heterogeneity of the tumours with regard to mutations in APC. K-ras and hMLHI expression was observed. Moreover, in contrast to suggestions in literature, the contribution of CTNNBI mutations to the development of colorectal carcinomas seems very small. Mutation status appeared to be related to tumour sub-localisation. Although observed associations were not very strong and further research in this area is warranted, the studies of meat and fat consumption and cigarette smoking support the idea that taking into account the genetic heterogeneity of colorectal cancer endpoint by analysing groups of tumours according to genetic aberrations, may add to our understanding of the complex relationship between dietary and lifestyle factors and the development of a carcinoma. Therefore, it is recommendable to both expand this type of research to more exposure factors as well as investigating the colorectal cancer endpoint according to more than one molecular endpoint, as the combination of genetic aberrations seems to more accurately describe the heterogeneity in tumours than studying one single genetic feature. 


\section{REFERENCES}

1. Powell SM, Zilz N, BeazerBarclay Y, Bryan TM. Hamilton SR, Thibadeau SN, Wogelstein B, Kinzler KW. APC mutations occur early dufing colorectal tumorigenesis. Nature 1992;359(6392):235-7.

2. Miyoshi $Y$. Noggase $H$, Ando $H$. Horil A, Ichil S, Nakatsuru S, Aoki T, Miki $Y$, Mori T. Nakamura $Y$. Somatic mutations of the APC gene in colorectal tumors: mutation cluster region in the APC gene. Hum Mol Genet 1992:1 (4):229-33.

3. Cottrell S, Bicknell D, Kaklomanis L. Bodmer WF. Molecular analysis of APC mutations in familial adenomatous polyposis and sporadic colon carcinomas. Lancet 1992:340:88:201:626-30.

4. Milyaki M. Konishi M, Klkuchi-Yanashita R. Enomato M, Igari T, Tanaka K, Muraoka M, Takahashi H. Amada $Y$. Fukayama $M$, et al. Characteristics of somatic mutation of the adenomatous polyposis coli gene in colorectial tumors. Cancer Res 1994:54! !11:3011-20.

5. Yashima K, Nakamari S. Murakami Y, Yamaguchi A. Hayashi K, Ishikawa O. Konishi Y, Sekiya I. Mutations of the adenomatous polyposis colif gene in the mutation cluster region: comparison of human pancreatic and colorectal cancers. int $J$ Cancer 1994:5911:43-7.

6. Konishi M, Kikuchi-Yanoshita R, Tanaka K, Muraoka M. Onda A, Okumura Y. Kishi N, Iwama T. Mori T. Koike M, Ushio K, Chiba M, Nomizu S, Konishi F. Utsunomiya J, Miyaki M. Molecular nature af colon tumars in hereditary nonpolyposis colon cancer, familial polyposis, and sporadic colon cancer. Gastroenterology 1996;111/2):307-17.

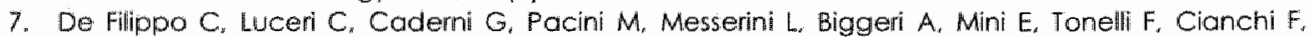
Dolara P. Mutations of the A.PC gene in muman sporadic calarectal cancers. Scand II Gastroenterol 2002,37(9):1048-53.

8. Kim Sh SH, Kaminker P, Campisi J. Telomeres, aging and cancer: in search of a happy ending. Oncogene 2002;21 [4]:503-1].

9. Diergaarde B, van Geloof $W L_{r}$ van Mulien GN, Kak FJ, Kampman E. Dietary factors and the occurrence of truncating APC mutations in sparadic colon carcinomas: a Dutch population. based study. Carcinagenesis 2003;24(2):283-90.

10. Fearon ER, Vagelstein B. A genetic modell for colorectal tumorigenesis. Cell 1990;611(5):759-67.

11. Smith KJ, Johnson KA, Bryan TM. Hill DE, Markowitz $\$$, Willson JK, Paraskeva C. Pejersen GM. Hamilton SR, Vogelstein B, et al. The APC gene product in normal and tumor cells. Proc Natl Acad Sci U S A 1993:90(7):2846-50.

12. Sparks AB. Monin PJ. Vogelstein B. Kinzler KW. Mutational analysis of the APC/beta-catenin/Tcf pathway in collorectal cancer. Cancer Res 1998:58:6):1130-4.

13. van den Brandt PA, Schouten LJ, Goldbohm RA, Dorant E. Hunen PM. Develapment af a record linkage protocol for use in the Dutch Cancer Registry for Epidemiological Research. Int I Epidemial 1990;19(3):553-8.

14. Cravo M. Lage P. Albuquerque C, Chaves P, Claro I, Gomes T, Gaspar C. Fidalgo P, Soares J. Nabre-Leitao C. BAT-26 identifies sporadic colorectal cancers with mutator phenolype: a correlative study with clinico-pathological features and mutations in mismatch repair genes. $J$ Palhol 1999:188(3):252-7

15. Collon SC, Sharp L, Little J. Brockton N. Glutathione S-transferase polymorphisms and colorectal cancer: a HuGE review [see comments]. Am J Epidemiol 2000:15111:7-32.

16. Vogelstein B. Fearon ER, Hamilton SR, Kern SE. Preisinger AC, Leppert $M$, Nakamura $Y$, white $R$, Smits $A M, B O S$ JL. Genetic alterations during colorectal-tumor development. N Engl J Med $1988: 319(9): 525-32$

17. Rowan AJ, Lamlum H. llyas $M$. Wheeler J, Straub J, Papadopoulou A, Bicknell D. Bodmer WF, Tomlinson IP. APC mutations in sporadic colorectal tumors: A mutational "hotspot" and interdependence of the "two hits", Proc Notl Acad Sci U S A 2000:97(7):3352-7.

18. Fodde R. Smits R, Clevers H. APC, signal transduction and genetic instability in colorectal cancer. Nature Rev Cancer 2001:1 11:1:55 -67.

19. Hiltunen MO, Alhonen L. Koistinaho J, Myohanen S. Paakkanen M. Marin S, Kosma VM, Janne J. Hypermethylation of the APC fadenomatious palyposis colit gene promoter region in human colorectal carcinoma. Int J Cancer 1997:70(6):644-8.

20. Esteller M. Sparks A, Toyota M. Sanchez. Cespedes M. Capella G. Peinado MA, Gonzalez S, Tarafa G. Sidransky D. Mellzer SJ, Baylin SB. Herman JG. Analysis of adenomatous palyposis coli promater Inpermethyllation in human cancer. Cancer Res $2000 ; 60(16): 4366-71$.

21. Shiloh K. Furukawa T. Kojima M Konishi F. Miyaki M. Isukamato T. Nagai H. Frequent activation of the beta-catenin-Tef signaling pathway in nonfamilial colorectal carcinomas with microsatelite instability. Genes Chromosomes Cancer 2001:30[1]:32-7. 
22. Shimizu $Y$. Keda S. Fujimon M. Kadama S. Nakahara M. Okajima M, Asahara T. Frequent alterations in the wht signaling pathwoy in colorectal cancer with microsatellite instability. Genes Chromosomes Cancer 2002:33111:73-81.

23. Breivik J. Gaudernack $G$. Carcinogenesis and natural selection: a new perspective to the genefics and epigenetics of colorectal cancer. Adv Cancer Res 1999:76:187-212.

24. Thibodeau SN, French AJ, Cunningham JM. Tester D. Burgart LJ, Roche PC. McDonnell SK "Schaid DJ. Vockley CW. Micheis WV, Far GH, Jr. O'Connell MJ. Microsatellite instability in calorectal cancer: different mutator phenotypes and the principal involvement of hMLHI. Cancer Res $1998 ; 58181: 1713-8$.

25. Herman JG. Umar A, Polyak. K. Graff JR, Ahujo N, Issa JP, Markowitz S, Wilison JK, Hamillon SR, Kinzler KW. Kane MF, Kolodner RD, Vogelstein B. Kunkel TA. Baylin SB. Incidence and functional consequences of hMLHI promoter hypermethylation in colorectal carcinoma. Proc Nati Acad Sci U) S A $1998 ; 951121: 6870-5$.

26. Kane MF, Loda M. Gaida GM. Lipman J. Mishra R. Goldman H. Jessup JM, Kotodiner R. Methylation of the hMLHI promoter correlates with lack of expression of hMLH1 in sporadic colon fumors and mismatch repair-defective human tumor cell lines. Cancer Res 1997:57 (51:808-11.

27. Miyakura Y. Sugano K. Konishi F. Ichikawa A. Maekawa M, Shitoh K. Igarashi S. Kolake K. Koyama $Y$. Nagai $H$. Extensive methylation of hMLH] promoter region predominates in proximal colon cancer with microsatellite instability. Gastroenterology 2001:121,6):1300-9.

28. Goldbohm RA, van den Brandt PA. Brants HA, van't Veer P. Al M. Sturmans $F$. Hermus RJ. Validatiom of a dietany questionnaire used in a large-scale prospective cohort study on diet and cancer. Eur J Clin Nutr 1994:48(4):253-65.

29. Goldbohm RA, van "t Veer P, van den Brandt PA, van 't Hot MA. Brants HA, Sturmans F. Hermus RJ. Reproducibility of a food frequency questionnaire and stability of dietary habits determined from five annually repeated measurements. Eur J Clin Nutr 1995;49(6):420\%.

30. Overvik E, Gustafsson JA. Cooked-food mutagens: cumen'knowledge of formation and biological significance. Mutagenesis 1990;5\{5\}:437-46.

31. Goldbohm RA, Voorrips LE, BOS G, Van den Brandt PA, Vlees en dikke darm kanker. TNO Voeding, 2000.

32. Bingham SA, Hughes R, Cross A.J. Effect of white versus red meat on endogenous N-nitrosation in the human colon and further evidence of a dose response. I Nutr 2002;132i11 Suppi):3522S-255.

33. Mirvish SS, Haorah J. Zhou L. Clapper ML. Harrison KL. Povey AC. Tolal N-nitroso compounds and their precursors in hot dogs and in the gastrointestinal tract and feces of rats and mice: possible etiologic agents for colon cancer. J Nutr 2002;132(11 Suppl):35265-29S.

4. Diergarde B, Bragm $H$ van Muilen $G N$ L Ligtenberg MJ, Kak FJ Kampman E. Dietary factors and microsatellite instability in sporadic colon carcinomas. Cancer Epidemial Biomarkers Prev 2003:12(1) Pt 1):1130-6.

35. Chaves P. Cruz C. Lage P, Clara I. Cravo M. Leitao CN, Soares J. Immunohistochenvical detection of mismatch repair gene proteins as a usefull tool for the identification of colorectal carcinoma of mismalch

Siattery ML Anderson K Curtin K Ma KN Schaffer D. Samowitz. W. Dietary intake and microsiatellite insticibility in colon tumors. Int J Cancer 2001:93(4):601-7.

Slattery ML Curtin K Anderson K, Ma KN. Ballard L. Edwards S, Schaffer D. Polter J, Leppert M

37. Slattery ML. Curtin K. Anderson K, Ma KN. Ballard $L$, Eawa lifestyle factors, and microsatellite Samowitz WS. Associations between cigarette 5moking:

instability in colon tumors. J Natl Cancer inst 2000\%92(22):1831-6.

38. Welfare MR, Cooper J. Bassendine MF, Daly AK. Relationship between ocelylator $1997: 1817 / 1351$ and diet and colorectai cancer risk in the north-east of England. 4.

39. Yang P. Cunningham JM. Halling KC. Lesnick TG. Burgart LJ. Wiegert EM, Christensen ER. Lindior NM. Katzmann JA. Thibadeau SN. Higher risk of mismalch repair-deficient colorectal cancer in alphall/-antitrypsin deficiency carriers and cigarette smokers. Mal Genet Metab 2000.71(4).a3

40. WU AH, Shibata D, YU MC, Lai MY, Ross RK. Dietary heterocyclic an instability in colon adenocarcinomas. Carcinogenesis 2001 . 2 (1O) Kampman E. Cigarette smoking

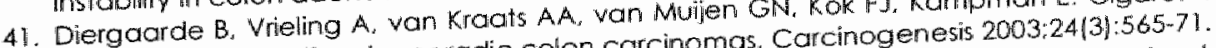
and genetic alterations in sporadic colon carcinomas. 42. Breivik J. Gaudernack $G$. Genomic instability. DNA 
43. Bardelli A, Cahill DP, Lederer $G$. Speicher MR, Kinzler KW. Vogelstein B, Lengauer $C$. Carcinogenspecific induction of genetic instabillty. Proc Nati Acad Sci U S A 2001:98110):5770-5.

44. Hoffmann D, Hoffmann 1. The changing cigarette, 1950-1995. J Toxicol Enwiron Health $1997: 50[4]: 307-64$.

45. Diergaarde B. Tiemersma E. Braam $H$, wan Mujen G. Nagengast F. Kok F. Kampman E. Dietary factors and truncating APC mutations in sporadic colorectal adenomas. Init I Cancer $2005 ; 113: 126-32$

46. Lacopetta B. Are there two sides to colorectal cancere int I Cancer 2002; 101(5):403-8. 
W. 
SUMMARY 
142 
Colorectal cancer affects a large number of people worldwide, in particular in Western countries. Like other cancers, cancer of the colon and rectum is a multi-factorial disease. Besides increasing age and a positive family history of colorectal cancer, dietary and lifestyle factors are likely candidates for affecting colorectal cancer risk. A high intake of fat, meat and alcohol as well as cigarette smoking are thought to increase the risk of developing a colorectal tumour, whereas vegetable, fibre and possibly fruit consumption may decrease the risk. However, observed associations are often weak and sometimes inconsistent.

The majority of colorectal carcinomas seem to arise through a series of welldefined histopathological changes, referred to as the adenoma-carcinoma sequence. A generally accepted paradigm for the mechanism underlying colorectal cancer development describes the sequential accumulation of genetic alterations in the adenomatous polyposis coli (APC). Kirsten ras (K-ras), and tumour protein 53 (TP53) genes. In addition to mutations in specific genes. most colorectal fumours display either chromosomal or microsatellite instability. In the majority of colorectal cancers chromosomal instability is abserved. A smaller fraction (10 to $15 \%)$ is marked by microsatellite instability, which in approximately $90 \%$ of sporadic colorectal tumours is related to defective human Mut-L homologue 1 (hMLHII) function. These two types of genetic instability seem to represent distinct pathways, and possibly reflect differences in aetiology. Environmental factors may exert a direct effect on carcinogenesis through induction of DNA damage that results in mutations in genes relevant to tumour formation or may drive the selection of tumours harbouring specific mutations. Different molecular pathways in colorectal cancer may therefore reflect exposure to various environmental factors. The aims of the studies described in this thesis were to investigate the occurrence of genetic alterations thought to be important to the early stages of colorectal cancer development and to gain insight in the relation between environmental exposures and colorectal cancer as well as these genetic alterations.

The studies described in this thesis were carried out within the framework of the Netherlands Cohort Study on diet and cancer (NLCS) that was initiated in September 1986. At baseline, 120,852 men and women between 55 and 69 years of age, completed a 150-itern food frequency and lifestyle questionnaire. A subcohort of 3,500 male and female subjects was randomly drawn from the cohort and followed-up biennially to determine accumulated person years. Through record linkage of the cohort with the Netherlands Cancer Registry and PALGA, 929 cases of colorectal cancer were identified after 7.3 years of followup of the cohort and excluding the first 2.3 years. From 54 pathology laboratories throughout the Netherlands, formalin-fixed, paraffin-embedded tumour material of 737 patients could be obtained, which was used for subsequent analyses of molecular alterations present in their tumours.

In the study described in chapter 2, the occurrence and type of mutations in the APC gene were studied in 665 patients for whom the mutation cluster region of the APC gene could be analysed completely. We observed a large number of the APC gene could be analysed completely. We observed a lat due occurrence of multiple
of mutations in total. which was in part due to the
mutations in $40 \%$ of tumours. However, despite $72 \%$ of the carcinomas harbouring one ar more mutations, only $37 \%$ of patients had a carcinoma with 
at least one mutation that would result in a truncated and therefore inactivated APC protein, whereas $29 \%$ of patients harboured at least one missense mutation, but no truncating mutation and $6 \%$ of patients had a silent mutation. but no truncating or missense mutation. Rectosigmoid and rectal tumours relatively more frequently harboured $C \rightarrow T$ point mutations or frameshift mutations that would result in a fruncated APC protein when compared to proximall and distai colon tumours, suggesting different aetiology of colon and rectal cancer.

Chapter 3 presents the results from our study on the occurrence of mutations in the APC, CTNNBI, K-ras genes and expression of hMLH1 in 656 carcinomas for which the analysis of these molecular features could be completed, and in which the characteristics of the patients and tumours were compared based on these genetic aberrations. Mutations at the phosphorylation sites of the CTNNB1 gene encoding $\beta$-catenin were a rare occurrence $[5 / 464]$. Striking differences between hMLHI deficient tumours and fumours harbouring a truncating $A P C$ and/or activating K-ras gene mutation were observed. Patients with a hMLH1 deficient tumour were older, more often women, their tumours were more often located in the proximal colon and showed poorer differentiation when compared to patients harbouring tumours with an APC and/or K-ras mutation.

Meat has been proposed as a risk factor for colorectal cancer based on its animal fat and haem iron content as well as its preparation. Due to varying means of preparation, different types of meat may contain heterocyclic aromatic amines, polycyclic aromatic hydrocarbons, and $\mathrm{N}$-nitrosamines that may cause specific DNA damage. Thus, constituents of meat may influence the risk of developing tumours harbouring different genetic alterations, i.e. mutations in the APC gene or mismatch repair deficiency. The study on the associations between meat and fish consumption and genetic alterations in colon and rectal tumours, described in chapter 4, showed no association between total fresh meat, poultry or fish consumption and risk of colon or rectal cancer overall, nor tumours with or without specific genetic alterations. Meat product (processed meat) consumption, however, showed a positive association with colon fumours harbouring a truncating APC mutation (incidence risk ratio (RR) 1.61,95\% confidence interval (CI) 0.96-2.71 for highest versus lowest quartile of intakel, whereas beef consumption was associated with an increased risk of colon tumours without a truncating APC mutation (RR $1.58,95 \% \mathrm{Cl} 1.10-2.25$ for highest versus lowest quartile of intakel. None of the meat and fish variables were found to be associated with lack of hMLH] expression. which led us to conclude that several types of meat may contribute differently to the aetiology of colon and rectal cancer, depending on APC mutation status, but not its $\mathrm{KMLHI}$ expression status.

Dietary fats may both constitute a risk for developing colorectal cancer or exert a protective effect, depending on the type of fat. In chapter 5, the study on the relation between various dietary fats and molecular aspects of colorectal cancer as determined by the APC and K-ras mutation status and hMLH 1 expression status is described. No clear associations were observed for intake of total, saturated and mono-unsaturated fat and risk of colon and rectal cancer or the different molecular subgroups. Linoleic acid, the main constituent of 
polyunsaturated fatty acid intake, was associated with an increased risk of colon cancer with only a K-ras mutation and no additional truncating APC mutation of lack of $\mathrm{MMLHI}$ expression (RR $6.74 .95 \% \mathrm{Cl} 2.36 \% 19.5$ ) for highest versus lowest quartile of intake). Linoleic acid intake was neither associated with risk of colon tumours without any of the gene defects. with tumours only lacking hMLHI expressing, nor with tumours only harbouring APC mutations. Our data suggest a unique aetiology of tumours that harbour specific genetic aberrations.

Cigarette smoke contains numerous carcinogens that through direct or systemic contact with the colorectal epithelium may contribute to an increased risk of developing colorectal cancer. The aim of the study described in chapter 6 was to study the contribution of cigarette smoking to sporadic colorectal cancer according to molecular alterations of the tumours and according to genefic susceptibility as determined by the glutathione S-transferase (GST) GSTMI and GSTIl genotypes. In comparison to never-smokers, a high smoking frequency was associated with an increased risk of colorectal cancer IRR 1.07, $95 \% \mathrm{Cl}$ 1.03-1.12 per five cigarettes/day incrementj and this association was stronger in tumours without a truncating APC mutation $I R R \quad 1.11 .95 \% \mathrm{Cl}$ $1.05,1.17]$. Long-term smoking was associated with tumours lacking hMLH] expression (RR 1.17,95\% Cl 1.00-1.37 per 10 years increment). No statistically significant interactions between smoking and GSTMI or GSTIl genotype were observed. We concluded that cigarette smoking is associated with risk of colorectal cancer, and that this association may depend on molecular characteristics of the tumour as defined by. APC mutation and hMLHI expression status.

In chapter 7 the main findings from the studies described in this thesis are summarised and discussed in the light of methodological considerations, the limited number of other studies that have investigated the relation between environmental factors and the genetic aberrations. With regard to methodological considerations, we can conclude that the quality of the exposure data and the molecular analyses was satisfactory and that the choice of rnolecular endpoints was appropriate with regard to their proposed relevance to colorectal fumourigenesis, and did not result in important misclassification. It seems unlikely that the results were subject to extensive bias due to loss to follow-up of tumour tissue or the success rate of the molecular analyses. However, including different molecular endpoints in our analyses inevitably led to multiple testing and considering that our results are not always in line with the very limited number of publications of this kind, they have to be treated with some caution. It is impossible to draw firm conclusions on the rale of dietary and lifestyle factors in the initiation or progression of the carcinogenic process, as the findings are derived from an observational study. Overall, our results support the hypothesis that various environmental exposures contribute differently to colorectal cancer risk depending on the genetic alterations that are considered to be important to its development. More research in this area is warranted and should ideally include more than one molecular endpoint as this seems to describe the heterogeneity in tumours more accurately than one single genetic feature. 
SAMENVATTING 
I. 
Colorectaalkanker treft wereldwijd een groot aantal mensen, met name in westerse landen. Zoals andere vormen van kanker, is kanker van het colon en het rectum een multifactoriële aandoening. Afgezien van een toenemende leeftijd en een positieve familiegeschiedenis van colorectaal kanker. zijn voedings- en leefstijlfactoren voor de hand liggende factoren die het risico op colorectaalkanker beïnvloeden. Een hoge inname van vet, vlees en alcohol alsmede het roken van sigareften verhogen waarschijnlijk het risico op het ontwikkelen van een colorectaaltumar, terwijl de consumptie van groente. vezel en mogelijk fruit het risico zou verkleinen. De gevonden associaties zijn echter vaak zwak en soms inconsistent.

De meerderheid van colorectaal carcinomen ontstaat via een serie goed gedefinieerde histopathologische veranderingen, welke bekend staat als de adenoom-carcinoom sequentie. Het mechanisme dat ten grondslag ligt aan de ontwikkeling van colorectaalkanker is het algemeen geaccepteerde paradigma van de stapsgewijze accumulatie van genetische veranderingen in de adenomateuze polyposis coli (APC). Kirsten ras ( $K$-ras). en tumour protein 53 (TP53) genen. Buiten mutaties in specifieke genen, worden de meeste colorectaal tumoren gekenmerkt door chromosomale of microsatelliet instabiliteit. In de meerderheid van de colorectaal tumoren wordt chromosomale instabiliteit waargenomen. Een kleiner deel (10 to 15\%) wordt gekenmerkt door microsatelliet instabiliteit, die in ongeveer $90 \%$ van de sporadische colorectaal tumoren gerelateerd is aan een defecte human Mut-L homologue ] (hMLHI) functie. Deze twee vormen van genetische instabiliteit lijken specifieke ontwikkelingsroutes te vertegenwoordigen en weerspiegelen mogelijk verschillen in etiologie.

Omgevingsfactoren hebben waarschijnlijk een direct effect op de carcinogenese via de inductie van DNA schade die resulteert in mutaties in genen die relevant zijn voor tumorvorming of sturen mogelijkerwijs de selectie van tumoren met specifieke mutaties. Verschillende moleculaire routes zouden daarom de blootstelling aan verschillende omgevingsiactoren kunnen weerspiegelen. Het doel van de studies die beschreven zijn in dit proefschrift, was om het voorkomen van genetische veranderingen die belangrijk zijn in de vroege ontwikkeling van colorectaalkanker te onderzoeken en inzicht te verwerven in de relatie tussen omgevingsfactoren en colorectaalkanker en deze genetische veranderingen.

De studies beschreven in dit proefschrift werden uitgevoerd binnen de Nederlandse Cohort Studie naar voeding en kanker (NLCS) die in september 1986 werd gestart. Bij aanvang van de studie vulden 120.852 mannen en vrouwen tussen de 55 en 69 jaar een voedlselfrequentie- en leefstijlvragenlijst in. Een subcohort van 3.500 mannelijke en vrouwelijke deelnemers werd aselect getrokken uit het cohort en werd tweejaarlijks gevolgd om de verzamelde persoonstijd vast te stellen. Via koppeling van het cohort met de Nederlandse Kankerregistratie en het Pathologisch Anatomisch Landelijk Gecutomatiseerd Archief (PALGA) konden na 7,3 jaar follow-up van het cohort - en met uitsluiting van de eerste 2,3 jaar - 929 gevallen van colorectaalkanker worden geidentificeerd. Van 737 patiënten kon tumorweefsel worden verzameld, dat gebruikt werd voor de analyse van genetische veranderingen in hun tumoren. 
In de studie die beschreven wordt in hoofdstuk 2, werd het vóórkomen van en het fype mutatie in het APC gen bestudeerd in 665 patiënten van wie de mutatie cluster regio van het $A P C$ gen volledig kon worden geanalyseerd. Er werd een groot aantal mutaties gevonden, wat gedeeltelijk toe te schrijven is aan het vóórkomen van multipele mutaties in $40 \%$ van de onderzochte tumoren. Hoewel in $72 \%$ van de carcinomen een of meerdere mutaties werd vastgesteld, had slechts $37 \%$ van de patiënten een fumar met tenminste één mutatie die zou leiden tot een verkort en daardoor inactief APC eiwit, terwijl $29 \%$ van de patiënten tenminste één missense, maar geen functionele mutatie bleek te hebben en $6 \%$ had een silent mutatie, maar geen functionele of missense mutatie. Tumoren in het rectosigmoid en rectum hadden relatief vaker een $\mathrm{C} \rightarrow \mathrm{T}$ puntmutatie of frameshift mutatie die zouden resulteren in een verkort eiwit in vergelijking met proximale en distale colontumoren, wat mogelijk duidt op een verschil in efiologie tussen het colon en het rectum.

Hoofdsfuk 3 beschrijft de studie naar het voorkomen van mutaties in de APC. CTNNB1, K-ras genen en expressie van hMLH1 in 656 carcinomen van welke de analyse van deze moleculaire karakteristieken volledig geanalyseerd kon worden en naar de vergelijking van patiënt- en tumorkarakteristieken op basis van deze genetische veranderingen. Mutaties in de fosforyleringsplaatsen van het CTNNBl gen dat codeert voor $\beta$-catenine waren zeldzaam $(5 / 646)$. Opvallende verschillen werden waargenomen tussen hMLHI deficiënte fumoren en tumoren die een functionele APC en/of een activerende K-ras mutatie hadden. Patiënten met een hMLHI-deficiënte tumor waren ouder, vaker vrouwen, hun fumoren waren vaker gelokaliseerd in hef proximale colon en waren slechter gedifferentieerd dan patiënten met een tumor die een APC en/of K-ras mutatie bevatten.

Vlees zou een risicofactor voor calorectaalkanker kunnen zijn op basis van het gehalte aan dierlijk vet en haemijzer alsook de bereidingswijze. Als gevolg van de verschillen in bereidingswijze kunnen de diverse vleessoorten heterocyclische aromatische amines, polycyclische aromatische koolwaterstoffen en $\mathrm{N}$-nitrosamines bevatten, die specifieke DNA-schade kunnen veroorzaken. Zodoende zouden bestanddelen in vlees het risico op de ontwikkeling van tumoren met verschillende genetische veranderingen (mutaties in het APC gen of mismatch repair deficiëntie) kunnen beïnvloeden. De studie naar de associaties lussen vlees- en visconsumptie en genetische veranderingen in colon- en rectumtumoren, zoals beschreven in hoofdstuk 4 , liet geen associatie zien tussen de consumptie van totaal vers vlees, gevogelte of vis en het risico op colon- en rectumkanker op zich, noch met tumoren met of zonder specifieke genetische veranderingen. Consumptie van vleeswaren liet echter een positief verband zien met colontumoren die een functionele APC mutatie hadden (relatief risico (RR) 1,61, 95\% betrouwbaarheidsinterval (BI) 0,96-2,71 voor het hoogste t.o.v. het laagste kwartiel van innamel, terwijl rundvleesconsumptie geassocieerd was met een verhoogd risico op colontumoren zonder een functionele APC mutatie (RR 1.58, 95\% BI 1.10-2,25 voor het hoogste t.o.v. het laagste kwartiel van innamel. Geen van de vlees- of visvariabelen bleek geassocieerd te zijn met de afwezigheid van hMLHI expressie, wat leidde tot de conclusie dat verscheidene soorten vlees op verschillende wijze kunnen bijdragen aan de etiologie van colon- en 
rectumkanker, afhankelijk van de APC mutatiestatus, maar niet de hMLHI expressiestafus.

Voedingsvetten kunnen zowel een risicofactor vormen voor de ontwikkeling van colorectaalkanker als een beschermend effect hebben, afhankelijk van het type vet. in hoofdstuk 5 wordt de studie naar de relatie tussen diverse voedingsvetten en moleculaire aspecten van colorectaalkanker op basis van de APC en K-ras mutatiestatus en hMLHI expressiestatus beschreven. Voor totaal, verzadigd en mono-onverzadigd vet werden geen associaties gevonden met het risico op colon- en rectumkanker. Linolzuur, het belangrijkste vetzuur uit de groep meervoudig onverzadigde vetzuren, was geassocieerd met een verhoogd risico op colonkanker met alleen een $K$-ras mutatie en geen additionele functionele APC mutatie of $\mathrm{hMLH}$ l deficiëntie (RR 6,74, 95\% BI 2,3619,51 voor het hoogste t.o.v. het laagste kwartiel van inname). De inname van linolzuur was niet geassocieerd met het risico op colon tumoren zonder enige genetische afwijking. met tumor die alleen hMLHI deficiënt waren, noch met tumoren met alleen een APC mutatie. Onze resultaten suggereren dat fumoren met specifieke genetische afwijkingen een unieke etiologie hebben.

Sigarettenrook bevat veel carcinagene stoffen die via direct of systemisch contact met het colorectale epitheel een bijdrage zouden kunnen leveren aan de ontwikkeling van colorectaalkanker. Het doel van de studie beschreven in hoofdstuk 6 was de bijdrage van het roken van sigaretten aan sporadische colorectaalkanker te onderzoeken, waarbij rekening werd gehouden met moleculaire veranderingen van de tumoren en de glutathion S-transferase (GST) GSTMI en GSTTI genotypen. In vergelijking met mensen die nooit gerookt hebben verhoogde een hoge rookfrequentie het risico op colorectaalkanker IRR 1,07, 95\% Bl 1,03-1.12 per toename van vijf sigaretten per dagl en dit verband was sterker voor tumoren zonder een functionele APC mutatie [RR $1,11,95 \%$ Bi 1,05-1,17). Langdurig roken was geassocieerd met tumoren zonder hMLH1 expressie (RR 1,17, 95\% BI 1,00-1,37 per toename van 10 jaar). Er werden geen statistisch significante interacties gevonden tussen roken en GSTMI en GSTI genotype. Wij concludeerden dat het roken van sigaretten geassocieerd is met het risico op colorectaalkanker en dat deze associatie afhankelijk zou kunnen zijn van de moleculaire karakteristieken van de tumor op basis van de APC mutatie en $\mathrm{hMLH}$ l expressie stafus.

In hoofdstuk 7 worden de belangrijkste resultaten van de studies die beschreven zijn in dit proefschrift samengevat en bediscussieerd in het licht van methodologische afwegingen en het beperkt aantal andere studies dat de relatie tussen omgevingsfactoren en genetische afwijkingen heeft onderzocht. Met betrekking tot de methodologische aspecten kunnen we concluderen dat de kwaliteit van de expositiedata en de moleculaire analyses goed was en dat de keuze voor de geanalyseerde eindpunten geschikt was met betrekking tof hun relevantie in de carcinogenese van het colon en rectum en niet geleid heeft tot belangrijke misclassificatie. Het lijkt onwaarschijnlijk dat onze resultaten sterk vertekend zijn door selectie door incomplete follow-up van de tumormateriaal of het succes van de moleculaire analyses. Het apart beschouwen van de verschillende moleculaire eindpunten heeft echter wel geleid tot het doen van multipele analyses. Daarnaast kwamen onze resultaten niet altijd overeen met de resultaten uit de beperkte vergelijkbare literatuur. 
Daarom is het van belang onze resultaten met enige terughoudendheid te beschouwen. Over de rol wan voedings- en leefstijlfactoren in de initiatie danwel progressie van hef carcinogene proces kunnen geen definitieve conclusies worden getrokken, aangezien onze bevindingen afkomstig zijn uit observafioneel onderzoek. In het algemeen ondersteunen onze resultaten de hypothese dat blootstelling aan verschillende omgevingsfactoren verschillend bijdraagt aan het risico op colorectaalkanker, afhankelijk van de genetische veranderingen die belangrijk worden geacht voor de ontwikkeling ervan. Meer onderzoek op dit gebied is geboden en zou bij voorkeur meer dan éen moleculair eindpunt beschouwen, aangezien dit de heterogeniteit van fumoren nauwkeuriger lijkt te beschrijven dan één enkele genetische component. 


DANKWOORD 
De laatste pagina's van dit boekje wil ik graag gebruiken om de vele mensen die betrokken zijn geweest bij de totstandkoming ervan te bedanken.

Allereerst mijn co-promotores Matty Weijenberg en Ton de Goeij en mijn promotores Piet van den Brandt en Pieter van 't Veer voor de geboden kans. Matfy, jij hebt me zo veel bijgebracht; bedankt dat ik altijd bij je terecht kon voor discussies, antwoorden en adviezen ten aanzien van het project, maar ook daarbuiten. Ton, de wekelijkse overleggen waren altijd zeer prettig en ontspannen; ik waardeer hef zeer dat je uitgebreid de tijd nam om alle puntjes op de i's te zetten in een poging tot perfectie te komen. Piet, ik ben blij dat je vanaf het begin de voortgang van het project en de haalbaarheid van de planning ten aanzien van publicaties hebt bewaakt; het heeft mij de nodige rust gegeven. Pieter, bedankt voor de brug die je hebt geslagen tussen Wageningen en Maastricht.

Geen promotie zonder project. Epidemiologie, Pathologie, Maastricht, Wageningen, Nijmegen en Zeist, CREAM'ers, NLCS'ers, POLIEP'ers; vele handen maken licht werk.

Mirian, ik ben je ontzettend dankbaar dat je mij wegwijs hebt gemaakt binnen CREAM en dat ik honderdduizend vraagjes op je mocht afvuren! Guido, je was een onmisbare factor voor het in handen krijgen van een berg betrouwbare en werkbare data. Marco, Marjoiein en Merdan bedankt voor jullie bijdrage aan de niet te onderschatten hoeveelheid labwerk! Manon, zelfs bij tegenwind wist jii steeds het enthousiasme voor onderzoek in mij aan te wakkeren. Adriaan, bedankt voor de beoordeling van alle coupes, je scherpe blik en humor. Janwillem Arends, ik wil jou bedanken voor je rol in de totstandkoming van het project.

Petra, je oprechte belangstelling en je betrokkenheid bij de artikelen heb ik zeer gewaardeerd. Ik kijk uit naar jouw promotie! Met betrekking tot de polymorfismen en hMLHI wil ik Ellen Kampman en Goos van Muijen bedanken voor de bijdrage aan de artikelen en Jan Harrywan en Hanneke Braam voor de bijdrage aan de lab-analyses.

Binnen de NLCS zijn er vele mensen (geweest) zonder wiens gedane werk ik het mijne niet had kunnen doen. Graag wil ik alle mensen in Madstricht en Zeist op deze plek hartelijk danken. In het bijzonder bedank ik Maurice voor de hulp bij de case-only en rook analyses en Sandra Bausch voor de nuttige bijdrage aan de artikelen.

Alle loud-jcollega's will ik bedanken voor de aangename werksfeer bij Epi. In het bijzonder wil ik noemen: Rik (wat was het saai geweest zonder alle werkonderbrekingen, kletsjes, hulp bij software troubles en je discrete belangstelling voor mijn persoonlijk wel \& weel. Bianca (voor de veiligheid volgende keer het skiën maar overslaan en meteen door naar de après-skię!). Boukje, Ischa. Rikkert en Stefan: het was prima toeven in ons gedeelde schuitje, zowel op de binnen-ais buitenwateren. 
Mijn werkend leven vindt ook ondersteuning in mijn persoonlijk leven. Lieve, gemiste vrienden in Holland, zie hier het resultaat van mijn verbanning naar het zujien. Wat fijn dat jullie onze vriendschap trouw zijn gebleven. Elske. laten we samen nog lang minstens zes, zeven jaar jonger blijven! Friends overseas, thanks for being there, on the other side of wires \& satellites, and the treasured occasional visits.

Roelinka en Frouke, lang leve mijn paranimfen! Lieve Roel, in Maastricht kwam op memorabele wijze een zeer waardevolle en hopelijk nog lang voortdurende vriendschap tof stand. Lieve Frouke, onze vriendschap bloeit - ondanks de afstand. Ik ben blij en trots je to mijn dierbaarste vrienden te kunnen rekenen.

Mama en Jaap, blood is thicker than water. Altijd.

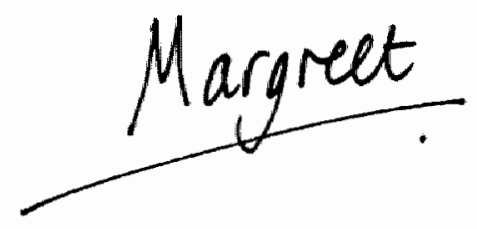


